\title{
Kicking the habit : the effectiveness of smoking cessation programs in Dutch worksites
}

Citation for published version (APA):

Willemsen, M. C. (1997). Kicking the habit : the effectiveness of smoking cessation programs in Dutch worksites. [Doctoral Thesis, Maastricht University]. Universiteit Maastricht. https://doi.org/10.26481/dis.19970321mw

Document status and date:

Published: 01/01/1997

DOI:

10.26481/dis.19970321mw

Document Version:

Publisher's PDF, also known as Version of record

\section{Please check the document version of this publication:}

- A submitted manuscript is the version of the article upon submission and before peer-review. There can be important differences between the submitted version and the official published version of record.

People interested in the research are advised to contact the author for the final version of the publication, or visit the DOI to the publisher's website.

- The final author version and the galley proof are versions of the publication after peer review.

- The final published version features the final layout of the paper including the volume, issue and page numbers.

Link to publication

\footnotetext{
General rights rights.

- You may freely distribute the URL identifying the publication in the public portal. please follow below link for the End User Agreement:

www.umlib.nl/taverne-license

Take down policy

If you believe that this document breaches copyright please contact us at:

repository@maastrichtuniversity.nl

providing details and we will investigate your claim.
}

Copyright and moral rights for the publications made accessible in the public portal are retained by the authors and/or other copyright owners and it is a condition of accessing publications that users recognise and abide by the legal requirements associated with these

- Users may download and print one copy of any publication from the public portal for the purpose of private study or research.

- You may not further distribute the material or use it for any profit-making activity or commercial gain

If the publication is distributed under the terms of Article $25 \mathrm{fa}$ of the Dutch Copyright Act, indicated by the "Taverne" license above, 


\section{Kicking the habit \\ The effectiveness of smoking cessation programs in Dutch worksites}




\title{
Kicking the habit \\ The effectiveness of smoking cessation programs in Dutch worksites
}

\author{
Proefschrift \\ ter verkrijging van de graad van doctor \\ aan de Universiteit Maastricht, \\ op gezag van de Rector Magnificus, \\ Prof.mr. M.J. Cohen, \\ volgens het besluit van het College van Dekanen, \\ in het openbaar te verdedigen op \\ vrijdag 21 maart 1997 om 14.00 uur \\ door
}

Marcus Christiaan Willemsen 
Promotor:

Prof.dr. G.J. Kok

Co-promotor:

Dr. H. de Vries

Beoordelingscommissie:

Prof.dr. F.J.N. Nịhuis (voorzitter)

Prof.dr. H.F.J.M. Crebolder

Dr. M.P. Eriksen (Centre for Disease Control, Verenigde Staten)

Prof.dr. B. Oldenburg (Queensland Uniwersity of Technology, Australië)

Prof.dr. H. Philipsen

ISBN: 90-5681-014-6

Cover design and art work: John Prop

Printed by Unigraphic, Maastricht

The studies presented in this thesis were conducted at the Institute HEALTH, part of the Netherlands School of Primary Care Research (CaRe), acknowledged in 1995 by the Royal Dutch Academy of Science (KNAW). The research was funded by grants from the Dutch Cancer Society (grant IKL 92-141) and the Dutch Heart Foundation (grant 41.002). Both organizations contributed equally to the research described in Chapters $3,4,5,7$, and 8 . The study presented in Chapter 6 was financed by PTT-Telecom. Financial support by the Dutch Cancer Society and by the Netherlands Heart Foundation for the publication of this thesis is gratefully acknowledged. 


\section{Contents}

1. Introduction 11

1.1 Historical overview of Dutch anti-smoking campaigns 12

$\begin{array}{ll}1.2 \text { Trends in national smoking prevalence } & 14\end{array}$

1.3 Governmental regulation $\quad 14$

1.3.1 Labeling of tobacco products $\quad 15$

1.3.2 Regulation of tobacco advertisements 16

$\begin{array}{ll}\text { 1.3.3 Increase in purchase price } & 16\end{array}$

1.3.4 Minimum purchase age $\quad 17$

1.3.5 Regulation of smoking in public places 17

1.3.6 Conclusion $\quad 18$

$\begin{array}{ll}1.4 \text { Health education } & 18\end{array}$

$\begin{array}{ll}\text { 1.4.1 Smoking prevention } & 18\end{array}$

$\begin{array}{ll}\text { 1.4.2 Smoking cessation } & 19\end{array}$

1.4.3 From a clinical to a public health perspective 19

$\begin{array}{ll}\text { 1.4.4 General practitioners } & 20\end{array}$

1.4.5 Mass media $\quad 20$

$\begin{array}{ll}\text { 1.4.6 Worksites } & 21\end{array}$

1.5 Outline of the thesis $\quad 22$

2. Smoking at the workplace 25

2.1 Introduction 26

2.2 Problem analysis from a public health perspective 28

2.3 Workers as target group 31

2.4 Problem analysis from the perspective of the worksite 33

2.4.1 Employers $\quad 33$

2.4.2 Employees $\quad 38$

2.5 Determinants of smoking cessation 39

2.5.1 Determinants of intention to quit $\quad 43$

2.5.2 Determinants of making a quit attempt 43

2.5.3 Determinants of long-term success $\quad 44$

2.5.4 Summary and discussion $\quad 44$

2.6 Access to worksites 46

2.7 Setting goals for interventions $\quad 47$

2.8 Choosing intervention strategies 47

2.9 Effectiveness of worksite programs 48

2.9.1 Smoking cessation programs $\quad 48$

2.9.2 Mass media strategies $\quad 49$

2.9.3 Smoking restrictions $\quad 50$

2.9.4 Comprehensive programs 51

2.10 Program evaluation $\quad 52$

2.11 Program continuation $\quad 52$ 
3. Annoyance from ETS and support for smoking policies

3.1 Introduction

3.2 Method

3.2.1 Research population

3.2.2 Measurements

3.2.3 Statistical analyses

3.3 Results

3.3.1 Comparison among company types

3.3.2 Demographic features

3.3.3 Smoking behavior

3.3.4 Smoking policy measures

3.3.5 Attitudes towards smoking in the workplace

3.3.6 Annoyance from tobacco smoke

3.3.7 Support for smoking bans

4. Intention to quit smoking among employees

4.1 Introduction

4.2 Method

4.2.1 Questionnaire

4.2.2 Regression analyses

4.2.3 Multi-level analyses

4.3 Results

4.4 Discussion

5. Assertiveness towards smoking colleagues

5.1 Introduction

5.2 Method

5.2.1 Questionnaire

5.2.2 Statistical Analyses

5.3 Results

5.3.1 Determinants of assertive behavior

5.3.2 Determinants of intention

5.3.3 Relations between proximal and distal variables

6. Evaluation of a pilot program: The PTT-Telecom study

6.2.2 Intervention 
6.3.1 Program evaluation 108

$\begin{array}{ll}\text { 6.3.2 Behavioral outcomes } & 109\end{array}$

6.3.3 Stages of change movement 110

6.4 Discussion $\quad 110$

7. Comparison of a comprehensive with a minimal program $\quad 115$

7.1 Introduction $\quad 116$

7.2 Method $\quad 118$

7.2.1 Setting and subjects $\quad 118$

7.2.2 Recruitment procedures $\quad 118$

7.2.3 Minimal intervention $\quad 119$

7.2.4 Comprehensive intervention $\quad 119$

7.2.5 Questionnaire and outcome measures $\quad 121$

7.2.6 Statistical analyses $\quad 122$

7.3 Results 122

7.3.1 Response 123

7.3.2 Smoking cessation $\quad 124$

7.3.3 Quit rates 125

7.3.4 Sustained abstinence $\quad 125$

7.3.5 Program exposure 126

$\begin{array}{ll}\text { 7.3.6 Effectiveness of continuation strategies } & 128\end{array}$

$\begin{array}{ll}7.4 \text { Discussion } & 128\end{array}$

8. Impact on employees not participating in the cessation program

8.1 Introduction $\quad 132$

8.2 Method 133

8.2.1 Study design $\quad 133$

8.2.2 Linkage groups $\quad 134$

8.2.3 Mass media campaign 134

8.2.4 Smoking restrictions $\quad 135$

$\begin{array}{ll}8.2 .5 \text { Subjects } & 135\end{array}$

8.2.6 Questionnaire 135

$\begin{array}{ll}\text { 8.2.7 Statistical analyses } & 137\end{array}$

8.3 Results 137

$\begin{array}{ll}\text { 8.3.1 Program exposure } & 138\end{array}$

$\begin{array}{ll}\text { 8.3.2 Participation } & 140\end{array}$

8.3.3 Impact on non-program participants 140

8.3.4 Impact on nonsmokers $\quad 142$

$\begin{array}{ll}\text { 8.4 Discussion } & 142\end{array}$ 
9. Main conclusions and general discussion

9.1 Summary and discussion of major findings

9.1.1 Smoking as a social problem

9.1.2 Smokers' intention to quit

9.1.3 Passive smoking and assertiveness

9.1.4 Tests of the ASE model

9.1.5 Program effectiveness

9.2 Suggestions for future research

9.4 Main conclusions

References

Summary

Samenvatting

Dankwoord 

$a_{3}$

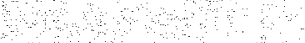

a d

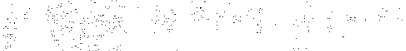

$\cos ^{2} \quad \therefore \quad \cdots$ 
"Marlboro Cowntry" was mpolluted. free of bazards to one's moral and physical bealth - precisely the opposite of what science and the government were sianing about smoking cigarettes (Kluger, 1996, p.295)

\section{1 \\ Introduction}

In the late 1940 s, epidemiologists noticed that lung cancer rates in several countries had increased dramatically since the beginning of the century. Between 1922 and 1947 , the annual number of deaths due to lung cancer increased roughly fifteen fold, which was clearly out of proportion to the population growth and could not be explained by improved standards of diagnosis (Doll \& Hill, 1950). Epidemiologists also certified that this increase was much greater among men. In the Netherlands, the following trends were observed: in 1924 the odds of dying from lung cancer were 2.5 times higher for men than for women (Korteweg, 1958). In 1948, this ratio had increased to 5.8 and in 1957 the ratio was 10 . Comparable observations led two groups of epidemiologists, one from the United States (US) and the other group from the United Kingdom (UK), to investigate the background of this epidemic. Both groups used retrospective data. In 1950, the first findings were published almost simultaneously in both countries (Doll \& Hill, 1950; Wynder \& Graham, 1950). Both studies concluded that by far the main cause of the rise in lung cancer 
deaths was smoking. Doll and Hill's conclusion was all the more powerful, because they had expected to find other causes to be important as well, notably traffic and air pollution. In 1951, Doll and Hill started a prospective study among 40,000 English physicians to substantiate their previous conclusions. Five years later, 82 dactors from their sample had died of lung cancer. The analyses showred a doseresponse relationship between the amount of smoked cigarettes and death rates from lung cancer (Doll \& Hill, 1956). In the same year that Doll and Hill began collecting their data among British doctors, a comparable study was set up in the United States (Hammond \& Horn, 1954). This study involved 187,766 male subjects and led to the conclusion that there is a definitive association between smoking habits and death rates due to lung cancer. In addition, the American study found appreciably higher mortality rates in smokers for cancer in sites other than the lung, and a strong association was found between cigarette use and coronary heart disease. In the following years, numerous additional epidemiological studies were undertaken to further examine these issues. Committees on smoking and health were set up in several countries to review the evidence. In 1954, in response to a report from the English Medical Research Council, the government of the UK was probably the first to warn the public of the harmful effects of smoking (Van Proosdij, 1957)1.

The remainder of this chapter presents an overview of governmental and nongovernmental anti-smoking actions that have been conducted in the Netherlands since the 1950s. It will be argued that the workplace may be an attractive setting for anti-smoking programs, but that this potential has not yet been realized and has not been studied in the Netherlands. The studies presented in this thesis explore this potential.

\subsection{Historical overview of Dutch anti-smoking campaigns}

In 1956, the Dutch Health Council reported on the basis of the existing epidemiological data that smoking was related to lung cancer (Wester, 1957). The Health Council advised the government to alert the Dutch people about the health risks,

The epidemiological evidence relating lung cancer and other diseases to smoking was so strong and unequivocal that the World Health Organization (WHO) and many governments immediately started to take measures, without needing biological evidence of causality. 
but that the warnings should only be aimed at children and adolescents. Official governmental warnings that smoking causes lung cancer and that it would be better to quit smoking altogether were considered too frightening for most addicted smokers and were assumed to cause severe agitation in the Dutch population (Gadourek, 1963; Van Proosdij, 1957). In these years, smoking was almost universal in industrialized nations, at least among men. In 1958,90\% of the male adult population smoked (Dutch Foundation on Smoking and Health, 1996a). Hardly any methods existed that could help people quit smoking.

In 1957, the Dutch Minister of Social Affairs and Health presented the Health Council's report to the press. It stated that children should be prevented from "premature and heavy smoking" (Korteweg, 1958). However, the first nation-wide mass media campaigns targeted at schools did not happen until 1964. Nevertheless, in 1957 the Dutch press paid abundant attention to harmful effects of smoking (Gadourek, 1963). Adults were advised to change smoking habits: to smoke less, to smoke without inhaling or to turn to pipes or cigars instead of cigarettes (Van Proosdij, 1957). Already in 1958,60\% of the Dutch population knew that smoking was bad for their health and $35 \%$ believed that smoking caused lung cancer (Gadourek, 1963). Smokers had received this information mostly through newspapers.

The harmful aspects of smoking became even more widely known to the general public when, in 1964, a report from the US Surgeon General was published, reviewing the evidence about the relationship between smoking and heart disease and cancer (US Department of Health and Human Services, 1982, 1983). In the same year, in the Netherlands, the first nation-wide anti-smoking campaign fully financed by the government was conducted ${ }^{2}$. Since 1975 , yearly national anti-smoking campaigns have been organized by the Dutch Foundation on Smoking and Health. These are aimed not only at the youth, but also at adults and high risk groups such as pregnant women, patients with cardiovascular disease, and sufferers from chronic obstructive lung disease.

2 This organized by the Bureau for Education of the National Foundation against Cancer (Stichting Landelijke Organisatie voor de Kankerbestrijding). This was practically a one-man operation conducted by Dr. Meinsma, whose campaigns lasted until 1974. 


\subsection{Trends in national smoking prevalence}

Smoking prevalence decreased quite rapidly from the 1950 s until the 1980 s. Howet er, whereas in several other West-European countries this decline continued, in th Netherlands it almost came to a halt at the end of the 1980 s. From 1980 to 1990 the smoking rate has declined on average with less than one percent per year (Dutd) Foundation on Smoking and Health, 1996a). Since 1990, national smoking rate seem to have almost stabilized. In 1993 and 1994 33\% of the adult population smoked. However, recently smoking rates were increasing again: the 1995 smoking rates were $39 \%$ for men and $31 \%$ for women, averaging 35\% smokers (Dutch Foun dation on Smoking and Health, 1996a). The Netherlands is among the West-Europe an countries with a high smoking prevalence (Joossens, Naet, Howie \& Muldoon 1994; Ruwaard \& Kramers, 1993). Figure 1.1 shows smoking prevalence in mos West-European countries ${ }^{3}$.

\subsection{Governmental regulation}

Despite the fact that the harmful aspects of tobacco smoke are widely known, many people continue to smoke. In 1986, the Dutch government endorsed the target of the World Health Organization (WHO) to decrease the national smoking prevalence to $20 \%$ by the end of this millennium ( $T$ weede Kamer, 1986). In the following years it became clear that this goal was too ambitious. The $20 \%$ target is not mentioned in more recent governmental publications (Tweede Kamer, 1994; Ministry of Public Health, Welfare and Sports, 1996).

Although part of the decline in tobacco consumption since the 1950's might be attributed to a general increase in health consciousness among smokers, govern. mental regulations seem to have had an impact as well (Simonich, 1991). Governments and national and local health departments have a number of instruments at their disposal to combat tobacco use (Brownson, Koffman, et al., 1995; Pierce, 1991;

\footnotetext{
${ }^{3}$ National data from reports from the European Bureau for Action on Smoking Prevention (1994) and the World Health Organization (WHO, 1995). The data should be interpreted with care. In Belgium (as in Ireland and the United Kingdom) the definition of a smoker is daily
smoker, whereas in the Nether Differences between countries may 


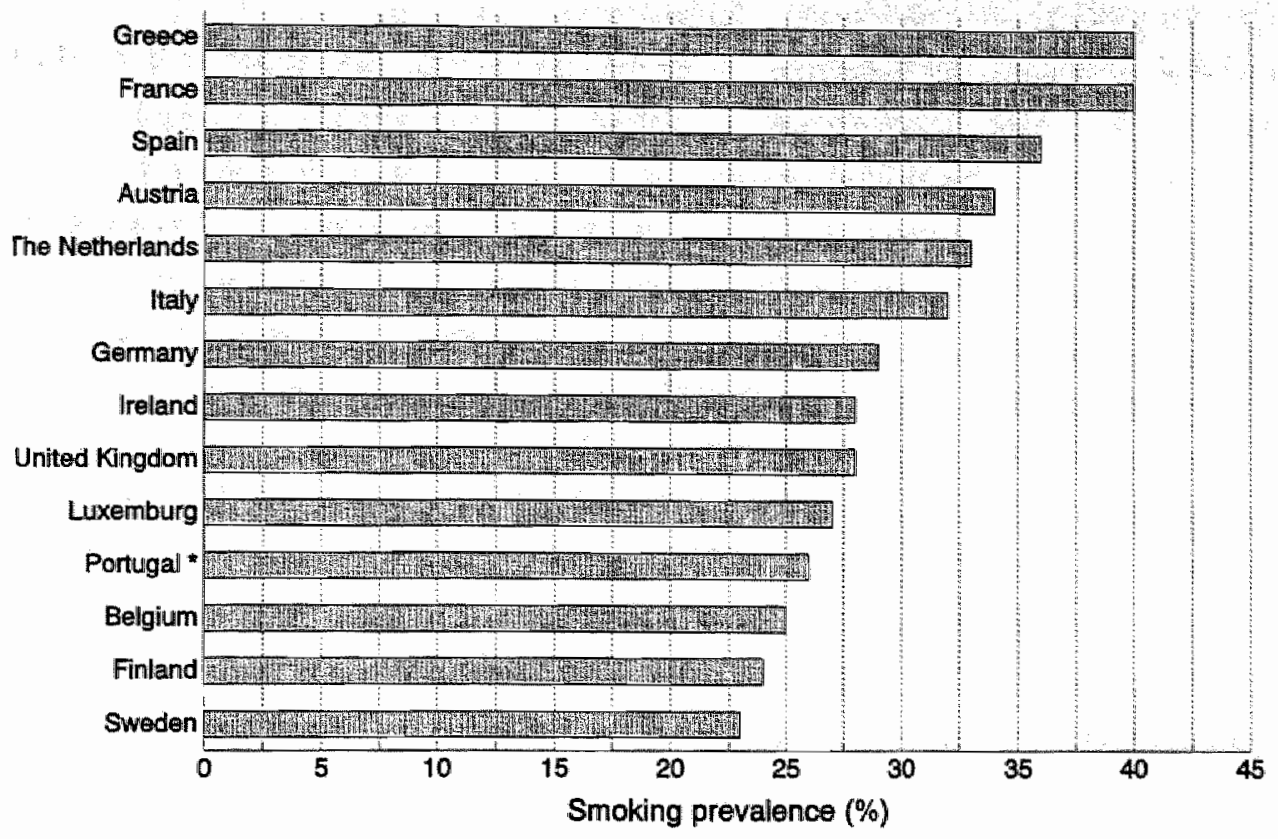

gure 1.1: Smoking prevalence in western Europe, 1992/1993 (15 years or older). European ureau for Action on Smoking and Health (1994), WHO (1995). "Portugal: 1994 data.

imonich, 1991). In the following paragraphs, these tools are summarized with secial emphasis on actions in the Netherlands (see also Joossens et al., 1992). First, re will look at four policy measures that are solely in the domain of the governlent.

\subsection{Labeling of tobacco products}

Jne instrument governments can use is labeling tobacco products with health warn1gs. In 1990, the Netherlands implemented European Directives on labeling tobaco products with clear health warnings. Warning labels on tobacco products and on dds contain rotating texts with health warnings. Several studies have shown that rarning labels are not very effective in changing smokers' knowledge about the ealth hazards of smoking and in influencing their smoking behavior (reviewed in irownson, Koffman, et al., 1995; Simonich, 1991). 


\subsubsection{Regulation of tobacco advertisements}

Another governmental instrument is to restrict the advertising of tobacco products. Allowing the tobacco industry to advertise its products decreases the credibility of governmental actions that discourage people to buy tobacco products. Moreover, tobacco advertising has been found to have an impact on teenage uptake of smoking (Tye et al., 1987 in Brownson, Koffman, et al., 1995). Voluntary agreements with the tobacco industry have resulted in the prohibition of tobacco advertising on Dutch television and radio (since 1980), on Dutch billboards along motor-ways (since 1994) and in Dutch cinemas (since 1996), but still many avenues are open for the tobacco industry to promote their products, such as advertising in magazines and on billboards. The Dutch government and the Dutch tobacco industry have agreed that advertisements are not directed at young people. However, bans have been circumvented by intensive sponsorship and indirect advertising. The selfimposed restrictions are valid until May 1999 (Ministry of Public Health, Welfare and Sports, 1996). Very recently, the restrictions have been sharpened somewhat by the government (Ministry of Public Health, Welfare and Sports, 1996). Until now, the Dutch government has opposed propositions from the European Council to restrict advertising tobacco products to tobacco-selling points. Already in the 1970 s, Italy and several Scandinavian countries completely prohibited tobacco advertisements (Smit et al., 1993). Meanwhile, France banned all advertising of tobacco products in 1993.

\subsubsection{Increase in purchase price}

Increasing the minimum purchase price of tobacco products is another policy option. Across a number of studies it was concluded that the price elasticity of the demand for cigarettes is between -0.3 and -0.5 (Pierce, 1991). A recent calculation produced a maximum of -0.7 (Trigg \& Bosanquet, 1992). This implies that for every $10 \%$ increase in the price of cigarettes, the number of cigarettes consumed falls by $7 \%$. For teenagers a price elasticity of -0.76 has been reported (Pierce, 1991). In an econometric study of governmental antismoking policies, Simonich (1991) concluded that increases in excise tax is an effective governmental tool. In 1992, the European Union (EU) imposed minimum taxation levels for cigarettes among the then twelve EU member states (Joossens et al., 1992), but individual member states are free to increase these rates beyond this minimum. In 1992, cigarette prices in the Netherlands were still somewhat below the average price in the EU (Bosanquet, 1992). 
Recently it has been decided that the price of both cigarette and 'roll-your-own' tobacco will be increased with 0.45 Dutch guilders, over a three years period. It has been noted that a rise in prices may have undesirable effects on low-income smokers who have been found to cut down on other vital expenditures instead, to maintain their smoking habit (Marsh \& McKay, 1994).

\subsubsection{Minimum purchase age}

Another governmental option that may affect young people is to restrict selling tobacco products to adults (i.e., above 18 years old). This has recently been proposed by the Dutch government (Ministry of Public Health, Welfare and Sports, 1996). However, several studies have shown that minors are successful in buying cigarettes despite legal bans (Landrine et al., 1994). In one study, 12 to 15-year-old children working 'under cover' attempted to buy cigarettes. They achieved a success rate of $53 \%$ over the counter and $79 \%$ from vending machines (Forster et al., 1992). Another American study found that more than $80 \%$ of tobacco retailers were willing to illegally sell cigarettes to minors (DiFranza \& Brown, 1992). An Australian study reported that $70 \%$ of purchase attempts by minors were successful (Sanson-Fisher et al., 1992). The prohibition of tobacco sales to minors will be effective only in combination with strong and systematic enforcement efforts (Radecki \& Zdunich, 1993). Programs of retailer education and warnings to prosecute retailers who do not comply, have been found to result in strong reductions in selling of cigarettes over-the-counter (US Department of Health and Human Services, 1994). Such efforts have not yet been decided upon in the Netherlands.

\subsubsection{Regulation of smoking in public places}

A fifth governmental strategy is to impose smoking bans. Since 1990, partial smoking bans have been in effect in Dutch governmental buildings. Smoking is not allowed in places accessible to the public. Authorities responsible for public buildings are obliged to impose the ban and to make smokers comply with the ban. The ban may be suspended in designated areas such as waiting rooms and canteens. The regulations do not apply to offices, meeting rooms and other places not accessible to the general public. The Netherlands have no legislation that prohibits smoking in private enterprises and this is not expected to change in the near future. However, future plans may extend smoking bans to places accessible to the public in service organizations such as post offices and the Dutch railways (Ministry of Public 
Health, Welfare and Sports, 1996). The decision to impose smoking bans in private industry is left to the business community.

\subsubsection{Conclusion}

On viewing the governmental policy options, it would appear that Dutch governmental actions have been limited and seem to lag behind those that have been taken in other West-European countries (see also Lamberts, 1989; Smit et al., 1993). The most important omission is a general ban on tobacco advertisements, which restricts publicity about tobacco products to selling points. It is doubtful whether governmental regulations will substantially improve in the near future. In order to bring down national smoking rates, a number of additional efforts are therefore needed. These are mostly educational and can be realized by national governmental and nongovernmental health organizations and local health departments (Reid et al., 1992). These health education strategies are reviewed in the next section.

\subsection{Health education}

\subsubsection{Smoking prevention}

An important health education strategy is the prevention of teenage smoking. As early as 1957, the Dutch Health Council advised the government to focus antismoking action on young people. In 1975, the Health Council again advised to give priority to strategies targeted at the youth (Ministry of Public and Environmental Health, 1975). Smoking prevalence in the 15 to 19 age group decreased from more Smoking and Health, 1996a). This has roughly stabilized since then. Smoking prevalence in the 10 to 14 age group was at a low of $7 \%$ in 1990 , but has even increased since then (Dutch Foundation on Smoking and Health, 1996a). One strategy for reaching children and adolescents is through mass media campaigns in
schools. These have intensified schools. These have intensified recently due to substantial increases in the governSmoking and Health (Ministry of Public Health, Welfare and Sports, 1996) strategy is smoking prevention through regular educational signed to help adolescents resist negative peer pressures. have been developed in the Netherlands for use in ver. Effective school programs 
al., 1994) and high schools (Dijkstra, 1995), but the diffusion of these programs to all Dutch schools has not yet been realized (E. Storm, personal communication, July 4 , 1996). It takes many years before school programs contribute significantly to reductions in adult smoking prevalence.

\subsubsection{Smoking cessation}

Traditionally, the way to encourage adults to quit smoking is to develop effective cessation methods and make these available to smokers. The effectiveness of various smoking cessation methods has been reviewed extensively (for example Klesges et al., 1987; Lando, 1993; Lichtenstein \& Glasgow, 1992; Schwarz, 1987). The most intensive treatments are clinical group programs that use a wide range of behavior modification strategies, cognitive treatments, and relapse prevention techniques. Under rigorous evaluation, such treatment programs produce 1-year quit rates of around $20-25 \%$ (Lando, 1993). For example, a large-scale study of 42 American Lung Association's smoking clinics (which are very similar to the group courses offered by the Dutch Foundation on Smoking and Health) showed that $29 \%$ of participants were not smoking after one year (Rosenbaum \& O'Shee, 1992). The most effective multicomponent programs may produce quit rates of $40-50 \%$ (Lando, 1993), but studies have failed to identify one clear 'magic bullet'. Instead, it is now understood that small differences in treatment content have little effect on outcome (Lichtenstein \& Glasgow, 1992). However, programs with more personal contacts produce better results (Lichtenstein \& Glasgow, 1992). Much less intensive methods are self-help materials. Quit rates at 1-year follow-up are in the 10-20\% range (Lichtenstein \& Glasgow, 1992). Self-help materials are most successful with lighter smokers (Cohen et al, 1989). Heavily addicted smokers might benefit from nicotine replacement therapy (NRT), which is intended to be used in combination with behavioral treatment or with self-help materials. NRT has been found to increase the effectiveness of behavioral treatments (Lichtenstein \& Glasgow, 1992; Hajek, 1996; Schotborg \& Breteler, 1994).

\subsubsection{From a clinical to a public health perspective}

Smoking cessation methods such as group programs, self-help materials and NRT are only used by a very small number of smokers who seek formal help (Lichtenstein \& Glasgow, 1992). Consequently, over the past decade it has been realized that a more comprehensive public health approach is needed to make a significant 
impact on smoking prevalence (Oldenburg, in press). In contrast to the traditional clinical perspective concentrating efforts on smokers seeking treatment, the public health perspective focusses on an entire community, and:

requires that a range of efforts be directed toward all smokers and the general public over time in order to increase the likelihood of quitting, to reduce risk in the population at large, and to strengthen the norms and values supporting nonsmoking (Gruman \& Lynn, 1993, p. 397).

In other words, interventions must be targeted at all smokers in a population, must be continued over a longer period of time and must focus on the social and physical environment of smokers as well. This can be accomplished through various channels. The most important are general practitioners, general mass media approaches and worksites.

\subsubsection{General practitioners}

One potentially effective channel to reach adult smokers is through family doctors. If all Dutch general practitioners would routinely advised their patients to quit smoking and offered them minimal support with quitting, this might double the number of smokers that stop smoking each year (Mudde et al., 1989). A minimal intervention strategy has been developed and is being diffused to Dutch general practitioners' offices (Pieterse et al., 1994). However, up to now this strategy is still considerably under-used by Dutch doctors.

\subsubsection{Mass media}

Another channel through which quitting can be encouraged is mass media (i.e., newspapers, billboards, advertisements, and especially through television). Mass media can be used in three ways: general campaigns informing smokers of negative health consequences of smoking, campaigns promoting smoking cessation, for example by calling a hotline or requesting specific materials, and televised self-help clinics for smokers wanting to quit (Flay, 1987a). Intensive national information campaigns have been shown to produce behavioral changes (Flay, 1987a), but in the Netherlands many campaigns have been rather shortlived and low profile (Van Reek \& Adriaanse, 1987). More recent campaigns by the Dutch Foundation on Smoking and Health focus on promoting specific cessation activities and have been more 
intensive. In 1991, an intensive nation-wide mass media campaign involving TV clinics had a perceptible impact on national smoking rates (Mudde, 1994; Mudde \& De Vries, in press). Since both information campaigns and campaigns promoting cessation are only effective if they are of adequate frequency, reach and duration, they are very expensive. In sum, mass media strategies have the potential to achieve small, rapid falls in adult smoking prevalence, but are rather costly.

\subsubsection{Worksites}

Another channel to reach large groups of smokers is worksites. Worksites are regarded as an ideal setting for a public health approach to smoking cessation (Gruman \& Lynn, 1993). Anti-smoking activities are still rare in Dutch worksites. In 1990 , in the Netherlands, only $25 \%$ of worksites paid attention to smoking among employees (Dutch Foundation on Smoking and Health, 1990). These activities were mostly limited to briefly informing employees about the health effects of smoking or passive smoking. A more recent representative survey of Dutch worksites (1104 organizations) revealed that $29 \%$ reported activities to reduce smoking at the workplace (GBW-NIPO, 1996). Of these, $42 \%$ had some form of smoking policy, $30 \%$ reported face-to-face education or advice, $11 \%$ provided educational materials on smoking cessation, and $3 \%$ provided smoking cessation classes. In contrast, in $198527 \%$ of US companies had a smoking control policy that prohibited or severely restricted smoking in the workplace. This grew to $59 \%$ in 1992 (Linnan et al., 1993). In 1992, smoking cessation activities were offered by $32 \%$ of worksites (Linnan et al, 1993).

Publications reviewing the literature on worksite smoking cessation usually include an enumeration of potential advantages of worksites (see for example Abrams et al., 1994; Glasgow \& Terborg, 1988; Gruman \& Lynn, 1993; Hallett, 1986; Hallett \& Sutton, 1988; Klesges, Cigrang \& Glasgow, 1987; Lichtenstein \& Glasgow, 1992; US Department of Health and Human Services, 1985). The most important advantage is that a large and diverse group of smokers may be reached. Briefly stated: worksites are where the people are. During working weeks, a typical employee spends half of all his/her waking hours at the worksite. In 1994,63\% of the Dutch adult population ( 15 - 64 years of age) participated in the labor force (Dutch Central Bureau for Statistics, 1995). Furthermore, worksites offer the opportunity to reach specific subgroups of smokers who may be hard to reach otherwise. In the aforementioned review papers, worksites are thought to be the best setting 
for reaching blue-collar workers, who have a higher smoking rate than white-collar workers. This issue is discussed in more detail in Chapter 2.

Another assumed advantage of worksites is the greater ease of reaching smokers. Health educators can use well established communication channels, such as company newsletters and bulletin boards. Furthermore, worksite programs allow health education to be continued on an ongoing basis to a fairly stable population (Glasgow \& Terborg, 1988; Haynes et al., 1990). This should increase the chance that interventions achieve lasting behavioral change (Haynes et al., 1990).

A final advantage is that programs can be directly targeted at the social and physical environment of smokers. This makes various environmental and incentive approaches to behavioral change possible (Abrams et all., 1994; Glasgow \& Terborg, 1988). One example of an environmental strategy is creating nonsmoking policies. Another example is social support from colleagues and bosses for behavioral change. The social environment of the workplace may reinforce smoking behavior or nonsmoking behavior depending on the prevailing norms.

The aforementioned benefits of worksites do not occur automatically (Lichtenstein \& Glasgow, 1992; US Department of Health and Human Services, 1985). The potential of worksites to reduce smoking has been extensively studied outside the Netherlands, predominantly in the United States (this literature is reviewed in paragraph 2.9 of this thesis). However, this research field still needs to be fully explored in the Netherlands. This thesis, therefore, examines the possibilities of Dutch worksites as settings for anti-smoking interventions.

The various studies brought together in this thesis originate from two research grants: the first was from PTT-Telecom company (for 1990), the second was from a collaborative grant from the Dutch Cancer Society and the Dutch Heart Foundation (1992 - 1995). The first grant made it possible to develop a preliminary worksite smoking cessation program and to study its effectiveness in two sites of PTTTelecom. The second grant allowed us to further elaborate on these results by examining the effectiveness of a more comprehensive smoking cessation program.

\subsection{Outline of the thesis}

Chapter 2 is organized according to a health promotion planning model ( $A B C$ model). This chapter features a review of the literature on health and social prob- 
lems associated with smoking, a review of the psychological and physiological determinants of smoking cessation, and a discussion of strategies to reduce smoking in work settings.

Chapter 3 presents data on smoking prevalence, hindrance from smoking at the worksite and support for no-smoking policy options among employrees in eight large Dutch worksites. These data, and the data for the studies presented in Chapter 4 and 5, were collected as part of a baseline survey that was used to measure the impact of the comprehensive smoking cessation program, as described in Chapter 8.

Chapter 4 presents a study examining psychological determinants of employees' intentions to quit smoking. More specifically, this study focused on the influence of the social environment on smoking employees, both within the worksite (colleagues, bosses) and outside the worksetting (family, friends, etc.). Social influences were expected to be important determinants of smoking cessation among employees, since smoking is a highly visible behavior that elicits both positive and negative reactions from the social environment. The study can also be seen as an evaluation of the Attitude-Social influence-Efficacy (ASE) model. We examined this model's power to predict intention to quit smoking. Many studies have attempted to unravel determinants of smoking cessation in worksites, but few used a clearly defined theoretical model.

Chapter 5 examines the determinants of a behavior very rarely examined in the smoking cessation literature, namely nonsmokers' assertiveness. Assertive behavior can be important in situations where there are no clear smoking bans. Furthermore, smokers" compliance with smoking bans may depend partly on nonsmokers" reactions to smokers who violate these bans. For this study the same theoretical model was used as in Chapter 4.

Chapter 6 presents a study of the effectiveness of a smoking cessation program for employees of the Dutch PTT-Telecom. The program basically consisted of smoking cessation classes (group program) and self-help manuals.

Based on the results of the PTT-Telecom pilot study, a comprehensive smoking cessation program was developed. This program consisted of the PTT-Telecom program with the addition of a mass media campaign, program continuation strategies and strengthening of smoking policies. Its effectiveness was examined using a research design in which four worksites were assigned to comprehensive treatment and four worksites to a minimal treatment. Two longitudinal surveys with different target groups were carried out. One survey was conducted among participants in the 
smoking cessation program and consisted of three measurements (pretest, 4 months follow-up, and 14 months follow-up). The results are presented in Chapter 7.

Another prospective survey was carried out among smoking employees who did not take part in the cessation program (Chapter 8 ). This study examined the impact of mass media strategies and smoking policy changes on participation rates among smokers and cognitive and behavioral changes in smokers who did not take part in the cessation program. Program impact on nonsmoking employees was also examined. With nonsmokers, primary outcome measures were assertive behavior towards smoking colleagues and supportive behavior when colleagues make an attempt to quit smoking.

The final chapter summarizes and discusses the major findings. A number of practical recommendations for program development and suggestions for future research are given.

Chapters 3 to 8 are based on articles that have been published or that are currently under review in scientific journals. Because these chapters were originally written to stand alone, parts of the thesis overlap somewhat. The studies are ordered according to the $\mathrm{ABC}$ model, starting with aspects of the problem analysis, followed by analyses of determinants and effectiveness studies. In reality however, the PTTTelecom study described in Chapter 6 preceded the studies in Chapters 3 to 5 . Furthermore, time elapsed between the studies in Chapter 3 and Chapter 5 , and the two effectiveness studies (Chapters 7 and 8), was very short. Consequently, recommendations in Chapters 3 to 5 could not be implemented during this research project and, therefore, are not followed up in subsequent chapters. 
People are tied to smoking as Gulliwer was tied to the ground by the Lillipu* tians - through bundreds of individual threads. (Krogh, cited in Christen \& Christen, 1994)

\title{
2 \\ Smoking at the workplace
}

\begin{abstract}
The ABC planning model is used as a framework to review the literature on detrimental aspects of smoking (botb from a public bealth perspective and a worksite perspective), determinants of smoking cessation, and strategies for reducing smoking in worksites. It bas been concluded that smoking is an important cause of premature mortality and illness that deserves to be singled out in bealth promotion campaigns. Working smokers comprise an impor. tant target group, since smoking prevalence among workers is high, especially among blue-collar workers. Employers seem more interested in reduction of absenteeism through smoking cessation programs and reduction of exposure to second hand smoke through smoking policies. Smoking cessation programs should aim at changing the cognitive determinants of smoking cessation and should belp smokers acquire the necessary skills to quit. Worksites can implement smoking cessation programs to improve smokers' bealth and implement smoking restrictions to improve nonsmokers" bealth and well-being. Mass media strategies may be needed to create supportive environments for quitting in worksites.
\end{abstract}




\subsection{Introduction}

The existing epidemiological and clinical evidence about the associations between smoking, chronic disease and premature death are sufficient justification for public health representatives to try to motivate smokers to quit smoking. This may be less obvious in worksites. For example, employers may see smoking habits primarily as employees" responsibilities, as long as company interests are not threatened. Employees may regard smoking as a behavior about which the boss should have little to say. Such differences in perspective can be a serious problem when health educators wish to implement smoking cessation interventions in worksites. To increase the chance that worksite programs will be implemented, it is important that they receive sufficient support both from employees and employers. Therefore, health educators working in organizational settings must be sensitive to how these two groups perceive the 'smoking problem'.

The idea that the perspective of various user groups should explicitly be taken into account when planning interventions, is central to the C-phase in the ABCplanning model (De Vries, 1989; De Vries \& Willemsen, 1996). This model combines insights from the field of diffusion research (Rogers, 1983) with the widely used health promotion planning model of Green and Kreuter (1991), the PRECEDE-PROCEED model. A pre-requisite for effectiveness is that programs are systematically planned. It has been shown that the effectiveness of health promotion interventions depends, to a large extent, on the quality of the planning process (Green \& Kreuter, 1991; Kok, 1992; Mullen et al., 1985).

The ABC planning model is shown in Figure 2.1. The ABC model states that the planning of health promotion interventions can best be conceptualized as a circular process with different starting points. The model consists of three basic phases: analysis of the problem, behavioral change and continued prevention. Each phase consists of several steps. In the analysis phase, five steps are distinguished: a. an examination of social and epidemiological problems, b. identification of behaviors most related to these problems, $c$. identifying target groups in which these intervention methods are most acceptable to the target group and to intermediaries. ing strategies to reach these consists of: a. setting goals for interventions, b. choos- 


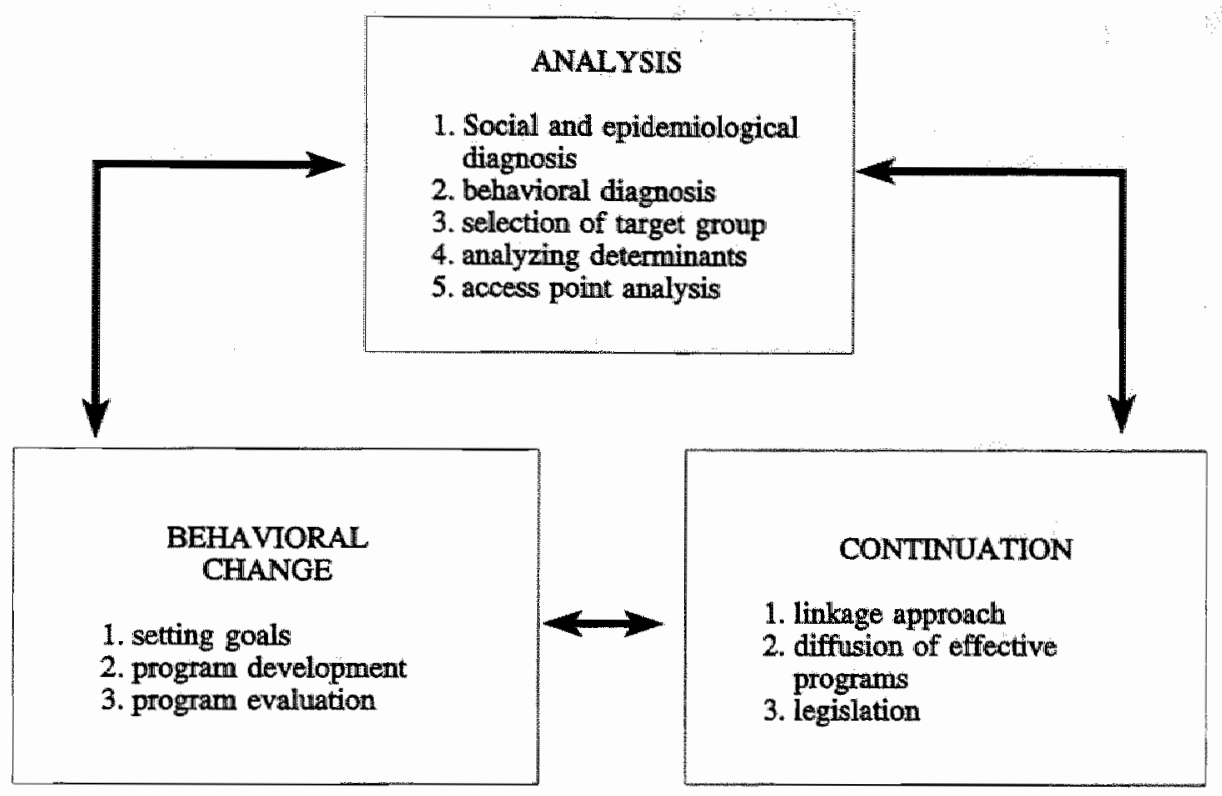

Figure 2.1: The ABC planning model for the development and evaluation of health promotion interventions.

health promotion programs, and c. program evaluation in pilot studies using experimental or quasi-experimental research designs. The continuation phase includes: a. the linkage approach, which is a collaboration between the original program developers and future user groups (Orlandi et al., 1990), b. diffusion strategies, and c. legislative aspects. In this chapter, the $\mathrm{ABC}$ model will be used as a framework to review the literature on detrimental aspects of smoking, determinants of smoking cessation, and strategies for reducing smoking in worksites. The first two steps of the problem analysis are brought together in Figure 2.2, which is a somewhat simplified version of the problem analysis as defined by Green \& Kreuter (1991). This involves an analysis of health problems contributing to quality of life (social and epidemiological diagnosis) and an analysis of factors causing these health problems (behavioral and environmental diagnosis). The starting points are extended longevity (through reduced illness) and improved quality of life (Green \& Kreuter, 1991). However, these are primarily of interest from a general public health perspective and may be less appealing to worksite representatives. Employers are more 
interested in so-called intermediate outcomes (Green \& Kreuter, 1991), such as increased productivity and reduced sickness absenteeism. Below, the problem analysis will first be presented from a strictly public health perspective (sections 2.2 and 2.3) and than from the viewpoint of worksite representatives (section 2.4).

Behavioral and

Environmental

Diagnosis

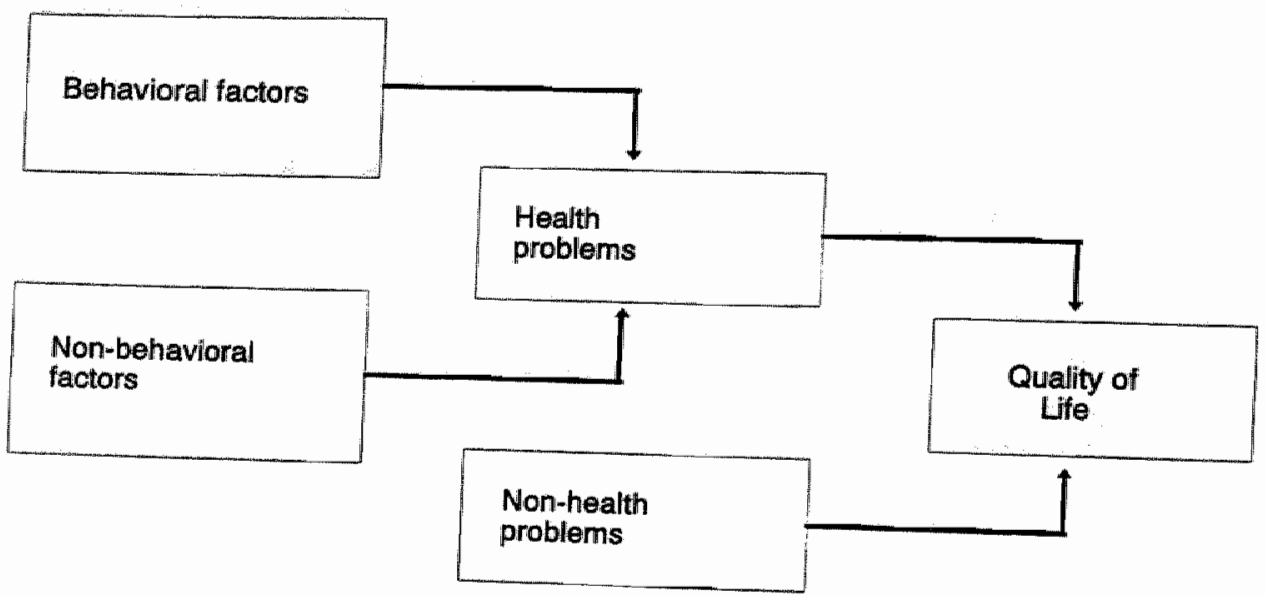

Social and Epidemiological Diagnosis Figure 2.2: Problem analysis in terms of social, epidemiological, behavioral,
and environmental diagnoses.

\subsection{Problem analysis from a public health perspective}

The challenge for public health is to delay mortality and morbidity until one reaches old age, to enable a long healthy life with little suffering from illness (Schaapveld et al., 1990). This has been called 'compression of morbidity' (Fries et al., 1989). In the Netherlands, the mean life expectancy is 74 years for men and 80 years for women (Ruwaard \& Kramers, 1993), but many people get sick and die before they reach these ages. In 1990 , the thre D the cancer) ( $27 \%$ of all mort 
morbidity, typical 'old age' diseases such as diabetes, rheumatoid arthritis, and senile dementia are important as well (Schaapveld et al., 1990). However, these illnesses are hardly preventible through health education, whereas premature coronary heart disease, chronic lung disease, and cancer to a large extent, are. Smoking is the most important behavioral cause of these latter three illnesses. Of all behaviors, smoking is most strongly related to both mortality and morbidity rates. In the Netherlands, $19 \%$ of all deaths in 1990 were attributed to smoking (Peto et al., 1992, 1994). Smoking not only affects quantity of life, it also reduces the quality of life, particularly in old age (Fries et al., 1989; Shopland \& Burns, 1993). Smokers have a greater risk of becoming chronically ill. The list of diseases caused by or associated with smoking is staggering (Shopland \& Burns, 1993). Diseases for which smoking is the major, single contributor to excess mortality are lung cancer, respiratory disease, peripheral vascular disease, and cancer in three specific sites (larynx, pharynx and esophagus). ${ }^{1}$ Indirect estimations from Dutch national statistics showed that among people who were between 35 and 69 years of age, $42 \%$ of all premature deaths were attributable to smoking (Peto et all, 1992). The effect of smoking on dying prematurely was convincingly shown in a 40-year follow-up study among male British doctors (Doll et al., 1994). Twenty percent of doctors who had never smoked, died before the age of 70 , whereas $41 \%$ of doctors who continued smoking died before that age. From this study it was estimated that the average loss of life for people who smoke is 7.5 years (see Figure 2.3). Many smokers tend to ignore the fact that the impact of smoking on health by far exceeds any other risky behavior (Shopland \& Burns, 1993). Thus, smoking does deserve to be singled out in public health campaigns.

Fortunately, quitting smoking always pays off. The risk of premature death is nearly back to normal after 15 years off cigarettes (Shopland \& Burns, 1993). The risk of lung cancer is reduced by 30 to $50 \%$ after 10 years (US Department of Health and Human Services, 1990). The risk of dying from coronary heart disease is reduced by about half after one year of smoking abstinence (US Department of Health and Human Services, 1990).

${ }^{1}$ Diseases for which smoking is one of several causes are stroke, coronary heart disease, and cancer of the bladder, kidney and pancreas. The list continues with a number of diseases for which the association with smoking has not been firmly established, such as cancer of the cervix, stomach, and liver, and pneumonia. 


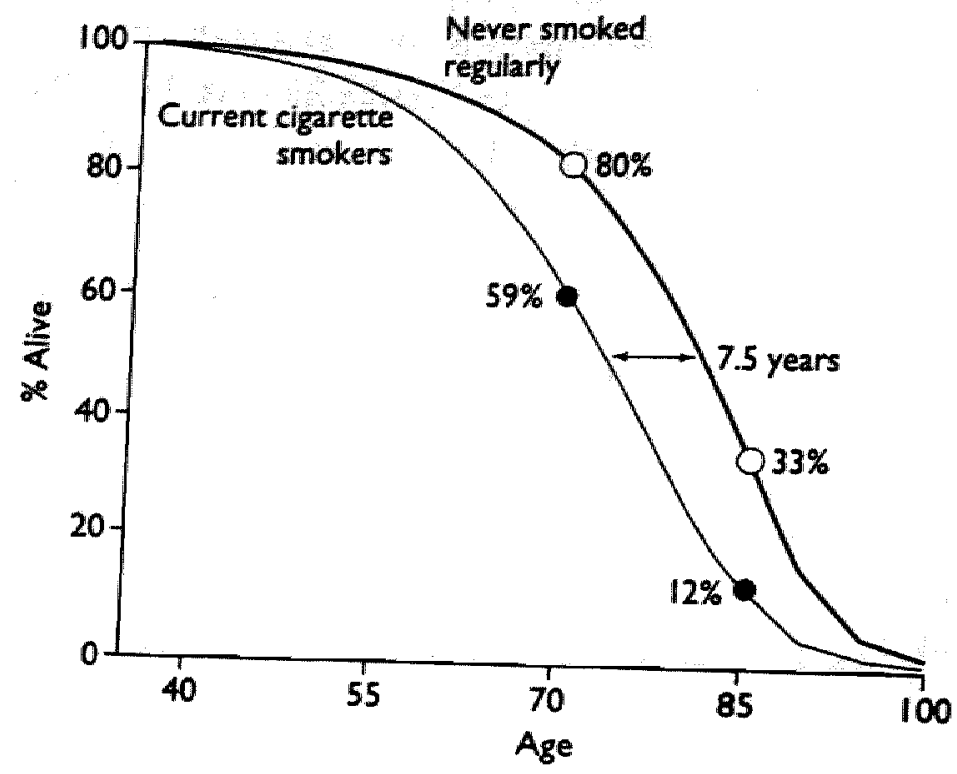
Figure 2.3: Overall survival after 35 years of age among cigarette smokers and nonsmokers,
based on age specific death rates. Reprinted with permission from Doll et al. (1994).

To summarize, smoking is an important cause of premature mortality and reduction of the quality of life, which can be prevented by quitting smoking. Be cause smoking is related to so many illnesses, smoking deserves to be singled out as a target for public health campaigns.

One of the channels to reach smokers is worksites. In the next paragraph the target group of workers will be examined more closely (the third step in the analysis
phase of the $A B C$ model). 


\subsection{Workers as target group}

From a public health perspective, smoking cessation programs should aim at workers who are most at risk, or at groups of workers with a high smoking prevalence. These two aspects are discussed below.

The interaction between tobacco smoking and exposure to asbestos dust and coal dust causes an increase in the severity of disease, often advancing its onset and accelerating its rate of development (Rothwell, 1992). In 1995, a comprehensive review was published (US Department of Health and Human Services, 1985), concluding that cigarette smoking may alter the amount of disease or level of disability resulting from hazardous occupational exposures. Workers who are regularly exposed to coal, grain, silica, or, to a lesser extent, sulfur dioxide or cement have an increased risk of chronic bronchitis. These risks are higher if workers also smoke. The same conclusion was reached for welders. The interaction of cigarette smoking and asbestos exposure is multiplicative: while smoking increases the risk of lung cancer approximately tenfold and asbestos exposure increases this risk more than fifty fold, those who both smoke and are exposed to asbestos have a 5,000 times greater risk of developing lung cancer (US Department of Health and Human Services, 1985).

Figure 2.4 provides recent data on smoking prevalence in various branches of Dutch industry. The mean smoking rate among all Dutch workers was $42 \%$, which is higher than in the general population, where smoking prevalence was $36 \%$ in 1993 (Swinkels, 1994). Smoking prevalence is highest in the catering industry (hotels, cafes and restaurants) and among construction workers, and lowest among employees in the banking and education sectors. This corresponds with studies examining the relationship between smoking and occupational status. These clearly show that blue-collar workers (e.g., taxi drivers, bus drivers, machinists, and metal workers) have higher smoking rates than white-collar workers (e.g., physicians, lawyers, engineers, teachers, business executives, and accountants) (Covey \& Wynder, 1981; Nelson et al., 1994; US Department of Health and Human Services, 1985). There are at least two explanations why workers in blue-collar occupations are more likely to smoke (Serxner et al., 1991). First, blue-collar workers might have certain characteristics that predispose them to smoke, notably more often being male and more often having a lower educational level, which are both associated with higher smoking prevalence. Secondly, characteristics of the occupation itself 
might cause blue-collar workers to smoke more. One important characteristic is the level of stress. Research has repeatedly shown that work related stress inhibits cessation of smoking and increases the intensity of smoking (Caplan et al., 1976; Green \& Johnson, 1990; Johansson et al., 1991). However, stress is not uncommon in white-collar professions too. Another job characteristic is group norms or culture. Worksites where a pro-smoking norm prevail reinforce smoking behavior more than worksites in which there is a no-smoking culture. It has been found that types of occupation differ in the extent to which workers support or discourage the quit attempts of colleagues (Sorensen et al., 1986). For example, blue-collar workers are more likely to report that most of their colleagues do not care whether they smoke or not (Serxner et al., 1991).

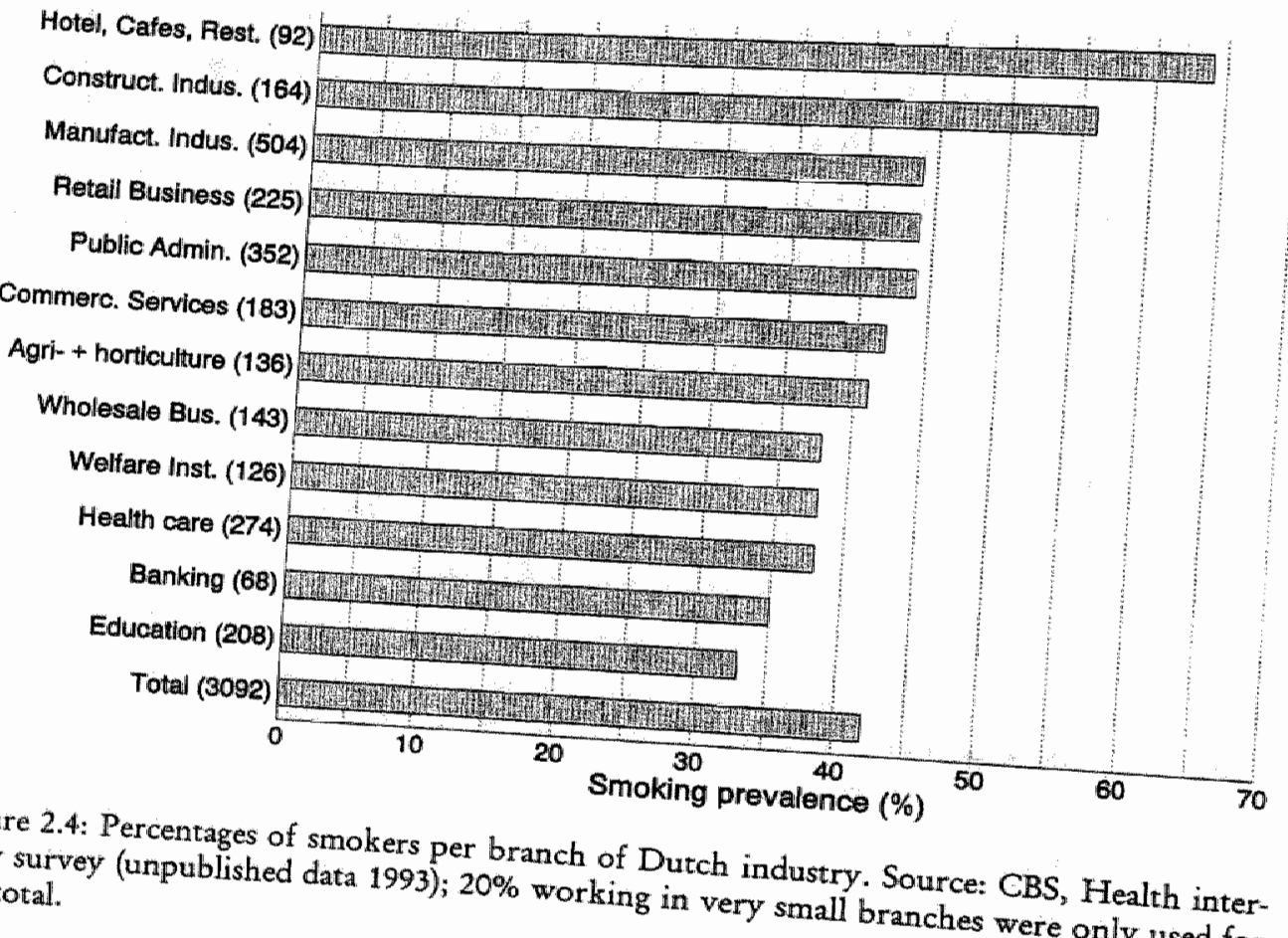

Figure 2.4: Percentages of smokers per branch of Dutch industry. Source: CBS, Health inter-
survey (unpublished data 1993); $20 \%$ working in very small branches were only used for
tal.

In the United States, smoking rates have declined most strongly among whitellar workers (Nelson et al., 1994). The same is true for smokers at higher socioconomic levels and with higher levels of education (Pierce \& Hatziandreau, 1989 
in Burns, 1991). The differences in smoking rates between lower and higher socioeconomic strata thus seem to be widening in Western countries (see also Warburton et a1, 1991).

It can be concluded from the aforementioned that smokers who work comprise an important target group for attempts to reduce national smoking rates. Smoking prevalence is especially high among less-educated, blue-collar workers. Specific blue-collar occupations have an increased risk of smoking related disease. The studies reported in this thesis were conducted in worksites with a relatively large number of blue-collar workers, such as the chemical industry.

\subsection{Problem analysis from the perspective of the worksite}

\subsubsection{Employers}

Profit is the bottom line for the corporate world. If it can be shown that making employees quit smoking is good business sense, company management might be less reluctant to provide smoking cessation programs for employees (Davis, 1993; Stoffelmayr et a., 1991). Although only limited research exists on the cost-benefit of antismoking programs in worksites, there seems to be a consensus in the United States (US) that successful smoking reduction is cost-effective (Stoffelmayr et al., 1991). From a recent simulation of economic returns to worksite smoking cessation programs, it was concluded that such programs have an excellent return on investment starting at about 5 years of continued implementation (Warner et al., 1996). In the US, a conservative estimate of the annual costs of a one-pack-per-day smoker to the average employer ranged from 336 to 661 US dollars (Kristein, 1983). These are 1982 dollars; due to inflation these figures are much higher today. Bertera (1991) calculated that smoking employees at the Du Pont company in the United States had excess illness costs of $\$ 960$ per smoker per year. The greater part of these costs were medical expenditures, because in the United States companies are health insurance providers. It must be noted that these gains still comprise only a very small fraction of a US companies' total medical expenditures (Warner et al., 1996). Medical costs are not very relevant to Dutch worksites, since most employees are not health insured through their worksite. Absenteeism, productivity and other reasons that might be relevant to Dutch employers, will be discussed in more detail below. 
Absenteeism. Absenteeism costs are very relevant in the Netherlands. Recent privatization of the National Sickness Law ('Ziektewet') resulted in companies now having to pay in full for workers' compensation costs resulting from sick leave. Due to the ageing of the working population, it is important to keep workers in good health as long as possible. According to Kristein's 1983 review, US smokers have $33 \%$ to $45 \%$ more short-term absenteeism than nonsmokers. A recent US study reported 34\% (Ryan et al., 1992). The claim that smokers are more likely to be absent from work has received support from other studies, even after adjusting for demographic variables, type of work and other lifestyle factors (Bush \& Wooden, 1995; Wooden \& Bush, 1995). One study showed that in Johnson \& Johnson worksites in the United States, smokers had approximately 52 sick hours per year compared to 37 sick hours among nonsmokers (Jones et al., 1990). Another study showed that during an outbreak of influenza, among healthy men, $68.5 \%$ of smokers had influenza compared with $47.2 \%$ of nonsmokers. Furthermore, influenza was more severe in smokers (Kark et al., 1982 cited in Rothwell, 1992).

These international studies are difficult to apply to the Dutch situation, because they are restricted to shorter term absenteeism, whereas absenteeism rates in the Netherlands include longer term absenteeism. Nevertheless, the association between smoking and frequent short-term absenteeism has also been observed in the Netherlands (Grosfeld, 1988; Schalk, 1989; Schröer et al, 1984). There are also reports of studies in which no relationship was found between smoking and absenteeism. For example, a study conducted among Dutch civil servants found no significant difference in the number of days absent due to illness between smokers, ex-smokers and nonsmokers (Van Deursen \& Teeuwen, 1988; Van Deursen et al., 1988).

The observation that smokers are more often absent from work does not necessarily mean that quitting smoking will result in less absenteeism. To date, there are no large scale prospective controlled studies that have compared changes in absenteeism between quitters and continued smokers (Wooden \& Bush, 1995). Wooden $\&$ Bush (1995) used an alternative procedure. They surveyed 4,812 Australian ex-smokers and examined how absence levels vary as a function of time elapsed since smoking cessation. Absence was defined as at least one day of illness or injury in the two weeks prior to the interview. The results showed that the likelihood of a worker who had quit smoking being absent, declined gradually over time. The lowest absent rates were observed among smokers who had not smoked for 20 
years. This study suggests that the health benefits from smoking cessation may reduce absenteeism rates, but that this process takes many years. Prospective studies are needed to further clarify this issue.

Productivity. Another economic loss is reduced productivity from work time lost, clean-up costs and damage to equipment. A Dutch company in which smoking was allowed only in designated areas, calculated that smokers loose 2.5 hours of work time each week because of their smoking habit (De Volkskrant, 1995). As a result, company management ordered smoking employees to compensate for their decrease in productivity by working one hour longer per week. Fire losses are another smoking-related company burden (Kristein, 1983).

Some employers might also have positive attitudes towards smoking at work, since smoking is sometimes believed to enhance performance. Many smokers feel that smoking cigarettes helps to concentrate. Some investigators found enhancement of cognitive performance after nicotine intake, but others failed to find evidence (reviewed in Jarvik, 1991 and in US Department of Health and Human Services, 1988). It remains unclear whether nicotine really increases concentration among smokers or whether nicotine intake just relieves smokers from temporary concentration impairment, which is a common withdrawal syndrome (Hughes et al., 1989; Jarvik, 1991). In nonsmokers, nicotine has been shown to decrease concentration and accuracy, but to improve performance in a tapping task (Jarvik, 1991).

Occupational hazards. A recent prospective study among postall employees who were allowed to smoke at work reported that smoking was associated with a higher prevalence of industrial accidents, occupational injuries and a higher rate of disciplinary actions, after controlling for age, gender, race, drug use, exercise, and occupational type (Ryan et al, 1992). However, this study did not control for the possible confounding effect of alcoholism. Kristein (1983) pointed to a synergism between smoking and exposure to specific occupational hazards (see paragraph 2.3).

Since 1990, a Dutch national Tobacco Law prohibits smoking in indoor places accessible to the general public, but no national legislation exists that restricts smoking in privately owned companies. However, national legislation concerning working conditions (Labor Conditions Act) can be interpreted to include exposure to environmental tobacco smoke. Article 3 of this act states that employers must provide maximum safety for employees, protect employees' health and promote employees' well-being. In light of the known harmful effects of environmental 
tobacco smoke $e^{2}$, exposure to environmental tobacco smoke (ETS) can be regarded as a labor condition from which employees should be protected. Recently, the American Environmental Protection Agency concluded that passive smoking is a "class A" carcinogen, which is a "known human carcinogen" (Environmental Protection Agency, 1992). The Netherlands has adopted these conclusions (Health Council, 1990; Jansen et al., 1993). The American National Institute for Occupational Safety Health declared that ETS meets their criteria for classification as an occupational carcinogen, placing environmental tobacco smoke in the same category as known carcinogens as asbestos and benzene (Brownson, Davis, et al., 1995; Repace, 1993). In the Netherlands however, this is not yet the case: the Dutch law only refers to risk factors directly related to the work situation, such as occupational hazards. Consequently, the lack of an official limit for permissible concentrations of tobacco smoke in workplaces makes it difficult for Dutch occupational health professionals to enforce the Labor Conditions Act to deal with smoking. However, a number of lawsuits in which individual nonsmoking employees demanded a smoke-free workplace on the basis of the Tobacco Law or the Labor Conditions Act have recently been won by the claimants (Schepel, 1992).

Litigation. Cigarette smoking is a greater threat to workers' health than other workplace hazards (US Department of Health and Human Services, 1985). After the recent proclamation that ETS is an occupational carcinogen, US companies are expected to simply ban smoking out of concern for litigation, that is, employees taking legal action against their employer (Abrams et al., 1994; Davis, 1993; Sees, 1990). Taday, concern about litigation from employees is a powerful reason for Australian workplaces to become smoke-free (Chapman, 1996). The litigation issue seems to be less relevant in the Netherlands due to differences in the legal system. from symptoms such as ady in 1968 it was reported that nonsmokers may suffer from symptoms such as headache, cough, irritation and nasal symptoms resulting

2 Nonsmokers' risk of death from lung cancer increases with about $20 \%$ by living with the risk of death from heart disease Although the lung cancer risk due to passive with about $30 \%$ (Glantz \& Parmley, 1991). the number of heart disease deaths due to passive has received most public attention, heart disease is much more common (Glantz \& Parmoking is ten times greater, because estimates are based on epidemiological studies among Parmley, 1991; Steenland, 1992). These It is unclear how these risks translate to the among nonsmokers who live with a smoker. 
from exposure to ETS (Speer \& Mission, 1968). These observations were confirmed in later studies (Eriksen, 1986; US Department of Health and Human Services, 1986; Weber, 1984). Whereas in the sixties smokers were in the majority (at least among men), nowadays nonsmokers are by far the largest group. Declining smoking rates have influenced social norms about smoking in public. Nonsmokers today are more assertive about claiming their right to a smoke-free environment (Strasser, 1991). For example, a survey in the then 12 countries of the European Union showed that $49 \%$ of nonsmokers said they were very bothered by tobacco smoke (Joossens et al, 1994). These societal changes can also be observed in workplaces. In the US, companies initially adopted no-smoking policies to meet the competing interests of smokers and nonsmokers (Fielding, 1991). In Chapter 3, data will be presented showing that the nuisance caused by tobacco smoke in various sectors of Dutch industry is considerable. The wish to do something about hindrance from ETS is the most frequently mentioned reason why Dutch companies ask for professional help to set up anti-smoking programs (A. Haartsen, personal communication, May 1996).

Company image. Many companies' initial interest in smoking control measures may be related to company image, such as the wish to bind employees to the company. Smoking is increasingly becoming a deviant behavior rather than normal behavior in social settings. This may be especially true in worksites with high percentages of white-collar workers. It can be attractive for such organizations to offer smokers smoking cessation programs and to guarantee nonsmokers a smokefree work environment. Nonsmoking facilities may thus be regarded as secondary labor conditions.

Summary and discussion. Despite the evidence that smoking employees are more expensive than nonsmoking employees, few companies have used costs as the sole justification for initiating smoking control programs (Haynes et al., 1990). The potential financial benefits for Dutch companies are much lower than in the United States. Thus, direct economic considerations probably play a marginal role for Dutch companies. A causal relationship between smoking and reduction in absenteeism seems to exist, but is probably not very strong. Nevertheless, the wish to reduce absenteeism rates may be a strong reason for Dutch employers to do something about smoking. Another compelling reason for Dutch private companies to start anti-smoking activities is probably the desire to comply with nonsmokers' demands to work in a smoke-free workplace (social problems and legal problems) and consid. erations of the relationships between employer and employees (company image). 
This means that worksite anti-smoking programs should not only aim at smoking employees (stimulating them to quir smoking), but also at nonsmokers and their environment (protecting them from exposure to passive smoking). For some companies, considerations of increased or decreased productivity resulting from smoking at work may be important as well. Dutch labor conditions legislation may become more important if environmental tobacco smoke is accepted as an occupational health hazard.

\subsubsection{Employees}

In this section the focus is on how employees might perceive the "smoking problem'. Employees may or may not appreciate that their company interferes with smoking at work. Smoking employees who want to quit smoking and appreciate help from their company may display a positive attitude. About $30 \%$ of Dutch smokers intends to quit smoking in the near future (within six months or sooner) (Mudde, Dolders \& De Vries, 1994). Although most smokers who quit do so without the aid of formal cessation programs (Fiore et al., 1990), cessation methods do attract smokers seeking extra help. Assuming this is not very different in working populations, a substantial proportion of smoking employees would be susceptible to worksite smoking cessation programs. More research is needed to examine whether the need for smoking cessation programs differs across sectors of industry and across occupations.

Opposition to anti-smoking actions might come from unions and other employee representatives with a negative attitude to smoking bans (Brown et al., 1988; Davis, 1993). This resistance may not be restricted to smoking bans, but may also concern the implementation of smoking cessation programs. Resistance may arise if anti-smoking actions originate as a means of achieving goals that are beneficial to the company only. Central to many worksite health promotion programs is the view that the individual is (partly) responsible for a specific company problem, such as high absenteeism rates or low productivity. The objective of improving the performance of organizations by modifying the behavior of individual workers so that medical-care costs will be reduced and productivity will increase, has achieved the status of a paradigm in the United States (Sloan, 1987). The point is that workers are held responsible for a problem area (absenteeism, productivity) over which they lack control (Green, 1988). This situation of 'blaming the victim" can be avoided by not relating smoking cessation activities to issues such as absenteeism 
and productivity. A related viewpoint of many employees is that smoking is an individual life-style behavior with which company management should not interfere (Brown et al., 1988). This will be less of a problem if smoking cessation methods are offered to employees voluntarily and without obligations. Another concern of workers is that anti-smoking programs are used by management to divert attention from real hazards at the workplace, such as safety issues (Brown et al., 1988). It is therefore important to pay sufficient attention to factors in the physical and psychosocial work environment that may also affect smoking-related health problems. Thus, in the second step of the problem analysis of the $A B C$ model, the behavioral and environmental factors are specified that are related to known health problems and quality of life concerns in a specific worksite. For example, where respiratory problems are concerned, not only tobacco smoke may be identified as a cause, but also other sources of bad indoor air quality, such as inadequate ventilation and exposure to other toxic materials, must be taken into account. Brown et al. (1988) surveyed union members and found that smoking policies were more acceptable if they were implemented in the context of an active program to improve health and safety conditions. Furthermore, employee resistance will be less when employees are given an active decision making role in the development of the program (Green, 1988). In Chapter 3, data are presented showing that the majority of both smokers and nonsmokers are in favor of fairly restrictive legislations.

\subsection{Determinants of smoking cessation}

Most smokers find it very difficult to quit smoking ${ }^{3}$. It often requires multiple attempts before one succeeds (Cohen et al., 1989; US Department of Health and Human Services, 1989). People who attempt to quit smoking without any form of individual support or with only self-help materials have about $14 \%$ chance of succeeding after a quit attempt (Cohen et al., 1989). Formal smoking cessation programs generally achieve low success rates too. Even with the most intensive methods (smoking cessation clinics) about $70 \%$ of quitters relapse in the first year after

${ }^{3}$ Exceptions are so-called "chippers": people who smoke less than 5 cigarettes per day without developing tobacco dependence. However, this group is very small: about $10 \%$ of all smokers (Christen \& Christen, 1994; Epstein et al., 1989). 
treatment (Schwarz, 1987). Why is it so difficult for smokers to quit? The reason is that smoking and smoking cessation are determined by a complex interplay of multiple causes: biological-addiction mechanisms, conditioning processes, and cognitive-social learning factors (Carmody, 1992).

Central to the smoking habit is addiction. According to Eiser (1983) "an addictive behavior is one which is associated with strong short-term positive reinforcement contingencies" (p. 23). These immediate contingencies of the act of smoking are much more powerful than any longer-term consequences of smoking, such as health risks. There are two powerful reinforcement contingencies that influence each other, namely behavioral conditioning and the addictive properties of nicotine (Christen \& Christen, 1994). Fisher et al. (1993) described this interplay as follows:

The biological power of nicotine may make the learned behaviors that form smoking patterns stronger and more resistant to change. At the same time, the plenitude of daily circumstances, activities, and emotions to which smoking is conditioned ties this behavior to numerous rituals of daily life and contributes to the difficulty of breaking the addiction. (p. 60)

It has been estimated that an average smoker consumes more than 90,000 cigarettes over his or her smoking lifetime, resulting in nearly one million puffs (Tiffany, 1991). The many circumstances in which smoking occurs become stimuli for smoking and the physical effects of nicotine reinforce smoking. Because smoking is a highly repetitive behavior, these conditioning effects "create a tightly and intricately woven fabric of smoking in daily life - not one likely to unravel with the loosening of a few threads" (Fisher et al., 1993, p. 62).

The addictive nature of smoking depends for a large part on the psycho-pharmacological effects of nicotine. In the 1988 review of the American Surgeon General on the addictive properties of nicotine, it was concluded unequivocally that tobacco is addictive, because nicotine satisfies all criteria that define a dependency drug (US Department of Health and Human services, 1988). The year before, in a revised version of the diagnostic and statistical manual of mental disorders (DSM-III-R),
nicotine dependence was regarded as a psychoactive substance dependence disorder 
(American Psychiatric Association, 1987). The psychoactive nature of nicotine means that nicotine acts on the central nervous system to produce euphoric effects that serve as a primary reinforcer. Novice smokers gradually develop tolerance to fairly high levels of nicotine, resulting in a stable level of consumption, usually from one to two packs per day (Henningfield et al., 1993). Smoking is maintained through negative reinforcement, that is, through avoidance of nicotine withdrawal symptoms or of anticipated negative emotions (US Department of Health and Human Services, 1988). The occurrence of withdrawal symptoms such as craving, irritability, anxiety and concentration problems after quitting smoking also point to the severity of the nicotine addiction. Indeed, most quitters relapse within two weeks, when nicotine withdrawal symptoms are most severe (US Department of Health and Human Services, 1988). Research focussing on nicotine dependency has led to the development of nicotine replacement therapy (chewing gum and patches containing nicotine).

The addictive properties of tobacco explain the perseverance of smokers, but they do not make clear why many smokers succeed in quitting smoking, whereas others do not. Studies that have compared successful quitters with relapsers have used a wide variety of predictor variables, including demographic characteristics (for example Freund et al., 1992; Kabat \& Wynder, 1987; Kok et al., 1982) and personality variables (for example Caplan et al., 1976). However, these studies are of limited use for the development of smoking cessation programs, since demographic and personality variables cannot be changed or are very difficult to modify by health education or therapy.

Other studies have used a social-cognitive approach. These include the transtheoretical model (for example: DiClemente et al., 1991; Gottlieb et al., 1990; Hennrikus et al., 1995), social-cognitive theory and self-efficacy theory (Bandura, 1986; see for example: Kavanagh et al., 1993 and Strecher et al., 1986), a stress and coping perspective (Carey et al., 1989), the relapse prevention model (Marlatt \&

${ }^{4}$ 'The labeling of smoking as an addiction has political and ethical consequences (Eiser, 1983). The advantage is that smokers are taken more seriously. The disadwantage is that smokers may be seen as less responsible for their behavior, suggesting that smokers are helpless victims of their addiction. Smokers relieve dissonance concerning their smoking in light of the well-known health risks, by saying that smoking is addictive, both physically and psychologically (Jenks, 1992). However, the fact that the vast majority of smokers quit smoking without professional help, suggests that smoking cessation is a common event (Schachter, 1982) and that smoking is ultimately under volitional control. 
Gordon, 1985; for example: Shiffman, 1984), the role of social support (Lichtenstein et al., 1986), the health belief model (Janz \& Becker, 1984; for example: Robert, 1992) and the theory of reasoned action (Ajzen \& Fishbein, 1980; Fishbein \& Ajzen, 1975) or its successor, the theory of planned behavior (Ajzen, 1985; Ajzen \& Madden, 1986; for example: Godin et al., 1992).

In this thesis, the attitude - social influence - efficacy (ASE) model is used. This model integrates the theory of reasoned action with Bandura's concept of self-efficacy (De Vries et al., 1988). According to the ASE model, beliefs are central to a person's tendency to behave in a certain way. Behavioral change is best predicted by someone's intention. The ASE model assumes that behavioral intention is determined by someone's attitude towards the behavior, perceived social influences, and self-efficacy expectations. Social influences include perceived social norms, perceived smoking behavior, and direct social pressure (De Vries, Backbier et al., 1995). By including self-efficacy (i.e., a person's beliefs about his or her abilities to quit smoking) in the ASE model, the theory deals with behaviors over which people have limited control, such as smoking. The ASE variables have been found to predict behavioral intentions with a fair degree of accuracy. Intentions and self-efficacy can account for a considerable proportion of variance in behavior change (De Vries et al., 1988; Mudde et al., 1995).

However, it is not enough to predict intention to quit smoking, because making a quit attempt is relatively easy for most smokers, but staying off cigarettes is more difficult. It is now realized that smoking cessation can best be seen as a dynamic process in which smokers move through the following phases: from a. not thinking about quitting, through $\mathrm{b}$. contemplating quitting to $\mathrm{c}$. preparing to quit, d. actually making a quit attempt, and finally e. definitive abstinence (Prochaska \& DiClemente, 1983, 1991). This process may extend over a number of years, since most smokers do not progress from the first phase to the final phase in one effort, but relapse frequently to previous phases. A brief glance at the literature concerning determinants of smoking cessation reveals that some studies examined intention to quit smoking, while others studied quit attempts (or participation in a smoking cessation program) or examined predictors of long-term abstinence. The determinants of these three outcome variables - intention to quit, making a quit attempt and long-term success - are quite different (De Vries et al., submitted; Fisher et al., 1993). This literature is discussed below. 


\subsubsection{Determinants of intention to quit}

The three ASE variables have quite consistently been identified as important predictors of intention to quit smoking. Godin et al. (1992) found that intention to quit smoking was predicted by an individual's attitude towards smoking, his or her perception of the prevailing social norms, and perceived behavioral control. Van-Oss Marin et al. (1990) found that intention to quit smoking was strongly related to attitude scores and, to a lesser extent, to perceptions of subjective norms in the general smoking population. Breteler (1988) found comparable results in a population of Dutch bank-employees. In addition, Breteler reported that intention to quit smoking was also related to the number of previous quit attempts and the level of nicotine addiction, but not by self-efficacy levels. Eiser et al. (1985) reported that intention to quit smoking was most strongly related to self-efficacy and attitude scores in a population of Dutch smokers motivated to quit. Lichtenstein \& Cohen (1990), in a study among unaided quitters, found that high motivation to quit was related to positive expectations about the benefits of smoking cessation.

\subsubsection{Determinants of making a quit attempt}

Studies that included intention in the analysis of the determinants of quit attempts, found without exception that intention was the single best predictor (Cummings et al., 1988; Eiser et al., 1985; Gottlieb et al., 1990; Hennrikus et al., 1995). Godin et al. (1992) found that making a quit attempt was significantly predicted by someone's intention to quit smoking and by perceived behavioral control. A relation between quit attempt and self-efficacy was also found by Lichtenstein \& Cohen (1990). The number of previous quit attempts is a predictor of subsequent quit attempts (Cummings et al., 1988; Eiser et al., 1985; Hellman et al., 1991). Hellmann et al. (1991) reported that the likelihood of making a quit attempt was positively associated with one's intention to quit smoking and the number of previous quit attempts, and was negatively associated with the level of nicotine dependency. These findings were confirmed by Hennrikus, Jeffery \& Lando (1995).

Not all smokers with a strong intention to quit smoking and with high selfefficacy levels automatically attempt to quit smoking. Sometimes a smoker may be confronted with uncontrollable factors preventing him or her from making an attempt to quit. These are incidental barriers, skills, and the availability of resources, such as quit methods (Carey et al., 1989; De Vries et al., 1988). 


\subsubsection{Determinants of long-term success}

Many studies have found that smokers with high self-efficacy beliefs about stopping smoking have a greater chance of long-term success (see Strecher et al., 1986 for a review). These include worksite smoking cessation studies (Gottlieb \& Nelson, 1990; Harris et al., 1994) and group programs (Kavanagh et al, 1993). Long-term abstinence among subjects in a group program was predicted by self-efficacy levels after the quit attempt, and changes in self-efficacy during treatment (Mudde et al., 1995). Another predictor is the level of nicotine dependency or the amount of cigarettes that one used to smoke. For example, in a study by Eiser et al. (1985) long-term success after a quit attempt was best predicted by high self-efficacy pretest scores, low nicotine dependency levels and low nicotine intake (smoking less cigarettes). Lichtenstein \& Cohen (1990) found in their examination of unaided quitters that long-term success was negatively associated with the number of cigarettes and the level of nicotine addiction. Similar results were reported in worksite smoking cessation studies (Daughton et al., 1990; Glasgow et al., 1988; Hallett \& Sutton, 1987; Hennrikus et al., 1995) and in a study among participants in a heart disease prevention program (Ockene et al., 1982). A third important determinant of longterm success is social support. A study among participants in a worksite smoking cessation program found that success after three months was associated with having a nonsmoking partner (Cummings et al., 1988). The impact of self-efficacy and social support from a nonsmoking partner on preventing relapse was confirmed in a recent prospective study among self-quitters (Gulliver et a., 1995). Others reported that relapse was associated with having more smokers in one's social network (Hanson et al., 1990; Mermelstein et al., 1986; Ockene et al., 1982). Harris et al. (1994) also reported that long-term success in a group course was higher among participants who had smoking friends or a smoking partner. Attitude variables (Eiser et al., 1985; Hellman et al., 1991; Kok et al., 1982) and pretest intention scores (Hellman et al., 1991; Lichtenstein \& Cohen, 1990) seem to be unrelated to long-term success.

\subsubsection{Summary and discussion}

Trying to stop smoking can be understood as a deliberate act to which expectancyvalue models can be applied. Intention to quit seems to depend most strongly on beliefs about the outcomes of smoking cessation and perceptions of social norms and, to a lesser degree, on self-efficacy levels. Intention is the single best predictor 
of whether a smoker will make a quit attempt, but self-efficacy levels seem to have additional predictive power. Having more past experiences with quitting smoking also increases the likelihood that motivated-to-quit smokers will make an attempt to quit again, suggesting a feedback-loop from previous quit attempts to present ASE cognitions and intention. Skills, barriers, and the availability of quit methods are external factors that increase or decrease the likelihood that intention will lead to a quit attempt. Eventual success after a quit attempt, seems to depend on self-efficacy levels and on the severity of the addiction. The social environment seems another important factor in preventing relapse. Figure 2.5 presents a simple framework summarizing these research findings. This framework may be refined by substituting intention by precontemplation, contemplation and preparation stages, as proposed by the transtheoretical model of change (Prochaska \& DiCLemente, 1983; 1991), and by a specification of the way the ASE variables affect movement through these stages (see De Vries \& Backbier, 1994 and De Vries et al., submitted). The framework can be used as a starting point for smoking cessation interventions. Thus, interventions should aim at changing the ASE variables, should help smokers acquire the necessary skills, should help them to overcome barriers to quitting smoking, should help highly addicted smokers with overcoming their nicotine addiction and they will be more effective if conducted in a supportive social environment.

A prerequisite for individual behavioral change to occur through health education is that an educational program successfully influences psychological determinants of behavior. An important issue is whether it would be necessary to adapt existing smoking cessation methods that had been proven effective in the general population (such as, self-help manuals and group courses) to characteristics of employees. It is now believed that small differences in behavioral treatment and differences in form and content of educational materials are not very important to get smokers to quit (Lichtenstein \& Glasgow, 1992). For example, quit rates in American Lung Association's smoking clinics, which are comparable to those offered by the Dutch Foundation on Smoking and Health, were similar in community clinics and in worksite groups, averaging $29 \%$ quit rate after 1 year (Rosenbaum \& O'Shea, 1992). A study among fire fighters illustrates this point with respect to self-help materials. A general self-help manual produced the same success rate (12\%) as a manual specifically designed for smoking fire fighters (O'Hara et al., 1993). Another study found that the format of a manual and the choice of quitting instructions had no effect on smoking cessation rates (Cummings et al., 1988). Therefore, for the 


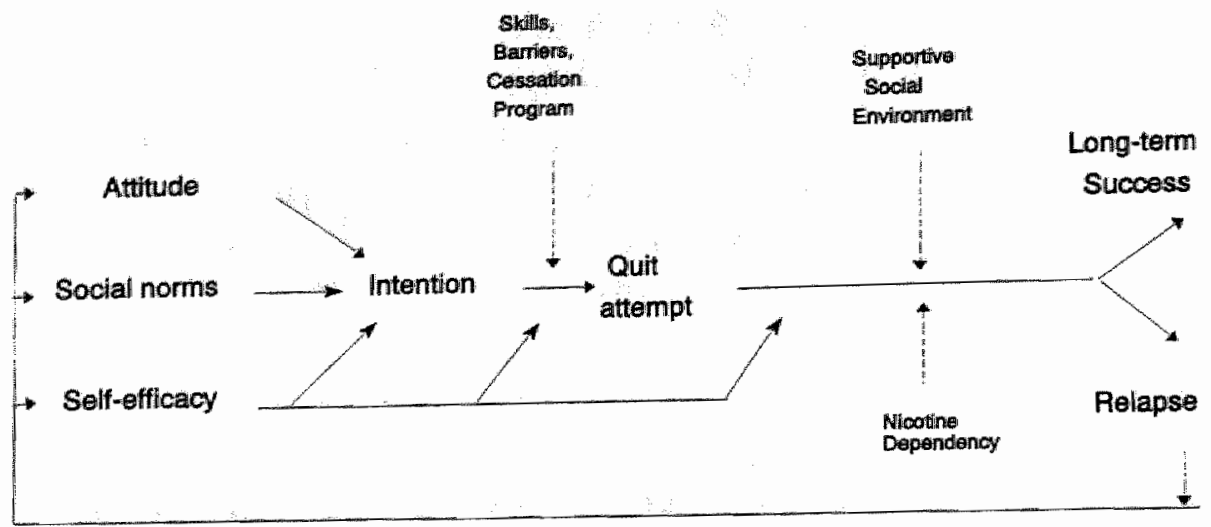

Figure 2.5: Determinants of smoking cessation.

effectiveness studies presented in Chapters 6 to 8, we used a general self-help manual and only made some minor adjustments to its format in order for it to be presentable as a worksite manual. However, we felt that it was still important to examine the psychological determinants of smoking cessation of Dutch employees, because these might differ from those found in, for example, US studies (see Chapter 4).

\subsection{Access to worksites}

Before specific intervention strategies are selected, it is important to conduct a needs assessment among employees. This might make clear, for example, which smoking policy options are feasible in a specific worksite. In addition, interviews with company representatives will help to choose appropriate intervention strategies. For example, company representatives participating in the research for this thesis, almost uniformly pointed out that incentive strategies or competitions would not fit with their company culture. They made it clear that nonsmoking employees would strongly disapprove of smokers receiving an incentive for quitting smoking. 


\subsection{Setting goals for interventions}

In the $\mathrm{ABC}$ model, information about target groups and behavioral determinants are used as starting points for developing an intervention designed to change these determinants (Behavioral change phase). This phase starts with setting specific goals. There are two goals that are related to the 'smoking problem' in worksites. First, one could strive to reduce smoking in a population of workers. A second goal could be to eliminate exposure to environmental tobacco smoke. The first goal is directed at smokers' health, the second goal is beneficial to nonsmokers' health. Achieving the first goal (reducing smoking or, preferably, reducing the proportion of employees who smoke) will also have a positive effect on the second goal.

\subsection{Choosing intervention strategies}

The second step in the behavioral change phase of the ABC model is to decide which strategies should be used and whether they should be merely educational or also include legislation and improvement of facilities. The type of strategy depends on the goal one wishes to achieve (see Figure 2.6). Basically, three strategies to reduce smoking in worksites can be distinguished (Abrams \& Biener, 1992; Dawley et al., 1984, 1993). These are: a. strategies targeted at the individual smoker (smoking cessation program such as group courses, self-help manuals, and nicotine replacement therapy), b. strategies aimed at the social environment (health education through mass media such as information displays, company newsletters, and brochures), and c. strategies targeted at the organization (smoking restrictions and other structural or policy changes).

As illustrated in Figure 2.6, worksite smoking cessation programs are expected to help smokers quit smoking, resulting in reductions of smoking prevalence. Smoking restrictions are expected to eliminate the exposure to ETS. Because little is known about the direct effects of health education through mass media strategies on quitting smoking in worksites and on reduction of ETS, these relationships are indicated by dotted arrows. The other arrows in Figure 2.6 illustrate some hypothesized ways in which the three strategies might reinforce each other. Most of these 
relationships have not yet been studied sufficiently. The existing evidence is reviewed in the next paragraphs.

Strategies

Goals

level

Social

level

Organizational

level'

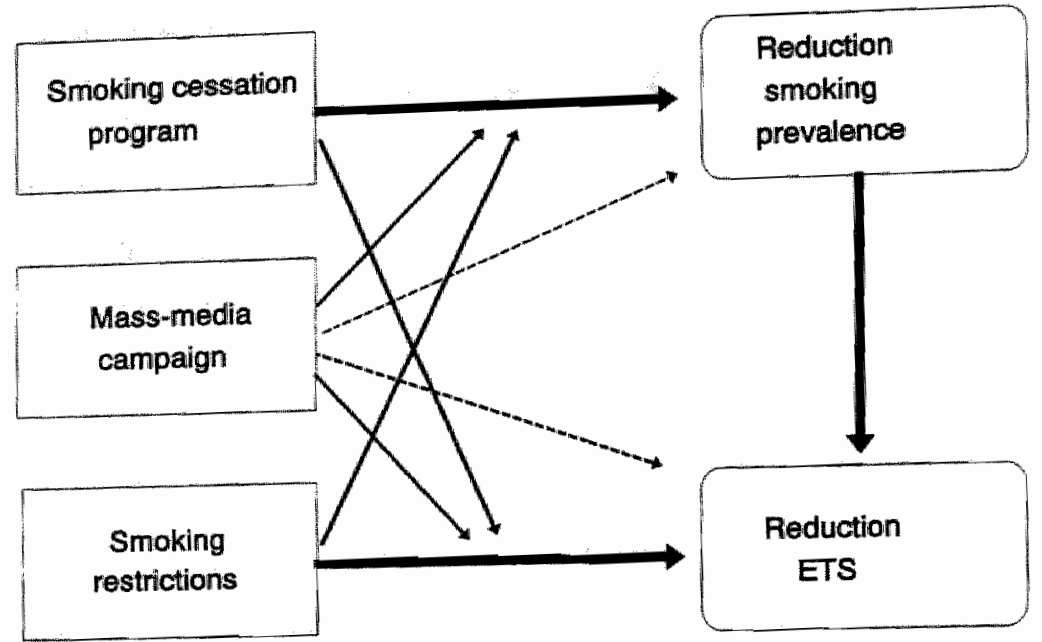

Figure 2.6: Hypothesized relationships between strategies and goals in comprehensive worksite smoking control programs.

\subsection{Effectiveness of worksite programs}

\subsubsection{Smoking cessation programs}

In the 1970 s and in the first half of the 1980 s, much research has been carried out on the effectiveness of smoking cessation programs in worksites, mainly in the United States (for reviews see: Bibeau et al, 1988; Hallet, 1986; Klesges et al., 1987; Schwarz, 1987; Stoffelmayer et al., 1991; Strasser, 1991; US Department of Health and Human Services, 1985). Many of the studies were only descriptive in nature, had no experimental designs or did not report long-term results (Strasser, 1992), but at the end of the 1980s, enough randomized, long-term (one year follow-up) studies were publicized to justify meta-analytic examination of program effects. From a meta-analysis of 20 such studies it was concluded that worksite cessation programs 
produce an average long-term quit rate of $13 \%$ (ranging from $1.5 \%$ to $33 \%$ ), regardless of intervention methods (Fisher et al., 1990). This seems low in comparison to outcomes reported outside worksites where a quit rate of approximately $20-25 \%$ is regarded as a benchmark for clinically-based interventions and $10-20 \%$ for selfhelp interventions (see Chapter 1). However, due to the low threshold character of programs conducted in worksites, many smokers participate who are less motivated to quit. Moreover, many worksite programs that were examined in Fisher's metaanalysis consisted (partly) of low intensity methods such as self-help materials, which produce smaller quit rates than group courses. Fisher et al. found that interventions of greater intensity (i.e., more contact hours) were associated with higher quit rates.

From a public health perspective it is important that studies report on a program's impact on all employees who smoke, not only on participants. Very few experimentally controlled studies examining this issue have been conducted to date. In the Healthy Worker Project, a randomized trial involving 32 worksites, the impact of smoking cessation programs on smoking prevalence throughout the worksite was examined (Jeffery et al., 1993). Interventions focussed on obesity and smoking. Over 2 years, about $12 \%$ of all smokers participated in a smoking program consisting of classes and an incentive system, resulting in a $4 \%$ net reduction in smoking prevalence throughout the worksite. A typical decrease would be, for example, from $26 \%$ to $22 \%$ of employees smoking. This demonstrates the potential value of worksite smoking cessation programs to reduce national smoking rates. If all Dutch worksites implemented such programs, national smoking rates in the adult population might decline by at least $2 \%$ to $3 \%$ every two years.

\subsubsection{Mass media strategies and incentives}

Mass-media type of health education is needed to attract smokers to a smoking cessation program. Active health education through mass media has been found to increase participation rates in a comprehensive worksite smoking cessation program (Dawley et al., 1993). Furthermore, health education through mass media is expected to change attitudes and social norms, which in turn will have a beneficial effect on quitting. A related issue is whether mass-media methods promoting a supportive environment for quitting will enhance program quit rates. One study that explicitly examined this, failed to demonstrate this potential advantage of mass-media campaigns (Hymowitz et al., 1991). 
A health educational campaign is important to ensure that smoking restrictions are understood and are accepted (Greenberg, 1994), thus increasing the impact of smoking restrictions. It has been argued that acceptance of smoking bans is more likely if bans are presented in conjunction with health information on smoking (Brown et al., 1988).

An alternative way to encourage smokers to take part in a cessation program is through incentives or competitions. Several studies have examined whether incentives (e.g., money paid to employees for quitting smoking or lotteries in which quitters had a change to win money) or competitions (e.g., teams competing for cash or prizes for the highest participation and the greatest quit rates) can improve program participation and enhance cessation rates. A recent review of eight studies with an appropriate comparison group reported that five studies showed enhanced smoking reduction, but no study showed that incentives and/or competition enhanced smoking cessation past 6 months (Matson et al, 1993). It was concluded that it remains to be seen whether incentives or competition can produce any long-term effects. However, it was also concluded that incentives and competitions may increase participation in cessation programs. The program that is examined in Chapters 7 and 8 did not include incentives or competitions. Apart from the modest effectiveness of these approaches, an important reason was that Dutch company representatives who participated in our program made it very clear that the use of monetary incentives for smoking cessation would not be acceptable to nonsmoking Dutch employees and managers. This might be different from the US and Australia, where incentive programs are more common.

\subsubsection{Smoking restrictions}

At the organizational level, smoking bans and other structural improvements can be realized. Smoking restrictions are effective in reducing exposure to ETS (for a review see Brenner \& Mielck, 1992). Smoking bans seem to result in reduced smoking at work, but it remains unclear whether they may also have a direct impact on quitting smoking and on company smoking prevalence rates (Brenner \& Mielck, 1992). See Chapter 3 for a more complete review of this literature. In addition, smoking restrictions might encourage smoking employees to take part in a smoking cessation program (Green \& Kreuter, 1991; Gottlieb \& Nelson, 1990; US Department of Health and Human Services, 1986). For example, Sorensen et al. (1995) reported about a worksite in which the implementation of smoking restrictions 
contributed to an exceptional high participation rate $(71 \%)$ in a hypnotherapy cessation program. Vice versa, the availability of a smoking cessation program is likely to make restrictive smoking policies more acceptable (Eriksen, 1986). Furthermore, well implemented policies may alter public attitudes and norms about smoking behavior (US Department of Health and Human Services, 1986). Chapter 7 presents data on Dutch employees" support for different types of smoking bans.

\subsubsection{Comprehensive programs}

The latest thinking about worksite smoking cessation is to develop programs focussing on both the individual and his environment (Linnan et al., 1993). It is now understood that smoking cessation programs in worksites should aim at all smoking employees, not only on those ready to quit, since most smokers have no intention to quit smoking. For example, in the Netherlands $70 \%$ of smokers have no intention to quit smoking in the near future (Mudde, Dolders \& De Vries, 1994). This implies that multi-faceted programs are needed in which smokers in different motivational stages are influenced with different intervention strategies. Thus, smoking cessation methods are only part of a more comprehensive approach aimed simultaneously at the individual, the social, and the organizational level. Such comprehensive interventions are expected to produce greater changes in worksite smoking prevalence (Abrams \& Biener, 1992; Dawley et al., 1984), but this assumption still needs to be verified empirically. One study presented preliminary results showing that such a comprehensive program consisting of smoking cessation, smoking encouragement and smoking control strategies was more effective than a program consisting of only smoking cessation strategies (Dawley et al., 1993). However, two recent large-scale US studies using a randomized research design failed to prove the superiority of a comprehensive program. One project - "Take Heart' - assigned 26 worksites to either a comprehensive smoking cessation and healthy food intervention or a waiting-list control status (Glasgow et al., 1995). The other project was even larger in scale. The 'Working Well Trial' involved 111 worksites, randomized to a 2-year comprehensive cancer prevention intervention or to a control condition (Sorensen et al., 1996). Both studies found no significant short-term (6 months) improvement in smoking cessation in experimental worksites compared to control worksites. One explanation is that these programs were not sufficiently intensive to bring about changes in the whole population of smokers. More research is needed to identify condritions under which comprehensive programs are successful. 


\subsection{Program evaluation}

Newly developed program components need to be pretested first, before they can be evaluated in pilot studies. Before a program is disseminated for wider use, we need to know whether the program is effective and whether the program can be further improved. Effect evaluation is important to assess a program's effectiveness to bring about anticipated changes. These changes can be social-cognitive changes (e.g., cognitions, attitudes, social norms, self-efficacy expectations, skills, etc.), behavioral changes (smoking cessation) or improvements in health or quality of life outcomes (for example sickness absenteeism). Internal validity can be optimalized by using quasi-experimental or experimental research designs. In Chapters 6, 7, and 8, data on the effectiveness and impact of a Dutch worksite smoking cessation program are presented. Furthermore, if a program is less effective than expected, process and program evaluation are used to examine to what extent this was caused by implementation failures (see Windsor et al., 1994). Finally, it can be important for public health organizations to obtain information about a program's cost-effectiveness relative to other programs.

\subsection{Program continuation}

A worksite smoking cessation program will only have a substantial impact on smoking prevalence and ETS levels if this program is continued over several years. The chances that the program will be continued are greater if key persons in the organization have participated in developing and implementing the program, which can be realized by means of a linkage approach to program development (Orlandi et al., 1990). The linkage system, usually a committee or project group, connects the original developers of the program (resource system) with the users of the program (user system). This linkage system is responsible for developing and implementing the program and for adapting the program to the worksite. The following key figures would ideally be recruited as members of a linkage group: an external expert on health promotion, a management representative, an employee representative, a 
representative from the personnel department, a company physician or nurse, and an internal communication specialist (Willemsen, Haartsen, et al., 1996).

When research has proven that a specific program is effective this often does not automatically result in large scale program implementation. To achieve nationwide implementation, effective diffusion strategies must be developed and supportive policies and legislations are needed. These issues fall outside the scope of this thesis. 



\title{
3 \\ Annoyance from ETS and support for smoking policies ${ }^{1}$
}

\begin{abstract}
Background Many employers do not impose smoking bans because they think that employees are not bothered by tobacco smoke at the workplace. This study presents descriptive data on annoyance from environmental tobacco smoke (ETS), attitudes to smoking at the workplace, and employee support for smoking policies.

Method $A$ representative sample of smoking and nonsmoking employees $(N=1480)$ was drawn from eight large companies in four sectors of Dutch industry.

Results Tbirty-five percent of nonsmoking employees felt it was "annoying" to "very annoying" when their colleagues smoked during work time, and $78 \%$ thought a smoky work environment was barmful to their health. About two-tbird's of nonsmokers "sometimes" to "often" experienced actual annoyance from ETS at their workplace. The individual solution approach (no explicit policy) is not only rejected by most nonsmokers but also by many smokers. In three sectors of industry, there was much support among employees for a smoking ban except for work areas designated for smoking.

Conclusions The results could encourage more companies to implement smoking restrictions and they may be used as reference data by companies wanting to develop effective smoking policies.
\end{abstract}

Based upon:

Willemsen, M.C., De Vries, H., \& Genders, R. (1995). Roken op het werk: Ervaren hinder van tabaksrook en steun voor niet-rokenbeleid. Tijdschrift voor Sociale Gezondheidszorg, 73, 448-454. Willemsen, M.C., De Vries, H., \& Genders, R. (1996). Annoyance from environmental tobacco smoke and support for no-smoking policies at eight large Dutch workplaces. Tobacco Control, 5 , $132-138$. 


\subsection{Introduction}

Although it has been known for decades that active smoking causes disease in smokers, conclusive evidence that passive smoking is also harmful to health has accumulated more recently. Research has shown that involuntary (passive) smoking is a cause of disease, including respiratory disease and lung cancer (US Department of Health and Human Services, 1986). A report of the US Environmental Protection Agency concluded that passive smoking is a human carcinogen (Environmental Protection Agency, 1992). The Dutch Institute of Cancer Research has confirmed this conclusion (Jansen et al, 1993) and the Dutch Health Council has declared that it is very likely that prolonged exposure to environmental tobacco smoke (ETS) increases the risk of lung cancer (Health Council, 1990). Publications such as these about the harmful health effects of passive smoking have led to measures against smoking in public buildings and workplaces in many developed countries. The best strategy to protect nonsmokers" health is to prohibit smoking altogether or to limit smoking to enclosed, separately ventilated areas, because it is not possible to indicate safe exposure levels for carcinogenic substances (Environmental Protection Agency, 1992; Health Council, 1990).

In 1989, the European Union (EU) adopted a resolution encouraging member states to adopt measures to ban smoking in public places and in all forms of public transport (Joossens, 1990). Many EU countries have now implemented such policies for state-owned premises. However, with the exception of France, very few countries have provisions relating to smoking on private premises accessible to the public (European Bureau for Action on Smoking Prevention, 1994). The health dangers of involuntary smoking are much more important at workplaces than in public places, because of the high frequency and long duration of exposure to ETS in workplaces. However, the absence of national legislation means that companies still have to be motivated to implement clear nonsmoking policies voluntarily. The extent of annoyance from ETS can be one important motive for decreasing smoking at the workplace, probably more so than health statistics. In addition to being unpleasant, exposure to ETS can cause irritation of the eyes and of the mucous membranes of the nasal and throat cavity (US Department of Health and Human Services, 1986;

An national survey showed that only $25 \%$ of Dutch worksites took action against ETS in 1990 (Dutch Foundation on Smoking and Health, 1990). However, 
most of these measures were limited to spreading posters to encourage nonsmoking; only $31 \%$ of these companies implemented bans on smoking. Many employers are reserved regarding smoking bans. Hearing no complaints about tobacco smoke was the reason most mentioned for deciding not to implement smoking bans. Quite often managers assume there is no annoyance problem, as long as workers do not voice complaints about ETS. A better strategy would be to ask employees directly about annoyance caused by tobacco smoke and the support for smoking restrictions. Surveys in the US have shown that most smokers and nonsmokers favour restrictions on smoking at the workplace (Gallup Poll, 1985). However, few data exist from European countries. This is especially important, because smoking prevalence continues to be higher in Europe than the US. In 1994, smoking prevalence in the EU was $34 \%$ ( $42 \%$ of men and $28 \%$ of women) (European Bureau for Action on Smoking Prevention, 1994), compared with less then $26 \%$ in 1990 in the US (Fiore et al., 1993). The Netherlands is among the European countries with a high smoking prevalence: $37 \%$ in 1993 according to one survey (Swinkels, 1994).

Another reason for the reservations expressed by companies could be the expectation that insufficient support within the company for smoking bans could lead to social unrest and conflicts at the workplace. However, studies show that measures to reduce smoking (except for a complete smoking ban) have led to very few conflicts or resistance at the workplace (Andrews, 1983; Biener, Abrams, Follick, \& Dean, 1989; Fielding, 1991; Rosenstock et al., 1986; Sorensen \& Pechacek, 1989). Some studies have shown that support for smoking bans increased after their implementation (Borland, Owen, et al., 1990; Brenner \& Fleischle, 1994). There are few studies about the attitudes of European employees towards smoking bans. Implementation of smoking restrictions results in a decrease in annoyance caused by tobacco smoke because of a reduction in tobacco consumption among employees at the worksite (Biener, Abrams, Follick \& Dean, 1989; Borland, Chapman, et al, 1990; Brenner \& Mielck, 1992; Brigham et al., 1994; Daughton et al., 1992; Jeffery et al., 1994; Petersen et al., 1988; Gottlieb, Eriksen et al., 1990). Some research studies show an effect of smoking bans on actual smoking prevalence among employees (Borland, Owen \& Hocking, 1991; Emmont \& Cummings, 1990; Millar, 1988; Sorensen et al., 1991; Stave \& Jackson, 1991; Woodruff et al., 1993), whereas other studies show no effect (Biener, Abrams, Follick \& Dean, 1989; Borland, Chapman, et al., 1990; Daughton et al., 1992; Gottlieb, Eriksen et al, 1990; Jeffery et al., 1994; Petersen et al., 1988). 
This chapter presents data from employees in four sectors of industry in the Netherlands on annoyance caused by tobacco smoke at workplaces and on support for measures to reducing worksite smoking. The results may be of interest to health educators and policy makers in countries that may be struggling to implement worksite bans.

\subsection{Method}

\subsubsection{Research population}

Random samples were taken from employees files of eight large companies. Because the size of the companies varied and we wanted to be able to relate the results to specific companies, a relatively larger sample at the smaller companies was taken: the sample fractions differed from 10\% at the largest company (3500 employees) to $33 \%$ at the smallest company (295 employees). The samples were drawn from files on which all employees were listed on alphabetic order. A sample of $10 \%$, for example, was attained by choosing each 10 th person from the list. The same procedure was used in each company.

After an announcement in company newsletters, employees who were in the random sample were approached by telephone for an interview. The interview started with an explanation about the purpose of the interview - namely, to assess employees' opinion about smoking at work - and about the fact that the results would be treated in strict confidence. After agreeing to participate, they were interviewed by means of computer assisted telephonic interviewing.

The eight companies belong to four sectors of industry: chemistry (1376 employees in two chemical production companies), transport (865 employees in two districts of a bus company), telecommunications (6359 employees in two districts of a telecommunications company), and local government (2318 employees in two midsized communities). The current smoking policy for each company was examined by interviewing company representatives and making observations during visits.

\subsubsection{Measurements}

5

of work (office work, manual labor, or a combination), age, education level, type
of 
Smoking behavior was measured by asking whether the respondent smoked, what was smoked ('roll-your-own' cigarettes, manufactured cigarettes, pipe, cigars) and how much was smoked daily and at the workplace.

Attitudes about smoking at the workplace were measured by the following questions: "Does it bother you when smoking is allowed at the workplace?", "Do you think a smoky work environment is harmfull to your health?", and "Do you think the chance of getting cancer for nonsmokers is greater when people smoke at the workplace?". The fourth item measured a possible aspect of smoking that is typically Dutch and difficult to translate - namely, whether smoking increases sociability when people are together. A 5-point scale was used that ranged from completely agree to completely disagree.

Annoyance from ETS among nonsmokers was measured by asking a general question: "How often do you experience annoyance resulting from ETS in your company?" The response choices were: never, sometimes, regularly, often, very often, and always. Secondly, nonsmokers were asked how often they found tobacco smoke a nuisance at their workplace, and in meeting rooms, canteens, corridors, elevators, and restrooms.

Both smokers and nonsmokers were asked whether they advocated smoking restrictions in the previously mentioned areas. In addition, they were asked to what extent they agreed with several alternative smoking policies $(-3=$ completely disagree to 3 = completely agree). Four policy options were considered, varying from no explicit policy to a complete smoking ban (see Table 3.4). These options correspond to international classifications of policies for nonsmoking measures (Fisher, Glasgow \& Terborg, 1990; Joossens, 1990; US Department of Health and Human Services, 1986).

\subsubsection{Statistical analyses}

Differences among the four sectors of industry were analysed with $\chi^{2}$ tests. Multiple logistic regression analysis was used to assess differences among sectors of industry with regard to employee support for smoking policy options while adjusting for demographic variables and smoking status. 


\subsection{Results}

Of 1730 employees who were approached for an interview, 1480 were completed. The response rates among the companies ranges from $75 \%$ to $93 \%$ (mean $=86 \%$ ). $\chi^{2}$ tests were used to compare the sex and age distributions of each sample to data from the full workforce provided by the companies' Departments of Human Resources. These comparisons showed the samples were representative, with the exception of older employees, who were over-represented in the samples of one the local governments $\left(\chi^{2}(4)=10.5 ; \mathrm{p}<.05\right)$ and a telecommunications company $\left(\chi^{2}(4)=20.6 ; \mathrm{p}<.001\right)$.

\subsubsection{Comparison among company types}

The smoking policies in place at the times of the interviews (March to September 1993) differed considerably among the four types of companies, but within each company type they were similar. This also applied to demographic features. Employees did not differ significantly from company to company within the same sector of industry concerning attitudes about smoking at the workplace. Companies within each sector were very similar regarding company size and type of work. Therefore, this study focuses on differences and similarities among sectors of industry, instead of focusing on differences among individual companies.

\subsubsection{Demographic features}

Table 3.1 shows the demographic features of each company type. Respondents in the chemical industry and transport were more likely to be male, to perform manual labor, and to work in shifts, compared with the respondents in the telecommunications sector and those working for the local government (in the chemical industry respondents usually worked as technicians and operators in the factory, whereas transport companies employed mainly bus drivers). The average level of education in the transport industry was lower than in the other types of industry. Respondents from the local government more often had a high level of education (they included different occupations, such as fire workers, social security workers, and civil servants). Common professions in the telecommunications sector were telephone operators, store employees, office employees, and technicians. 


\subsubsection{Smoking behavior}

Smoking prevalence did not differ significantly among the industry sectors: on average $34.4 \%$ smoked (Table 3.1). By comparison, in 1993 between $33 \%$ and $37 \%$ of the Dutch adult population smoked, depending on the survey method used (Swinkels, 1994; Dutch Foundation on Smoking and Health, 1996). Smoking respondents in the chemical and transport industry more often consumed rol-your-own cigarettes (versus manufactured cigarettes) ( $75 \%$ and $85 \%$ of smokers, respectively) than the smoking respondents in the telecommunications sector and local government $\left(51 \%\right.$ and $54 \%$, respectively) $\left(\chi^{2}(3)=39.0 ; p<.001\right)$. The prevalence of cigar and pipe smokers did not differ among the sectors. Between $7 \%$ and $12 \%$ of all smoking respondents smoked cigars and between $3 \%$ and $5 \%$ smoked pipe tobacco (the percentages add to more then $100 \%$ because some smokers used more then one tobacco product).

The smokers reported an average daily consumption of 16 pieces of smoking articles (roll-your-own cigarettes, manufactured cigarettes, pipe and/or cigars). A one-wray analysis of variance showed no significant differences among sectors at the $\mathrm{p}=.05$ level. About half this amount was consumed at the workplace (8.3 cigarettes). Workplace consumption was significantly lower in the chemical industry than in the telecommunications companies $(7.3$ vs 9.3 cigarettes; $F(3 ; 501)=3.52 ; \mathrm{p}$ $<.05)$.

\subsubsection{Smoking policy measures}

Interviews with company representatives and personal observations provided details about company smoking policies. All worksites had a moderate smoking restriction - that is, restrictions were in place only in specific areas. Substantial differences existed among the four sectors of industry concerning which areas were smoke-free.

Because of the danger of explosion smoking was not allowed in the chemical companies at all outdoor premises, in factories and in laboratories. In addition, smoking was not allowed in two-thirds of the canteens. Furthermore, smoking limitations were operative in control rooms, where smoking was only allowed in designated smoking areas. Employees in most work offices were encouraged to come to mutual agreements about smoking, but no formal restrictions existed in these offices. 
Table 3.1. Demographic features of each type of company

$\begin{array}{llll}\text { Chemical } & \text { Telecom- } & \text { Local } & \text { All } \\ \text { industry } & \text { munications Transport } & \text { Government } & \text { companies } \\ (N=391) & (N=506) \quad(N=198) & (N=385) & (N=1480)\end{array}$

$\begin{array}{llllll}\text { Smoker (\%) } & 30.2 & 37.0 & 36.0 & 34.0 & 34.4 \\ \text { Male (\%) } & 92.1 & 71.3 & 91.9 & 69.9 & 79.2 \\ \text { Age (mean (SD)) } & 41.2(9.1) & 39.9(9.3) & 41.6(7.9) & 39.4(8.7) & 40.4(8.9) \\ \text { Type of work }(\%) & & & & & \\ \text { Manual labor } & 38.6 & 15.6 & 41.9 & 17.7 & 25.7 \\ \text { Office work } & 22.0 & 10.9 & 48.0 & 13.9 & 19.6 \\ \text { Combination manualioffice } & 39.4 & 73.5 & 10.1 & 68.6 & 54.7\end{array}$

Education level $(\%)^{\text {a }}$

$\begin{array}{lccccc}\text { Low } & 15.1 & 24.4 & 58.6 & 14.5 & 24.0 \\ \text { Medium } & 55.1 & 58.5 & 36.9 & 41.9 & 50.3 \\ \text { High } & 29.8 & 17.1 & 4.5 & 43.6 & 25.7 \\ \text { Working in shifts }(\%) & 40.4 & 12.5 & 85.4 & 9.4 & 28.8\end{array}$

" $\mathrm{p}<.001\left(x^{2}\right.$ tests between four company types).

"Low = primary school, lower vocational training; Medium = preparatory school, middle voca" tional training; High = university, higher vocational training.

At the local governmental worksites, smoking bans were in place in common rooms such as meeting rooms, corridors, restrooms, elevators, waiting rooms and (sections of) canteens. However, interviews with staff members of one of the local government organizations revealed that these smoking restrictions were hardly observed, despite a national tobacco law stating that smoking is prohibited in public places, which came into effect in 1990. Little attention was paid to smoking bans, and restrictions were incompletely identified by posted signs. Thus, for many 
employees it was unclear where smoking was allowed. No restrictions existed in offices.

In the transport companies, smoking restrictions were only operative on buses (the workplace of the drivers). Although violations could lead to sanctions, many drivers still smoked on buses. There were no smoking restrictions for canteens, and employees were allowed to smoke in offices.

In the telecommunications sector, smoking restrictions existed in rooms with smoke-sensitive equipment and in small sections of canteens. In almost all other places smoking was allowed, including conference rooms and work offices.

\subsubsection{Attitudes towards smoking in the workplace}

The four sectors did not differ significantly from each other concerning attitudes of nonsmokers towards smoking at the workplace. An average of $54 \%$ of the nonsmokers claimed to be bothered or very bothered by smoking at the workplace (compared with $7 \%$ of the smokers), $79 \%$ thought a smoky work environment was harmful to their health (compared to $60 \%$ of the smokers); $79 \%$ thought that smoking at the workplace increases sociability when people get together (compared with $25 \%$ of the smokers), and $49 \%$ thought nonsmokers had more chance of getting cancer because of smoking at the workplace (compared with 20\% of the smokers).

\subsubsection{Annoyance from tobacco smoke}

Table 3.2 shows how often nonsmokers perveived tobacco smoke as annoying at various places in the companies. In all sectors of industry, more than two-thirds of nonsmokers claimed to be annoyed at least sometimes by ETS in their company as a whole. Depending on the type of sector, the percentage of nonsmokers who experienced annoyance in meeting rooms varied from $37 \%$ to $51 \%$, in canteens from $18 \%$ to $62 \%$, in corridors from $11 \%$ to $21 \%$ and in elevators or restrooms from $3 \%$ to $17 \%$.

More employees in the transport sector were annoyed by tobacco smoke in canteens, compared with the other types of companies. On the other hand, respondents from the transport sector experienced significantly less annoyance at their own work office. This is because these employees consider the bus as their work office. This is in contrast to nonsmokers in the telecommunications and government sector, where $35 \%$ and $38 \%$, respectively, were annoyed by ETS at their work office. 
Table 3.2: Proportion of nonsmoking employees experiencing anvoyance from ETS, by company types.

\begin{tabular}{|c|c|c|c|c|}
\hline Places & $\begin{array}{l}\text { Chemical } \\
\text { industry } \\
(N=273)(\%)\end{array}$ & $\begin{array}{l}\text { Telecommunica- } \\
\text { tion sector } \\
(N=319)(\%)\end{array}$ & $\begin{array}{l}\text { Transport } \\
\text { sector } \\
(\mathrm{N}=125)(\%)\end{array}$ & $\begin{array}{l}\text { Local Gove } \\
(\mathrm{N}=254)\end{array}$ \\
\hline Company as a whole & 69.3 & 71.2 & 67.2 & 67.7 \\
\hline Own Work office & 26.4 & 35.1 & 16.8 & $37.8^{* * *}$ \\
\hline Meeting rooms & 38.8 & 51.4 & 36.8 & $37.0^{* * *}$ \\
\hline Canteens & 17.6 & 32.9 & 62.4 & $28.3^{* *}$ \\
\hline Corridors & 11.0 & 14.4 & 14.4 & $20.5^{*}$ \\
\hline Elevators, restrooms b & 2.9 & 17.2 & 5.7 & $13.3 *$ \\
\hline
\end{tabular}

"Proportion nonsmokers who are at least sometimes annoyed by ETS at their workplace, based on the question: "How often do you experience annoyance resulting from ETS in your company?" (with answers ranging from never to always).

$b$ Because answers concerning elevators and restrooms were practically identical the average from both categories is presented.

${ }_{\mathrm{P}}^{\mathrm{P}}<.05 ;{ }^{4 * 4} \mathrm{p}<.01 ;{ }^{4+40+4} \mathrm{p}<.001$

\subsubsection{Support for smoking bans}

In all sectors of industry most nonsmokers and smokers supported a smoking ban in meeting rooms (Table 3.3). Regardless of company type, a smoking ban for one's own work office was endorsed by nonsmokers, whereas most smokers rejected this policy. Only in the chemical sector did most nonsmokers and smokers support a smoking ban in canteens. Support among nonsmokers for smoking bans in corridors, elevators, and restrooms was lowest in the transport sector.

Table 3.4 shows that few nonsmokers favoured the 'individual solution' approach in which there is no explicit policy (option 1). Only a bare majority of smokers in the telecommunications and transport sector supported this policy. 
Table 3.3: Percentages of employees in each company ype in favour of smoking bans in different rooms, by smoking status.

\begin{tabular}{|c|c|c|c|c|c|c|c|c|c|}
\hline \multicolumn{5}{|c|}{ Nansmokers } & \multicolumn{5}{|c|}{ Smokers } \\
\hline $\begin{array}{l}\text { Chemical } \\
\text { Industry }\end{array}$ & $\begin{array}{l}\text { Telecomi- } \\
\text { munica- } \\
\text { tions }\end{array}$ & Transport & $\begin{array}{l}\text { Local } \\
\text { Gowern- } \\
\text { ment }\end{array}$ & Tatal & $\begin{array}{l}\text { Chemical } \\
\text { Industry }\end{array}$ & $\begin{array}{l}\text { Telecam- } \\
\text { munica. } \\
\text { tions }\end{array}$ & Transport & $\begin{array}{l}\text { Local } \\
\text { Govern- } \\
\text { ment }\end{array}$ & Total \\
\hline$(\mathrm{N}=273)$ & $\mathbb{N}=3191$ & $N=125$ & $(N=254)$ & $(\mathrm{N}=971)$ & $(N=118)$ & $|N=187|$ & $(\mathbb{N}=73)$ & & $(N-509)$ \\
\hline
\end{tabular}

$\mid N-131)$

$\begin{array}{lllllllllll}\text { Own work room } & 65.2 & 58.6 & 71.2 & 55.1 & 61.2 & 39.0 & 20.9 & 32.9 & 31.3 & 29.5 \\ \text { Meeting rooms } & 81.3 & 84.3 & 72.0 & 84.6 & 82.0 & 63.6 & 58.8 & 50.7 & 77.1^{*} & 63.5 \\ \text { Canteens } & 68.5 & 35.1 & 44.8 & 54.3^{*} & 50.8 & 52.5 & 23.0 & 20.5 & 33.6 * & 32.2 \\ \text { Corridors } & 51.6 & 35.1 & 25.6 & 44.5^{*} & 41.0 & 60.2 & 47.1 & 38.4 & 64.9 & 53.4 \\ \text { Lifts } & 81.7 & 82.4 & 32.8 & 81.5^{*} & 75.6 & 81.4 & 84.0 & 42.5 & 79.4 * & 76.2 \\ \text { Rlestrooms } & 71.4 & 67.4 & 52.0 & 72.0^{*} & 67.8 & 78.8 & 74.3 & 67.1 & 74.0 & 74.3\end{array}$

"Differences across sectors significant, $\mathrm{p}<.001\left(\chi^{2}\right.$ test).

Support for a moderate restriction (smoking bans in public areas only: option 2) was significantly higher among nonsmokers in local government than among nonsmokers in other sectors. Smokers in local government were more often in favour of smoking bans during meetings (also option 2) than smokers in the other sectors.. The policy restricting smoking in the company except for designated smoking rooms (option 3), was supported more by employees in the chemical sector than in the other sectors. In addition, a narrow majority of smokers and nonsmokers in the transport and local government sector supported this option. In all company types, the percentage of nonsmoking respondents who favoured a worksite-wide smoking ban (option 4) was less than $12 \%$. The two questions covering option 2 were not mutually exclusive.

Table 3.5 shows odds ratios from logistic regression analyses for support for smoking bans in one"s own office room, for a general smoking ban (smoking restricted to designated areas) and for a complete smoking ban, for each variable of interest, adjusted for all other variables in the table. Support for a smoking ban in 
Table 3.4: Percentage of employees per type of company favouring various smoking policy options, by smoking status.

\begin{tabular}{|c|c|c|c|c|c|c|c|c|c|c|}
\hline \multirow[b]{3}{*}{ Nonsmoking policy options } & \multicolumn{5}{|c|}{ Nonsmokers } & \multicolumn{5}{|c|}{ Smokers } \\
\hline & $\begin{array}{l}\text { Chem: } \\
\text { Industry }\end{array}$ & Telecom. & $\begin{array}{l}\text { Trans. } \\
\text { port }\end{array}$ & $\begin{array}{l}\text { Local } \\
\text { Governm }\end{array}$ & $\begin{array}{l}\text { Total } \\
\text { Nonsmo } \\
\text { kers }\end{array}$ & $\begin{array}{l}\text { Chem. } \\
\text { Industry }\end{array}$ & $\begin{array}{l}\text { Teiecomm. } \\
\text { y }\end{array}$ & $\begin{array}{l}\text { 1. Trans- } \\
\text { port }\end{array}$ & $\begin{array}{l}\text { Locall } \\
\text { governmm. }\end{array}$ & $\begin{array}{l}\text { Total } \\
\text { Smakers }\end{array}$ \\
\hline & $(N-273)$ & $(N-319)$ & $(N=125)$ & $\mid(N=254)$ & $(N=-971)$ & $(N=11 B$ & 3) $(N=187)$ & $(N=73)$ & $(N=131)$ & $(N=509]$ \\
\hline 1. No explicit policy al & 17.6 & 22.9 & 36.0 & $19.7^{*}$ & 22.2 & 28.8 & 51.9 & 53.4 & $42.7^{\circ}$ & 44.4 \\
\hline $\begin{array}{l}\text { 2. Moderate smoking } \\
\text { restriction: }\end{array}$ & & & & & & & & & & \\
\hline Bans in public placess & 59.3 & 47.6 & 44.8 & $68.1 *$ & 55.9 & 70.3 & 60.4 & 56.2 & 70.2 & 64.6 \\
\hline Bans during meetings ${ }^{c}$ & 89.4 & 89.0 & 83.2 & 91.3 & 89.0 & 77.1 & 67.4 & 61.6 & $86.3^{*}$ & 73.7 \\
\hline $\begin{array}{l}\text { 3. Gentral nosmoking } \\
\text { policy d }\end{array}$ & 79.9 & 65.8 & 65.6 & $68.9^{\circ} 7$ & 70.5 & 76.3 & 37.4 & 54.8 & $53.4^{*}$ & 53.0 \\
\hline 4. Complete smoking ban ${ }^{8}$ & 5.1 & 8.5 & 11.2 & 9.1 & 8.0 & 2.5 & 1.1 & 2.7 & 3.1 & 2.2 \\
\hline
\end{tabular}

" "Employees come to agreements about where and when smoking is allowed"

" "For public places, such as corridors, smoking should be prohibited"

d "During conferences and other meetings, employees should not be allowed to smoke"

" "Smoking should not be allowed anywhere in our workplace, except in designated smoking areas"

" "Smoking should be prohibited on all company premises, without exceprions"

"Differences across sectors significant, $\mathrm{p}<.001\left(\chi^{2}\right.$ test). Answer choices "completely agree", "agree" and "somewhat agree" were combined into one category ("agree").

one's own office was positively associated with being nonsmoker, being female, and doing shift work. Doing office work was only of marginal significance (lower $95 \%$ confidence limit $=1.01$ ). Workers in the telecommunications sector and workers in local government had a lowrer odds of supporting bans for one's own office. Support for a general smoking ban (except in designated areas) was greater with nonsmokers, older employees ( $>45$ years), office workers, and workers in government and chemical industry. Support of a total smoking ban was positively associated with being nonsmoker, being older ( $>45$ years) and doing manual labor. Workers in the chemical industry had marginally lower odds of supporting this policy than workers in the transport sector ( $95 \%$ confidence interval close to 1 ). 
Table 3.5: Logistic regression analysis of employees" likelibood of supporting nonsmoking policy options $(N=1480)$; adds ratio's and 95\% confudence intervals.

\begin{tabular}{|c|c|c|c|}
\hline Variable & $\begin{array}{l}\text { Smoking ban in one's own } \\
\text { office }\end{array}$ & General no-snoking policy & Complete smoking ban \\
\hline \multicolumn{4}{|l|}{ Smoking status } \\
\hline Smoker & 1.0 & 1.0 & 1.0 \\
\hline Nonsmaker & $3.55(2.79-4.52)^{\prime \prime *}$ & $2.25(1.78 .2 .84)^{* \cdots}$ & $4.27(2.23-8.14)^{\cdots}$ \\
\hline \multicolumn{4}{|l|}{ Age } \\
\hline$<35$ & 1.0 & 1.0 & 1.0 \\
\hline $35 \cdot 45$ & $1.26(.95 \cdot 1.66)$ & $1.18(.89 \cdot 1.56)$ & $1.03(.55 \cdot 1.90)$ \\
\hline$>45$ & $1.03(.76-1.39)$ & $1.55(1.142 .111)^{* *}$ & $2.26(1.25 .4 .11)^{m *}$ \\
\hline \multicolumn{4}{|l|}{ Sex } \\
\hline Female & 1.0 & 1.0 & 1.0 \\
\hline Male & $57(.42 .77)^{* \ldots *}$ & $.70(.52-94)$ & $1.06(.57 \cdot 1.96)$ \\
\hline \multicolumn{4}{|l|}{ Educational level } \\
\hline Law & 1.0 & 1.0 & 1.0 \\
\hline Medium & $1.23(.92-1.71)$ & $.97(.71-1.32)$ & $1.07(.59-1.93)$ \\
\hline High & $2.04(11.40 \cdot 2.99)$ & $.89(.61 \cdot 1.32)$ & $1.28(.61 \cdot 2.68)$ \\
\hline \multicolumn{4}{|l|}{ Trpe of work } \\
\hline Mixed type of work & 1.0 & 1.0 & 1.0 \\
\hline Manual labor & $1.13(.78 \cdot 1.62)$ & $1.30[.90-1.87)$ & $2.17(1.10-4.291)$ \\
\hline Dffice work & $1.37[1.01 \cdot 1.88\}^{*}$ & $1.82(1,31-2.52)^{* *}$ & $1.78(.99-3.23)$ \\
\hline \multicolumn{4}{|l|}{ Shift system } \\
\hline No Shifts & 1.0 & 1.0 & 1.0 \\
\hline Shifft Worker & $2.33(1.69 \cdot 3.211)^{\cdots *}$ & $1.41(1.01-1.98)^{*}$ & $.61(.39+1.20)$ \\
\hline \multicolumn{4}{|l|}{ Company Type } \\
\hline Transport & 1.0 & 1.0 & 1.0 \\
\hline Chemical industry & $.65(.43-.99)$ & $3.02(1.96-4.65]^{* * *}$ & $.43(.199 .98)^{*}$ \\
\hline Telecommunication & $.49(.31-.77)^{* *}$ & $1.22(.79 \cdot 1.89)$ & $.70(.30-1.62)$ \\
\hline Local Goverament & $.42(.27 .67)^{\ldots * *}$ & $1.75\|1.10 .2 .77\|^{\circ}$ & $.82(.35 \cdot 1.92)$ \\
\hline
\end{tabular}

$\mathrm{p}<.05 ;^{* * 28} \mathrm{p}<.01 ;{ }^{* * * * *} \mathrm{p}<.001$ 


\subsection{Discussion}

One important reason why many employers do not impose smoking bans is their perception that employees are not bothered by tobacco smoke at the workplace (Dutch Foundation on Smoking and Health, 1990). The main conclusion of this study is that annoyance caused by tobacco smoke in various sectors of Dutch industry was considerable. In all sectors, more than $66 \%$ of nonsmokers claimed to be bothered by tobacco smoke at the workplace (at least sometimes). This is still lower compared with a Dutch study involving bank employees, in which $80 \%$ was found to be annoyed by ETS (Breteler $\&$ Rombouts, 1986). However, that study was limited by a very low response rate (29\%), which may have led to an overrepresentation of employees in the sample who were more often irritated by tobacco smoke. A recent study reported that $53 \%$ of employees in the United States say they are bothered by smoke at their workplace, of which $35 \%$ at least once a week (Thompson et al., 1995). The discomfort reported in our study most often occurred in work offices, meeting rooms, and canteens. Seventy-nine percent of nonsmokers thought ETS was harmful to their health.

Strikingly, only $20 \%$ of smokers thought ETS exposure at the workplace would increase nonsmokers' chances of getting cancer. In our opinion, health education can and should increase efforts to change this opinion.

Knowledge of current smoking policies in individual companies is important for a thorough understanding of our research findings. As part of the study, interviews with staff members were supplemented with observations during visits. During the visits notes were taken, but there was no systematic use of checklists to examine the extent to which employees complied with smoking restrictions - for example, whether no-smoking signs were present, the presence of environmental tobacco smoke, or whether ashtrays were around (Rigotti et al., 1993). Since 1990, Dutch tobacco law asserts that, in state-owned organizations, smoking is prohibited in areas that are accessible to the public. Nevertheless, interviews and observations indicated that there was substantial non-compliance by governmental employees and employers. Employees did not obey the rules and no-smoking signs were not on display. This affirms the findings from inspections conducted in 1994 for the Ministry of Health, Welfare and Sports, which revealed that, in $59 \%$ of Dutch public healthcare institutions, nonsmoking sings were displayed only partially or not at all (Ministry of Public Health, Welfare and Sports, 1994). Further research is needed to 
determine the extent to which the tobacco law in general is observed and what determines non-compliance.

With reference to support for smoking restrictions, it was striking that few smokers and few nonsmokers favoured the 'no explicit policy' option. This finding conflicts with the 'common courtesy' solution endorsed by the Dutch tobacco industry as an alternative to policies that restrict or ban smoking. Others have found that the 'common courtesy' approach, by itself, is unlikely to substantially reduce exposure to ETS, because most nonsmokers who are bothered by ETS do nothing or simply move away instead of asking smokers to put out their cigarettes (Davis et al., 1990). Particularly smokers in the telecommunications and transport sectors favoured this laissez-faire option (by a narrow majority). A possible explanation is that these companies had imposed very few restrictions.

Most smokers and nonsmokers favoured a smoking ban in meeting rooms, regardless of the type of company they worked for. This suggests that this measure could be implemented in many Dutch companies, and probably in other European companies as well, without significant problems.

Most smokers and nonsmokers in the chemical and transportation companies and in local government supported a smoking ban except in designated areas. Through this option, nonsmoking is established as the social norm. This policy includes a ban for work areas. A multivariate analysis revealed that support for a general smoking ban (except in designated areas) was greatest with workers in the chemical industry and in governmental worksites. This may be because the policies that were in place in both these sectors resembled the general no-smoking policy in that in chemical industry smoking was not allowed ourdoors and designated smoking areas existed in several production plants, and in governmental organizations smoking was officially restricted to work offices.

Cross-sectional data from a California survey showed that a moderate smoking restriction (option 2) made no difference compared with no policy at all, but that bans for work areas significantly decreased the likelihood of being exposed to ETS, although not as much as a total ban (Borland, Pierce, et al., 1992). Our results indicated that the idea of a smoking ban for one's own work offices is welcomed by most nonsmokers, but not by smokers (about 30\%). Support was lowest in telecommunications and governmental worksites and highest in the transport sector. High support for smoking bans among bus drivers can be understood because smoking was prohibited on their place of work (buses). 
Studies have shown that employee support for smoking bans increases after smoking restrictions are introduced (Borland, Owen, et al., 1990; Brenner \& Fleischle, 1994). In our study, this phenomenon was observed cross-sectionally. In the local governmental workplaces, smoking was not allowed in rooms accessible to the general public. Indeed, most governmental employees were in favour of general smoking bans. In the chemical sector, employee smoking was restricted in canteens. Many respondents in this sector favoured a smoking ban in canteens in contrast to respondents in the telecommunications and transport sector, where employees could smoke with few restrictions in canteens.

The results show that employee support for a total smoking ban is extremely low. This may be explained by the Dutch traditional culture of tolerance and respect of individual freedom. However, recent years have seen much publicity in Dutch press about smokers becoming "the new social pariahs". This clearly demonstrates that social norms about smoking are changing. However, in our opinion, support for total bans is still too low to make it feasible to promote nation-wide adoption of complete worksite wide smoking bans. Indeed, for many European companies the goal of smoke-free workplaces may still be too far away in the future. However, if more worksites become smoke-free and their positive experiences are diffused to other worksites, support for complete smoking bans may increase in European companies. At present in the Netherlands, however, there are hardly any worksites to be found that have implemented a complete smoking ban. It will be very difficult for managment to make employees comply with the ban, as long as employee support is so low. In such a situation, the effectiveness of a total ban on workplace smoking will be questionable. Dutch managers currently appear to prefer looking for a consensus solution that fits both smokers' and nonsmokers' interests. Our data show that the "designated smoking areas' option can garner a fair amount of support from employees. Managers will have to be willing to pay the costs associated with creating designated smoking areas (ideally with separate ventilation systems), as long as support for complete smoking bans has not increased substantially.

For the companies participating in this study, the results have offered compelling reasons to strengthen their smoking policy (a general no-smoking policy instead of a moderate policy). We hope these findings will encourage more large companies to impose smoking restrictions to protect nonsmoking employees from ETS exposure. Conditions that favour successful implementation of no-smoking policies in 
large companies have been described elsewhere (Fielding, 1984; Sorensen et al., 1990; US Department of Health and Human Services, 1985, 1986). Active management support, the establishment of an executive committee with representatives of employers and employees, and assessment of employee support for smoking policy options are all important prerequisites. The questionnaire employed in this study can be used to determine employee support for smoking policy options at workplaces, and the data from different sectors of Dutch industry can be used as reference data for future efforts in the field of workplace smoking policy in countries with high smoking rates similar to those in the Netherlands. 


\section{4 \\ Intention to quit smoking among employees ${ }^{1}$}

\section{Abstract}

Background This study examines the influence of the social environment in worksites on employees' intention to quit smoking by applying the attitudesocial influence-efficacy (ASE) model.

Method Regression analyses were conducted with 509 smoking employees from eight Dutch worksites. Variables of interest were attitudes towards smoking, perceived social pressure to quit, perceived smoking behavior of otbers, self. efficacy, demographics, smoking history variables, company type, and smoking tolerance.

Results Attitude, social pressure from people outside the worksetting (partner, cbildren) and self-efficacy explained 23\% of the variance for intention. Past behavior increased the adjusted $R^{2}$ from .23 to .29 . Social influences in the worksite were unrelated to employees' intention to quit smoking.

Conclusions It was concluded that in Dutch worksites, social influences stemming from people at work have less influence on employees' intention to quit smoking than important other people outside the work situation. Implications for smoking control strategies in worksites are briefly discussed.

Published as;

Willemsen, M.C., De Vries, H., Van Breukelen, G., \& Oldenburg, B. (1996). Determinants of intention to quir smoking among Dutch employees: The influence of the social environment. Preventive Medicine, 25, 195-202. 


\subsection{Introduction}

In the Netherlands, as in most countries around the world, smoking remains one of the major public health problems. About $37 \%$ of the Dutch adult population smokes (Swinkels, 1994) and, of these, the majority $(70 \%)$ has no intention to quit smoking within the next 6 months (Mudde, Dolders \& De Vries, 1994). An important public health challenge is to encourage these smokers to contemplate making an attempt to quit (Abrams \& Biener, 1992). The worksite is regarded as an important setting to accomplish this, because large numbers of smokers can be reached within defined populations (Abrams et al., 1994; US Department of Health and Human Services, 1985). A large part of the working population spends eight hours per day in the worksite, five days a week.

While in other developed countries, such as the United States of America and Australia, smoking in the workplace has received a great deal of attention and workplace smoking control programs are well developed (Abrams et al, 1994; Bibeau, Mullen et a., 1988; Fisher et al., 1990; US Department of Health and Human Services, 1985), programs and research in Europe are less well developed. For example, in the Netherlands smoking in the workplace is still quite common and in 1990 less than $8 \%$ of workplaces had smoking restrictions (Dutch Foundation on Smoking and Health, 1990), whereas in the United States $27 \%$ of worksites had a formal policy restricting smoking (Fielding, 1990). Hence, smoking in the workplace is a public health problem which requires considerable attention in countries such as the Netherlands. Research is needed to understand whether findings from other countries apply and whether it is then possible to develop and implement effective intervention strategies.

One of the possible advantages of the workplace as a setting for smoking control has not yet been fully explored, namely the influence that social pressures and social norms from coworkers may have on employees" smoking cessation. Therefore, this study focuses on the importance of social influences in and outside the work setting on smoking cessation among employees. Several studies have attempted to examine the influence of the social environment within worksites on smoking cessation. The results of these studies are not unequivocal. Sorensen et al. (1993) studied determinants of smoking cessation among workers and found that actual cessation was highest among smokers whose colleagues frequently asked them not to smoke. Moreover, working with nonsmokers contributed to quit attempts. 
Others have found that the belief that smoking was socially unacceptable predicts employees' intention to quirt (Abrams \& Biener, 1992). Gottlieb and Nelson (1990) also reported that social pressure from nonsmokers is an important predictor of intention to quit. It should be noted that their "pressure to quit smoking scale" reflected social pressure both from colleagues and from people in general. In contrast, one study failed to find positive associations between intention to quit and the social influence of colleagues (Stephens et al., 1989). One explanation for these null results is that the influence of social norms in the workplace is canceled out by peer pressure from sources outside the worksetting. However, this assumption has not been examined before. The current study examines if social influences from coworkers have an impact on employees' intention to quit smoking, by using a theoretical model in which social influences are measured separately from influences stemming from people inside and from people outside the worksetting.

While research to date has focused primarily on employees' intention to quit smoking as the major dependent variable, there is a considerable body of research showing that intention is an important precursor to subsequent quit attempts (Eiser et al., 1985; Gottlieb et al., 1990; Hallet \& Sutton, 1987; Hellman et al., 1991), which in turn lead to successful cessation. Smoking cessation can best be conceptualized as a process in which smokers repeatedly recycle through various motivational and action stages until finally maintenance of the nonsmoking status is reached (Prochaska et al., 1988). Increases in intention are thus important intermediate outcomes of smoking cessation programs (Velicer et al., 1992).

The Theory of Planned Behavior is often used to explain and predict behaviors that are partly under volitional control (Ajzen, 1991; Ajzen \& Madden, 1986). This theory states that behavior is a function of someone's intention, which is primarily determined by attitudes, social norms and perceived behavioral control. In the current study, the attitude-social influence-efficacy model, or ASE model, is used instead (De Vries \& Backbier, 1994; De Vries et al., 1988). The ASE model differs in two ways from the Theory of Planned Behavior. First, the ASE model measures self-efficacy instead of perceived behavioral control (Bandura, 1986). Both concepts are very close in meaning. Secondly, according to the ASE model, social influences can be operationalized by measuring perceived social pressure and perceived behavior of others (De Vries, Backbier et al., 1995). Perceived behavior of others is a measure of indirect social influence, resulting from observational learning (Bandura, 
1986). This variable was found to have a unique contribution to the prediction of intention and behavior (De Vries, Backbier et al., 1995; Grube et al., 1986).

The ASE model postulates that other relevant variables are external to the theoretical model. Variables such as smoking frequency, past behavior and demographics only have an indirect impact on intention, through their influence on the direct predictors attitude, social influence and self-efficacy. These variables merely serve to characterize individuals and therefore have been called descriptive variables (Evans et al., 1988). The direct predictors can be called mediating variables, since they mediate the relationship between descriptive variables and intention. By making a clear distinction between mediating (proximal) and descriptive (distal) variables, the possible paths of influence can be statistically examined in an orderly manner, consistent with the theoretical assumptions of the ASE model. The theoretical model used is presented in Figure 4.1.

\section{Distal Predictors}

Demographic vartables

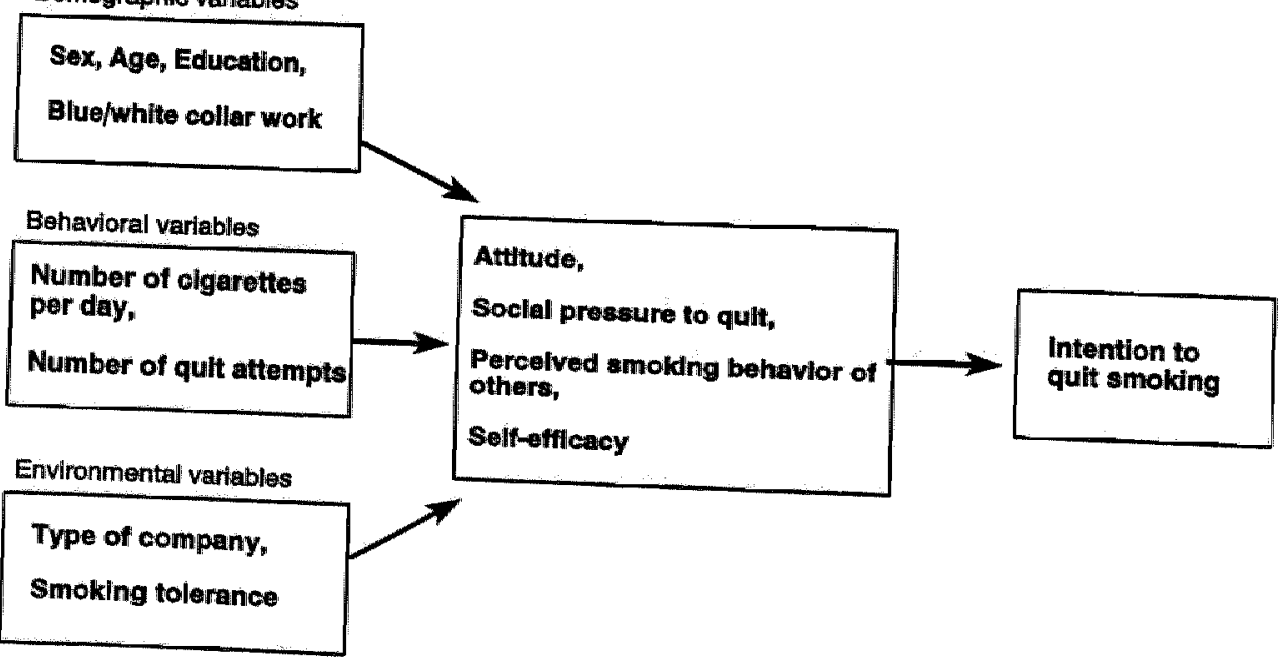

Figure 4.1: Theoretical model of determinants of employees' intention to quit smoking. 


\subsection{Method}

Data were collected as part of a baseline survey of employees in eight large worksites in the Netherlands. Worksites from four different work sectors (industry, telecommunications, public transport, and local government) were included in the study. Two worksites were recruited from each sector. Data were collected as part of an ongoing evaluation study. Characteristics of the worksites are listed in Table 4.1. The eight companies employed 10687 people. Of those, 1730 were selected randomly and then interviewed, resulting in 1480 respondents ( $86 \%$ response), of whom 508 (34\%) smoked. These 508 smokers formed the study sample.

Nonsmoking policies at the worksites were as follows. In all worksites, workers were allowed to smoke in their work offices and work rooms as long as coworkers did not object. There were smoking restrictions for meeting rooms. Smoking restrictions for communal places such as corridors and waiting rooms were only in effect in the governmental worksites, but compliance was very low. With the exception of the two chemical companies, there were hardly any smoking restrictions in canteens and restaurants.

Table 4.1: Characteristics of worksites.

\begin{tabular}{lccccc}
\hline Type of Business & $\begin{array}{l}\text { No. of } \\
\text { Employees }\end{array}$ & $\begin{array}{l}\text { No. of Respon- } \\
\text { dents }\end{array}$ & $\begin{array}{l}\text { Smoking } \\
\text { prevalence } \\
(\%)\end{array}$ & $\begin{array}{l}\text { Male } \\
(\%)\end{array}$ & $\begin{array}{l}\text { Blue- } \\
\text { collar } \\
(\%)\end{array}$ \\
\hline Chemical industry & 1294 & 391 & 30 & 92 & 39 \\
Telecommunications & 6360 & 506 & 37 & 71 & 16 \\
Public Transport & 715 & 198 & 36 & 92 & 42 \\
Local Government & 2318 & 385 & 34 & 69 & 18 \\
All worksites & 10687 & 1480 & 34 & 79 & 26 \\
\hline
\end{tabular}


Data were collected by means of computer assisted telephonic interviewing. Study subjects were interviewed while at home, mostly in the evenings, with the exception of two worksites where employees were interviewed during working hours.

\subsubsection{Questionnaire}

Questionnaire items were partly based on previous research (Eiser et al., 1985; Mudde et al., 1995) and partly based on qualitative interviews with smoking employees.

Intention to quit Intention was operationalized as "Do you intend to quit smoking within 6 months?" followed by a 5-point Likert scale ranging from "Certainly yes" to "Certainly not".

Attitude Attitude was assessed by measuring the general normative evaluation of quitting smoking ("Do you think quitting smoking is good or bad?") and four questions measuring the health, social and personal consequences of quitting smoking, using 4-point one-sided scales. The five items were summed to one attitude scale (Cronbach's $\alpha=.77$ ). Because the questionnaire also included a large number of questions that were not used for the current study, only the most salient beliefs could be included in the questionnaire. These were the effect of quitting smoking on general health, physical condition, ability to relax, and ability to socialize with others. For example, one item was "Do you think your physical condition will improve by quitting smoking?". Answers ranged from $0=$ "No, will not improve" to $3=$ "Will improve very much".

Social pressure Social pressure at work was assessed with two questions $(\alpha=$ .76), namely "Do your colleagues encourage you to quit smoking?" and "Does your boss encourage you to quit smoking?". Social pressure outside work was assessed with four items measuring pressure from the spouse, children, friends and close relatives $(\alpha=.64)$. For all items 7-point scales were used.

Perceived behavior among peers Perceived behavior at work was assessed by asking how many colleagues smoke. The number of smoking colleagues was then divided by the number of colleagues, resulting in a proportion of smoking coworkers. Perceived behavior outside work consisted of four items measuring how many friends, family members and children smoke and whether the spouse smokes. This measure should be regarded as an index of the number of important others outside the work situation who smoke. 
Self-efficacy Self-efficacy was measured as a single summation across situations. Velicer et al. (1990) recommend including items measuring social situations, affective situations and habit/addictive situations. The questions measured whether respondents found it difficult $(+3)$ or easy $(-3)$ to avoid smoking if someone offers a cigarette (social), when going out with friends (social), after a meal (habit) and when feeling tense (affective). Five-point Likert scales were used; Cronbach's $\alpha$ was .73.

Bebavioral and demographic variables Behavioral variables were number of cigarettes smoked per day and past behavior. Past behavior was measured with the question "How often have you seriously tried to quit smoking in the past?" $(0,1$, $2,3,4,5$, and 6 or more). Demographic variables were age, sex, educational level and type of work. Education was measured by asking respondents to choose between six types of education, which could be categorized according to Dutch standards as 1 = low, 2 = mediate, and $3=$ high. Self-reported type of work was measured by making respondents choose between one of the following options: 1 = "My work primarily consists of deskwork" (white-collar workers), 2 = "My work consists of both desk-work and manual labor", 3 = "My work primarily consists of manual labor" (blue-collar workers).

Environmental variables Tolerance towards smoking at work was assessed with six 5-point Likert scale items $(\alpha=.78)$, for example, "It must be completely left to the decision of employees if and where they smoke", "A smoky work environment is harmful to my health", and "I find it sociable if people smoke at work". Smoking tolerance scores were computed from all 1480 respondents who were interviewed, including nonsmokers. Smoking tolerance scores were then aggregated to the level of sites within companies. The eight companies were composed of 62 geographically distinct sites. The smoking tolerance score for each site was then assigned to all smoking respondents who work at that site. Company type was a second environmental variable, with four values (i.e., chemical industry, telecommunications, transport, and local government).

\subsubsection{Regression analyses}

The relationships of the descriptive and mediating variables to intention were examined by means of three multiple regression analyses, ensuring a systematic analysis of the hypothesized path of influences from the descriptive variables to intention via mediating variables. First, intention was regressed directly on the descriptive variables. Second, intention was regressed on both the descriptive and the mediating 
variables. In this analysis, the descriptive variables should have hardly any additional influence over and above the mediating variables, as hypothesized by the ASE model and the Theory of Planned Behavior. Third, the path of influence was completed by regressing the mediating variables on the descriptive variables that were found to significantly predict intention. In each analysis, variables with a $p$ value smaller than .05 were included in the equation (stepwise regression analysis using SPSSX software).

\subsubsection{Multi-level analyses}

In normal linear regression it is assumed that the residuals of the dependent variable of all subjects in a sample are independent. In this study, because subjects were nested within sites within companies, the residuals of ordinary linear regression with subjects as units of analysis may show intra-class correlation, e.g., contain a site and/or company effect. Such effects may lead to incorrect results, notably underestimated standard errors and type 1 errors (Bryk \& Raudenbusch, 1992). Therefore, company effects were accommodated by including the fixed factor "company type" as covariate in the regression model. In view of the large number of sites $(N=62)$, the final model was re-analyzed with VARCL (multi-level) software (Kreft et al., 1994) to check if any substantial between-sites effects occurred that might distort the SPSSX results (Longford, 1986).

\subsection{Results}

The mean age of the smoking sample was 40.6 years $(\mathrm{SD}=9.12)$. There were 391 males and 116 females ( 1 missing value). One hundred nineteen (23\%) were bluecollar workers, 138 had a profession that included both manual labor and desk work $(27 \%)$, and 250 were white-collar workers (49\%). The mean daily tobacco consumption was 16.1 , of which 8.3 cigarettes were smoked during worktime and 7.8 were smoked during leisure time. In comparison, the Dutch population smoked 16.6 cigarettes per day in 1990 (Mudde, 1994). Roll-your-own cigarettes constitute almost half of the annual tobacco consumption in the Netherlands (Dutch Foundation on Smoking and Health, 1996b). In our sample, roll-your-own cigarettes were indeed popular: 226 (44\%) smoked only hand-rolled cigarettes, 152 (30\%) smoked only manufactured cigarettes and $70(14 \%)$ combined roll-your-won cigarettes with 
factory-made cigarettes. Of the remaining respondents, 61 (12\%) smoked pipe, cigars, or a combination of pipe or cigars and cigarettes. A total of $147(29 \%)$ had received only a low education, whereas $250(49 \%)$ had a medium and $111(22 \%)$ a higher education (university level). The majority had made at least one attempt to quit smoking in the past (354 or $69.5 \%$ ). The mean number of past quit attempts was 2.8. About half (252 of 509) had made their last quit attempt in the year preceding the survey. The distribution of responses to the intention measure "Do you intend to quit smoking within six months?" was certainly yes, $14 \%$; probably yes, $20 \%$; probably not, $25 \%$; certainly not, $33 \%$. Forty-two ( $8 \%$ ) gave a neutral answer.

Table 4.2 presents Pearson correlations of all potential predictors of intention.

Table 4.2: Pearson correlations of determinants of intention to quit smoking and intention $(N=1480)$

$\begin{array}{lllllllllllll}1 & 2 & 3 & 4 & 5 & 6 & 7 & 8 & 9 & 10 & 11 & 12 & 13\end{array}$

1. Attündule

2 Social pressure at work $\quad .12^{* *}$

3 Social pressure outside work $20^{\circ *} .51^{* *}$

$\begin{array}{lllll}4 & \text { Smoking behavior at work } \quad .02 \quad & .08 & .00\end{array}$

5 Smoking behavior outside wark .01 $.09^{*}+21^{* \prime} \quad .09$

$\begin{array}{lllllll}6 & \text { Self-efficacy } & .05 & .03 & .05 & .05 & .07\end{array}$

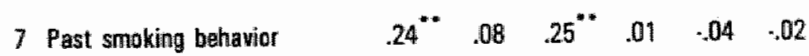

8 Number of dailly cigarettes $\quad \begin{array}{llllllll}.03 & .08 & .05 & .05 & .15 & .05 & .25 & .07\end{array}$

9 AgE

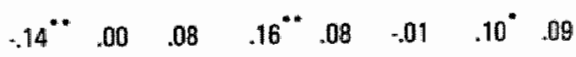

$\operatorname{Sex}$

11 Educational level

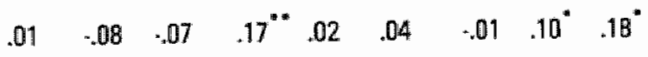

12 Bluelwhite-collar worker

$.04 \quad .03 \quad .03 \quad \cdot .12^{* *} \cdot .19^{* *} .21^{* *} \quad .03 \quad .14^{* * *} \cdot 02 \quad .04$

13. Tolerance to smoking

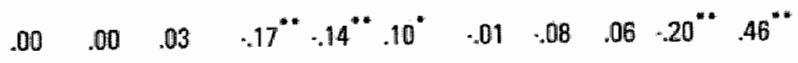

$.00 \quad .02 \quad .07 \quad-.34 \quad .08 \quad .16^{* *} \quad .01 \quad .15^{* *} \cdot .05 \cdot .20^{* *} .37^{* *} \quad .33^{* *}$

14. Intertion to quit smoking

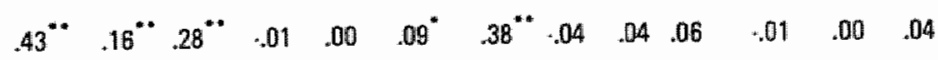

$\mathrm{p}<.05 ; \mathrm{p}<.01$ 
A series of regression analyses were conducted. First, all descriptive variables (demographics, behavioral, and environmental variables) were regressed on the intention measure. Only past behavior entered the final equation $(B=.39 ; \mathrm{T}=9.09 ; \mathrm{p}<$ $.0001)$. This variable accounted for $16 \%$ of the variance in intention.

The second analysis was a stepwise regression involving three steps. First, all mediating variables were entered, resulting in $23 \%$ of intention's variance predicted by attitude, social pressure outside work and self-efficacy. Examination of item-total correlations showed that social pressure outside work was highest with smokers who experienced pressure from their partner and from their children not to smoke. Then the descriptive variables were entered, showing that past behavior made a significant contribution to the prediction of intention, increasing the $R^{2}$ from .23 to .29 .

In the third step, four relevant interaction terms were entered (Past Behavior * Attitude, Past behavior * Social pressure, Past behavior * Self-efficacy and Attitude * Social pressure). The interactions involving past behavior were selected because it was hypothesized that people who had made more quit-attempts in the past, would have more 'experience' with quitting, resulting in a stronger association between mediating (ASE) variables and intention. In previous research, the interaction between artitude and social pressure has been found to significantly improve the prediction of intention to quit smoking (Grube et al., 1986). Our analysis showed that only Attitude * Social Pressure outside work slightly increased the predictive power of the model from .29 to .30. Because this increase was not substantial, the model withour interaction terms was preferred for reasons of simplicity.

The assumptions of linear regression analysis were satisfied: none of the independent variables showed high collinearity; examination of scatterplots showed that intention was linearly related to the independent variables; the residuals of intention were approximately normally distributed, and there were no outliers nor influential cases.

Comparison of the SPSSX output with a reanalysis of the final model with VARCL software showed no substantial discrepancies with respect to B's and Standard Errors (SE). Therefore, only the SPSSX results are presented. The results of the regression analyses are summarized in Table 4.3.

Three regression analyses were performed in which attitude, social pressure from people outside work, and self-efficacy were regressed on the descriptive variables. A positive attitude towards smoking cessation was associated with past behav- 
ior $(B=.29 ; p<.0001)$ and with lower age $(B=-.15 ; p<.005)$. The adjusted $R^{2}$ was .09. Social pressure outside work was associated with past behavior $(B=.25 ; \mathrm{p}$ $<.0001$ with a $\mathrm{R}^{2}$ of .06 ). Self-efficacy was significantly associated with a lower number of smoked cigarettes per day $(B=.22 ; p<.0001)$, and having received a higher education $(\mathbb{B}=.17 ; \mathrm{p}<.0001)$, with an $\mathbb{R}^{2}$ of 10 .

Table 4.3: Stepwise multiple regression analyses with smoker's intention to quit smoking $(N=509)$.

\begin{tabular}{|c|c|c|c|c|c|c|c|c|}
\hline Step & p Variable & $\mathrm{H}$ & 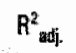 & $R^{2}$ change & $B^{b}$ & $T$ & SE & $p$ \\
\hline 1 & Attitude & .43 & .18 & .18 & .33 & 8.44 & .038 & $<.0001$ \\
\hline 2 & Social pressure outside work & .47 & .22 & .04 & .16 & 4.03 & .039 & .0001 \\
\hline 3 & Self-efficacy & .48 & .23 & .01 & .09 & 2.37 & .038 & .018 \\
\hline 4 & Past behavior Inumber of quit & .54 & .29 & .06 & .26 & 6.63 & .040 & $<.0001$ \\
\hline
\end{tabular}
attempts)

\footnotetext{
airst the mediating variables were entered as one block (resulting in step 1-3), followed by the other variables (step 4).

${ }^{b}$ the standard $B^{\prime}$ s and $T$ values refer to those obtained with the final model.
}

\subsection{Discussion}

The purpose of this study was to examine the extent to which the social environment of the wrorkplace impacts on employees" intention to quit smoking. We focused primarily on intention, because this is an important precursor of smoking cessation. None of the indices of social influence from the work environment had a unique contribution to the prediction of intention (e.g., the perceived social pressure from people at work, perceived smoking behavior of colleagues, and smoking tolerance). In contrast, social pressure from people outside the worksetting (notably partner and children) increased the explained variance in intention significantly (with $3 \%$ ). These findings suggest that social influences encountered during worktime probably do not have a very strong impact on Dutch smokers' intention to quit smoking. Dutch smoking employees might regard smoking as a private 
matter that falls outside the influence of the worksite, maybe more so than in other countries where smoking bans are more customary in worksites. Dutch smokers simply might care less about what colleagues think and say about their smoking behavior. An alternative explanation is that Dutch workers less often openly express discomfort from exposure to smoke at work.

Attitude towards quitting smoking, perceived negative social pressure from people outside work and a higher self-efficacy best predicted intention to quit smoking, resulting in an adjusted $\mathrm{R}^{2}$ of .23 . Attitude was the best predictor, a finding that has been repeatedly reported in the literature (Borland, Owen, Hill \& Schofield, 1991; Godin et al., 1992; Gottlieb, Galavotti, et al., 1990; Van Oss-Marin et al., 1990). An $\mathrm{R}^{2}$ of .23 means that much of the variance in intention is not accounted for, even after the addition of a measure of past behavior, which should account for the effects of extraneous variables (Budd et al., 1984). Howrever, others have reported even more modest results with worksite studies. For example, $\mathrm{R}^{2 x} \mathrm{~s}$ of .06 (Sorensen et al., 1986), .11 (Biener \& Abrams, 1991), and .12 (Gottlieb \& Nelson, 1990) have been reported. These studies examined the determinants of employees intention to quit smoking using a variety of predictor variables that were not guided by a clear theoretical model. This suggests that the usage of a theoretical model might improve the prediction of employees" intention to quit smoking, but that still much needs to be done to attain satisfying predictive power. For example, with nonworksite populations, much greater explained variances have been reported (Godin et al., 1992). One of the reasons why much of the variance in intention was left unexplained, may be less than optimal construct validity of the mediating variables. Attitude and self-efficacy were measured with only four beliefs to restrict the length of the questionnaire, because the interview also included a large number of questions that were not used for the current study. Although the most salient beliefs had been carefully chosen from a larger set, this possibly did not assure that enough relevant aspects of attitude and self-efficacy were included.

Although self-efficacy did enter the final model, its correlation with intention was weak $(r=.09 ; \mathrm{p}<.05)$. This finding is not surprising in light of recent research in which the relation between Prochaska et al.'s motivational stages of change (Prochaska et al., 1988) and social-psychological variables such as self-efficacy were examined (De Vries \& Backbier, 1994; De Vries, Mudde, et al., 1995). These studies present cross-sectional data showing that the association between self-efficacy and intention strongly depends on the operationalization of intention. In these 
studies, self-efficacy scores for smokers intending to quit smoking within six months (contemplation stage) were not higher compared with smokers who were in the precontemplation stage. In contrast, self-efficacy scores were strongly associated with 'movement' from contemplation to the preparation stage (intention to quit smoking within one month).

Addition of past behavior increased the ASE model's predictive power from $23 \%$ to $29 \%$. This finding is in line with other studies showing that the addition of a measure of past behavior to the original Theory of Reasoned Action leads to small, but significant increases in the predictive power of that model (Ajzen, 1991; De Vries, Backbier et al., 1995; De Vries, Mudde et al., 1995). Ajzen (1991), however, states that past behavior should not improve the prediction of intention (and subsequent behavior), because the impact of previous behavior would be expected to be fully mediated by the ASE variables. If one finds a significant effect of past behavior, this wrould mean that intention is not predicted well enough from the mediating variables.

Our findings show that past behavior also exerted an indirect 'impact' on intention, mediated by attitude and perceived social pressure: smokers with more quit attempts in the past had a more positive attitude towards quitting smoking and experienced more pressure from people outside work to quit. This suggests that failures with quitting in the past are not always negative experiences for smokers. For example, making quit attempts might make smokers more aware of specific benefits associated with non-smoking and of anti-social aspects of smoking. It should also be noted that past behavior did not relate to self-efficacy, suggesting that past failures to quit do not necessarily lead to low self-efficacy levels.

The main findings from the regression analyses could be replicated by means of multi-level analysis, showing that 'site' did not significantly affect the results. Because no effects of company type were found either, this increases the generalizibility of the findings to Dutch worksites. Another strength of the study was the high response rate and the fact that we report on motivational characteristics of a population of working smokers who did not volunteer for a cessation program. Furthermore, a clearly defined theoretical model was used to guide the regression analyses.

Several study limitations should be noted. The ASE-model assumes that attitude, perceived social influences and self-efficacy predict intention and not vice versa. However, based on the present cross-sectional data, no firm conclusions can 
be drawn regarding the causality of the observed relations. For example, once a person decides to quit, self-efficacy and attitude may increase. Another weakness of the study is that, although intention is an important predictor of making a quit attempt, the determinants of intention to quit smoking are different from determinants of actual success with smoking cessation (Borland, Owen, Hill \& Schofield, 1991). Hence, longitudinal research is needed to examine what determines whether an employee who intends to quit smoking will actually make a serious quit attempt (with or without help of a worksite smoking cessation program), and whether that person will eventually quit smoking successfully.

Despite the limitations, the results of this study have several public health implications. First, our research suggests that, at least with the Dutch working population, educational and other campaigns directed at promoting attitudinal change in order to increase the preparedness of smoking employees to make a quit attempt are still important. Since the vast majority of smoking employees have no intention to quit smoking in the near future, interventions should be targeted at all smokers in a worksite population, not only at those who are ready to quit (Abrams et al., 1994). Second, the results suggest that smokers who fail after a quit attempt do not automatically become demotivated to quit again in the near future. Therefore, smokers who relapse should be encouraged to make a new quit attempt by recycling them into a worksite smoking cessation program which offers various cessation options (such as self-help, nicotine replacement therapy, and group therapy). Third, the important role played by family members suggests that worksite interventions should also try to include the employees' family in program activities. 


\title{
5 \\ Assertiveness towards smoking colleagues ${ }^{1}$
}

\begin{abstract}
Background Nonsmokers" assertiveness can belp regulate smoking in worksites by enbancing the salience of nonsmoking social norms. This study examined determinants of employees' assertiveness towards smoking colleagues.

Method Cross-sectional data were collected from 898 nonsmaking Dutch employees. Potential determinants were chosen using the Attitude-Social Influence-Efficacy (ASE) model.

Results Fifty-one percent of nonsmoking employees asked corerorkers not to smoke. Assertive respondents bad colleagues who more often acted assertively towards smokers at work, had a more positive attitude to asking colleagues not to smoke, and bad a bigher perceived self-efficacy. Moreover, assertive employees more often perceived bindrance from environmental tobacco smoke (ETS) and bad more negative beliefs about ETS at work.

Conclusions What matters is whether ETS is perceived as bothersome and barmful. It is likely that both conditions must be met for nonsmokers to bebave assertively. Worksite educational programs could focus more on increasing nonsmokers" awareness of the barmfulness of regular exposure to ETS at work to increase social pressure on employees who smoke in places that are shared by smokers and nonsmokers. However, the effectiveness of such strategies is yet unknown.
\end{abstract}

"Published as:

Willemsen, M.C., \& De Vries, H. (1996). Saying "no" to environmental tobacco smoke: Determinants of assertiweness among nonsmoking employees. Preventive Medicine, 25, 575-582. 


\subsection{Introduction}

The health risks of involuntary smoking are smaller than the risks of active smoking, but are still large, both in absolute terms and in comparison with the number of injuries caused by exposure to other toxic agents in the worksite (US Department of Health and Human Services, 1986). Secondhand smoke has recently been declared as a known carcinogen (Environmental Protection Agency, 1992). A smoking ban for workplaces is regarded as the only effective strategy to eliminate the health risks of environmental tobacco smoke (ETS), because there is no 'safe' level of exposure.

Restrictive smoking policies support nonsmoking as the social norm, making it easier for smokers to refrain from smoking and for nonsmokers to ask smokers not to smoke. Nonsmoking norms can be made more salient by increasing the nonsmoking nature of public places through, for instance, clear nonsmoking signs. Another factor that might strengthen social norms is nonsmokers' assertiveness towards smokers. This study will focus on assertive behavior of nonsmokers.

Assertiveness may be important for several reasons. First, it has been suggested that social control processes can help regulate smoking in public places (Gottlieb, Eriksen, et al., 1990). Specifically, compliance with smoking bans may depend partly on nonsmokers' reactions to smokers who violate these bans. In smoke-free places where smokers continue to smoke, nonsmokers who are annoyed by tobacco smoke can first try to point out that smoking is not allowed. Most smokers will usually comply with this request, especially if nonsmoking signs are clearly visible. Second, assertiveness will make some smokers feel uncomfortable when lighting up a cigarette in places where smokers and nonsmokers interact. This may make them more susceptible to clear smoking policies that relieve them from inconvenient encounters with complaining nonsmokers. Third, assertiveness is still important in cases where there are no smoking bans or where nonsmoking regulations are not implemented effectively. This may be even more so in Europe, where smoking bans are still much less common compared to the United States, Canada and Australia. In 1990, less then $10 \%$ of Dutch private companies had implemented smoking bans (Dutch Foundation on Smoking and Health, 1990). In the Netherlands, since 1990, smoking is officially prohibited in establishments run by the State. However, inspections conducted in 1994 for the Ministry of Health, Welfare and Sports revealed that in 453 of 762 Dutch public health care institutions (59\%), despite the national legislation, nonsmoking signs were only partly placed or were not placed at all (Ministry 
of Public Health, Welfare and Sports, 1994). Given the difficulty of enforcing clear smoking bans, nonsmokers' assertiveness is important to keep shared spaces free from cigarette smoke.

National data from the US reported that only $4 \%$ of nonsmokers ask someone else not to smoke in public places (Davis et al., 1990). Results from a survey among restaurateurs and customers in Australian restaurants suggested that although $90 \%$ of costumers said to prefer smoke-free areas, few openly expressed this concern (Schofield et al., 1993). In 1992, a survey on passive smoking was conducted among 12,800 Europeans in the twelve countries of the European Union showing that 25\% of nonsmokers "sometimes" and $13 \%$ of nonsmokers "often" asked smokers to stop smoking when bothered by tobacco smoke (European Bureau for Action on Smoking Prevention, 1993). The settings in which nonsmokers behaved assertively included both public places and worksites. The published findings that specifically relate to worksites, show higher percentages. A Canadian study reported that $30 \%$ of governmental employees (sometimes) had asked coworkers not to smoke (Millar, 1988). A study from the United States found that $49 \%$ of employees had asked someone around them not to smoke in the month prior to the study (Gottlieb \& Nelson, 1990). In a study with hospital employees, it was found that about half of nonsmokers sometimes asked colleagues not to smoke (Biener, Abrams, Emmons \& Follick, 1989). A 1990 survey among Californian adults showed that nonsmokers who were exposed to ETS at work were more likely to have asked someone not to smoke compared to those not exposed at work (66\% versus 56\%) (Elder et al., 1992). It may be that nonsmokers behave more assertively when confronted with tobacco smoke at their worksite than in public places, which are more anonymous. Thus, especially in worksites, smoking discouragement efforts might benefit from strategies that stimulate workers' readiness to express their dislike of tobacco-use at work. To develop such interventions, information is needed about the determinants of employees' assertive behavior towards smoking colleagues. However, very few studies have explicitly examined nonsmokers' assertive behavior (Elder et al., 1992; Gottlieb \& Nelson, 1990), none using an explicitly stated theoretical model.

The present study examines the determinants of assertive behavior towards smoking behavior of colleagues. Potential determinants are suggested by the Theory of Reasoned Action (Ajzen \& Fishbein, 1980; Fishbein \& Ajzen, 1975) and Bandura's Self-efficacy Theory (Bandura, 1977; 1986). For this study we used the AttitudeSocial influence-Efficacy model, or ASE model, that integrates these two theories 
(De Vries, Backbier et al., 1995; De Vries et al., 1988). The ASE model assumes that behavior is a function of someone's intention, which is primarily determined by one's attitude towards the desired behavior, perceived social influences and one's estimated self-efficacy to perform the desired behavior. These variables are expected to mediate the possible influence of other factors that are supposed to be more distal to intentions such as demographic variables and beliefs that are not directly related to the specific behavior that one wants to explain. Such factors are called 'distal' because they are expected to have no direct relation with intention and behavior, but will exert their influence only or mainly via attitudes, social influences and selfefficacy expectations. Others make comparable distinctions between proximal and distal variables (Evans et al., 1988; Fishbein \& Ajzen, 1975; Flay \& Petraitis, 1994). The explaining power of the ASE model has been demonstrated in several studies in the field of smoking cessation (for example, De Vries \& Backbier, 1994; Willemsen, De Vries, van Breukelen \& Oldenburg, 1996) and smoking onset (De Vries, Backbier, et al., 1995). The current study will test the model with assertive behavior of nonsmokers.

Obviously, one potentially important additional determinant of assertiveness is hindrance from tobacco smoke. More than two-thirds of nonsmokers in various Dutch worksites are sometimes hindered by second hand smoke at work (Willemsen, De Vries \& Genders, 1995). Therefore this factor was included in this study. According to the ASE model, this variable must be treated as a variable more distal to intention and behavior than the ASE variables.

Furthermore, one reason for nonsmokers to behave assertively might be beliefs about the consequences of exposure to ETS at work. For example, many nonsmokers underestimate the health risks of passive smoking. In a previous study from the Netherlands it was found that only $49 \%$ of nonsmoking employees believed that exposure to passive smoking at work would increase their chance of getting cancer (Willemsen, De Vries \& Genders, 1995). A clearer understanding of such consequences of ETS among nonsmokers could enhance their assertiveness towards smokers. Therefore, beliefs about the consequences of ETS at work are included in the study as well. Like perceived hindrance, in the analyses this variable will be treated as a more distal 'predictor' of intention and behavior. Although obviously related to the attitude in the ASE-model, this theory assumes that beliefs that are not explicitly operationalized as beliefs towards the desired behavior, are more distal 'predictors' of intention and behavior. 
The present study separately examined the determinants of assertive behavior and the determinants of intention to behave assertively, using cross-sectional data. It was expected that the ASE variables would significantly contribute to the explanation of intention and behavior and that the addition of hindrance of ETS and beliefs about ETS at work could further improve the power of the ASE model.

\subsection{Method}

Data were collected as part of a baseline survey of employees in eight large worksites in the Netherlands. These worksites belonged to four work sectors (chemical industry, telecommunications, public transport, and local government). Smoking prevalence varied from $34 \%$ (chemical industry) to $40 \%$ (local government), the percentage of blue-collar workers varied from $16 \%$ (communication sector) to $42 \%$ (public transport), and the percentage of male workers varied from $71 \%$ (communications sector) to $92 \%$ (chemical industry, public transport). Characteristics of the worksites and sectors are described in more detail elsewhere (Willemsen, De Vries \& Genders, 1995). A total of 10,687 people were employed in the eight companies. Of those, 1730 were randomly selected and then contacted by telephone, resulting in 1480 respondents ( $86 \%$ response). Inclusion criteria for the analyses in the current study were being nonsmoker (as defined by the question "Do you smoke?") and having smoking colleagues. Following these criteria 898 nonsmokers were participants in the study [ 509 were smokers ( $34 \%$ of all respondents), 66 did not have colleagues who smoked, and 7 were rejected because of missing data].

None of the worksites had extensive nonsmoking restrictions. Workers were allowed to smoke at their work offices as long as coworkers did not object. There were minimal smoking restrictions in meeting rooms in each worksite. Smoking restrictions for communal places such as corridors, waiting rooms, restrooms and elevators were only in effect in the governmental worksites, but compliance was very low. Except for the two chemical plants, there were hardly any smoking restrictions in canteens and company restaurants.

Data were collected by means of computer assisted telephonic interviewing. Study subjects were interviewed while at home, mostly in the evenings. However, the employees from the local governmental organizations were interviewed during 
working hours, because management did not permit to contact them at their private address.

\subsubsection{Questionnaire}

The questionnaire items were partly based on qualitative interviews with smokingand nonsmoking employees in various occupations. Assertive behavior was measured by asking nonsmokers how often they ask smoking colleagues not to smoke. A 6-point scale was used with answers ranging from "never" $(0)$ to "always" $(+5)$. Intention was measured with the question "Do you intend to ask colleagues to smoke less at your workplace?". Answers ranged from "certainly no" (-2), to "certainly yes" $(+2)$.

Attitude towards assertive behavior was measured with one item "Is it good or bad to ask smoking colleagues not to smoke, for example by asking to extinguish a cigarette?" (7-point Likert scale, ranging from -3 = "very bad" to 3 = "very good"). According to the ASE model, social influences can be operationalized by measuring perceived social pressure and perceived behavior of others (modeling) (De Vries, Backbier, et al., 1995). However, in the present study, a question measuring 'perceived social pressure to behave assertively' was expected to be regarded by respondents as awkward. Therefore, only a measure of indirect social influence (modeling) was included in the questionnaire. This was assessed by asking how often colleagues ask smokers not to smoke at work ( 0 = "never", 5 = "always"). Self-efficacy was measured with three questions using 5-point scales $(\alpha=.74)$. Respondents were asked if they thought they would succeed in asking a smoking colleague not to smoke if someone smokes in the presence of the respondent, if there is a nonsmoking policy, and if the respondent is bothered by tobacco-smoke.

Perceived hindrance from ETS was measured with the question "How often are you bothered by smoke at your company?" ( $\mathrm{O}=$ "never", $5=$ "always") and the question "How many people who work in your office, smoke?". Nonsmokers" beliefs about ETS at work were assessed by means of four questions on 4-point scales, for example "How harmful is environmental tobacco smoke at work to your health?" $(\mathrm{O}=$ "not harmful", 3 = "very harmful"). Other items were "Do you think that nonsmokers" chance of getting cancer increases because of exposure to passive smoke at work?" and "Is tobacco smoke at work annoying to you?". The fourth item measured a possible aspect of smoking typically Dutch and therefore difficult 
to translate, namely whether smoking increases sociability when people are together. The four items formed one scale measuring beliefs towards ETS $(\alpha=.71)$.

Demographic variables were age, sex, educational level (low, medium, high), white/blue-collar worker, percentage of smoking colleagues, whether the respondent had smoked in the past, and number of subordinates the respondent had (categorized as follows: $0=$ none, $1=1-6 ; 2=7-15 ; 3=16-99 ; 4=$ more than 100). The percentage of smoking colleagues was measured by asking two questions: "How many people work at your deparment?" and "How many of these smoke?". The percentage of smoking colleagues was calculated by dividing the answer to the second question by the answer to the first question. Type of company was a categorical variable with four categories (chemical industry, telecommunications, public transport, and local government).

\subsubsection{Statistical analyses}

Data were analyzed using SPSS-X statistical package. Multiple analyses of variance and logistic regression were used to examine the relationships between assertive behavior and the determinants, including relationships between distal and proximal predictors. In all analyses, individuals were the unit of analysis. Because individuals were nested within companies analyses were conducted to examine the possible confounding effect of company type. Preliminary one-way analysis of variance with Scheffé contrasts showed that respondents in the chemical industry had a more positive intention to behave assertively than respondents in the telecommunications sector $[F(3,900)=3.4 ; p<.05)]$. Furthermore, respondents in the public transport sector less often behaved assertively compared with respondents in the other three sectors $\left(X^{2}(3)=11.4 ; p<.01\right)$. Thus, to control for the confounding effect of companies, it was decided to include 'type of company" as a confounder in the regression analyses.

The distribution of the variable measuring assertive behavior was strongly skewed. About half (49\%) of the nonsmoking employees never asked coworkers not to smoke. The other percentages were $35 \%$ sometimes, $10 \%$ frequently, $4 \%$ often, and $2 \%$ very often or always. Therefore, in regression analyses involving this behavioral variable, logistic regression was preferred instead of linear regression. The answers were dichotomized resulting in two categories: respondents who "never" $(=0)$ and respondents who "sometimes to always" asked colleagues not to smoke $(=1)$. 


\subsection{Results}

The sample consisted predominantly of male $(80 \%)$ employees. More than half (56\%) were white-collar workers. Mean age was 40.2 years $(S D=8.90)$. Twenty-two percent had only a low education, whereas $51 \%$ had a medium and $27 \%$ a higher education (university level). More than half (58\%) has previously smoked (ex-smoker).

\subsubsection{Determinants of assertive behavior}

Table 5.1 presents the association between all variables and assertive behavior. Respondents who sometimes ask colleagues not to smoke were more likely to have a positive intention to behave assertively in the future, to have a positive attitude towards asking colleagues not to smoke, to have colleagues who themselves ask smokers not to smoke during worktime, and to think that asking colleagues not to smoke is easy (e.g., have a higher self-efficacy). All variables differed at the $\mathrm{p}<.001$ level. Compared to nonassertive respondents, those who did ask coworkers not to smoke more often perceived hindrance from ETS at work $(p<.001)$, had more negative beliefs about ETS at work $(\mathrm{p}<.001)$, were significantly more likely to have a higher education $(p<.05)$, and to have white-collar jobs $(p<.01)$. Nonassertive respondents were more likely to be ex-smokers $(p<.01)$. The proportion of smoking colleagues was not related to assertiveness: $35 \%$ of nonassertive respondents' colleagues smoked and $36 \%$ of assertive respondents' colleagues smoked.

Two of the variables in Table 5.1, namely self-efficacy and beliefs towards ETS, are scales that are composed of various items. Separate analysis indicated that all individual items were significantly associated with assertive behavior $(p<.001)$. Assertive respondents were more convinced of the harmfulness of ETS, more often thought that nonsmokers' chance of getting cancer increases because of ETS at work, less often thought that smoking at work is sociable, and more often felt that smoking at work was annoying. Furthermore, they thought they were more capable of asking colleagues not to smoke when someone smoked in their presence, when there was a nonsmoking policy, and when they were bothered by tobacco smoke.

A multiple logistic regression was performed to examine the joint effect of the psychological determinants on assertive behavior. This analysis consisted of two steps. First, to control for the effect of type of company, three dummy variables representing the four company types were entered as a first block in the regression 
Table 5. 1: Association between assertiveness and possible determinants."

\begin{tabular}{|c|c|c|c|}
\hline Variable & $\begin{array}{l}\text { Not Assertive } \\
N=439\end{array}$ & $\begin{array}{l}\text { Assertive } \\
N=459\end{array}$ & P \\
\hline Intention $(-2$ to +2$)$ & -.89 & .51 & $<.001$ \\
\hline Attitude $(-3$ to +3$)$ & 1.14 & 2.10 & $<.001$ \\
\hline Social Influence (modeling) $(0$ to +5 ) & .68 & 1.42 & $<.001$ \\
\hline Self-Efficacy $(-2$ to +2$)$ & 1.40 & "1.66 & $<.001$ \\
\hline Perceived hindrance of ETS 10 to +51 & .89 & 1.75 & $<.001$ \\
\hline Beliefs towards ETS 10 to +41 & 1.66 & 2.13 & $<.001$ \\
\hline \multicolumn{4}{|l|}{ Demographics } \\
\hline Mean age & 40.2 & 40.3 & NS \\
\hline Male $(\%)$ & 77.7 & 82.4 & NS \\
\hline Education low (\%) & 23.5 & 19.4 & \\
\hline medium $(\%)$ & 52.5 & 49.3 & $<.05$ \\
\hline high $(\%)$ & 24.0 & 31.2 & \\
\hline White-collar (\% yes) & 51.0 & 61.9 & $<.01$ \\
\hline Subrordinates ( $\% 1$ or more) & 34.9 & 43.6 & $<.01$ \\
\hline Percentage of smoking colleagues & .35 & .36 & Ns \\
\hline Percentage ex-smoker & .62 & .53 & $<.01$ \\
\hline
\end{tabular}

a In order to compare assertive with nonassertive respondents, ANOVA was used with ordinal scale variables and $\chi^{2}$ tests with nomirnal scale variables (sex, education, blue/white-collar).

(forced entry). Second, behavior was regressed on intention, the social-psychological (ASE) variables, hindrance, beliefs about ETS, and demographic variables significantly $(\mathrm{p}<.01)$ related to assertive behavior (i.e., the number of subordinates and whether the respondent has a blue-collar job or a white-collar job). After controlling for type of company, intention was the first variable to enter the equation resulting in $70 \%$ correct classification. This improved to $75 \%$ after entering the ASE variables. Table 5.2 shows the variables in the final model. The confidence intervals of attitude, social influence, self-efficacy, hindrance from ETS, and type of work (white- 
collar work) were also above 1 , indicating a significant positive association with assertive behavior.

Table 5.2: Logistic regression analysis of assertive behavior with potential predictors, controlling for company type.

Variable

Type of company

(transport is reference category)

\begin{abstract}
Governmental
Telecommunication

Chemical industry
\end{abstract}

intention

ASE variables

Attitude

Social influence (modeiing)

Self-Efficacy

Distal variables:

Hindrance from ETS
$1.34(1.18-1.53)$

$<.001$

$2.71(2.13-3.43)$

$<.001$

$1.47(1.14-1.89)$

$<.01$

$1.47(1.27-1.69)$

\subsubsection{Determinants of intention}

To analyze the determinants of intention to behave assertive, we applied a three-step procedure: first we entered type of company, followed by the proximal predictors (attitude, social influence and self-efficacy), followed by distal variables. Multiple linear regression analysis was used because intention was measured with an interval scale. Number of subordinates was the only demographic variable that significantly correlated with intention $(\mathrm{r}=.12 ; \mathrm{p}<.01)$. Therefore, this variable was included in the analysis. Table 5.3 presents the results. The 'company type' variable accounted for less than $1 \%$ of the variance in intention scores. The social-psychological (ASE) determinants together accounted for $23 \%$ of the variance in intention scores. 
The beliefs towards smoking at work accounted for another $9 \%$ of the variance. Hindrance from ETS and the variable measuring the number of subordinates made small but significant contributions to the 'predictive" power. All variables together explained $34 \%$ of the variability in intention.

Table 5.3: Results of steproise regression analysis. Predictors of intention to ask colleagues not to smoke, by company type $(n=903)$.

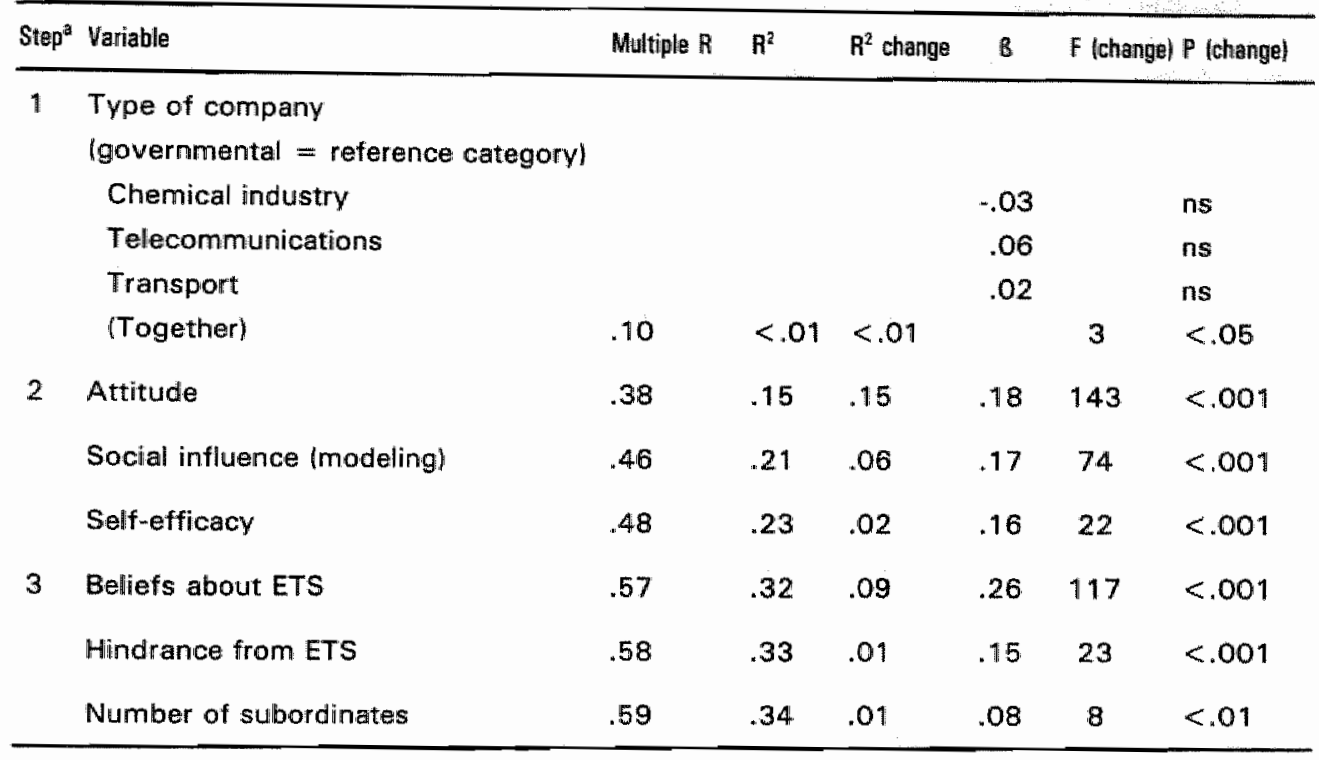

a Step 1, controlling for type of company; step 2, proximal variables; step 3, distal wariables.

\subsubsection{Relations between proximal and distal variables}

Table 5.4 shows correlation coefficients between proximal and distal variables. Multiple regression analyses were used to examine the multi-variate relations of distal variables to proximal variables, controlling for type of company. Attitude was found to be related only to beliefs towards ETS $\left(R^{2}=14 ; B=.35\right)$. Self-efficacy was significantly related to having a higher educational level $(B=.14)$, being male $(B=$ $.23)$, being younger $(B=-.10)$, having less smoking colleagues $(B=-.12)$, and having subordinates $(B=.09)$. These variables explained .06 percent of variability in selfefficacy scores. Eight percent of the variance in social influence scores was account- 
ed for by the following variables: hindrance from ETS $(\beta=.21)$, number of subordinates $(B=.09)$ and beliefs about ETS $(B=.09)$.

Table 5.4: Correlation coefficients of determinants of assertiveness.

\begin{tabular}{llllllllllllll} 
Variables $^{\text {a }}$ & 1 & 2 & 3 & 4 & 5 & 6 & 7 & 8 & 9 & 10 & 11 & 12 & 13 \\
\hline
\end{tabular}

1 Assertive behavion 1.00

2 Intention $\quad .45^{* *} 1.00$

3 Attitude $33^{* *} .38^{* *} 1.00$

4 Social influence $.40^{\circ *} \quad .32^{* *} .20^{\circ *} 1.00$

5 Sell-efficacy $\quad 188^{* \prime} .21^{* *} .16^{* *}, 09^{*} \quad 1.00$

6 Hindrance $\quad .31^{* *} .36^{* *} \quad .21^{* *} \quad .25^{* *} .03 \quad 1.00$

7 Beliefs ETS $\quad .33^{*} \quad .44^{* *} .38^{* *} \quad .21^{* *} .02 \quad .47^{* *} 1.00$

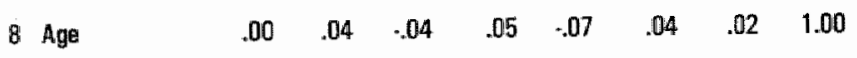

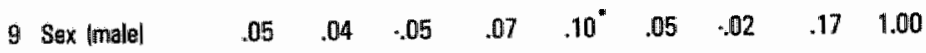

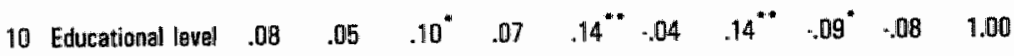

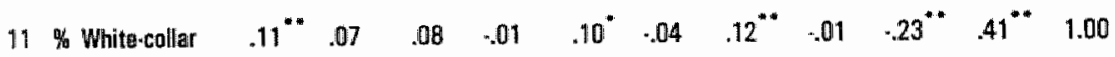

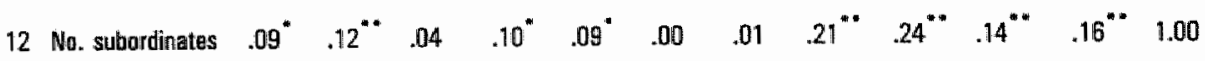

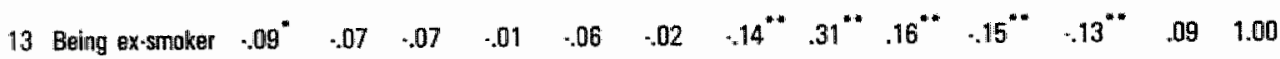

14 \% smoking $\quad \begin{array}{lllllllllllll}.07 & .03 & .03 & .09^{*} & . .11^{*} & .23^{*} & .01 & .00 & .08 & .16^{* *} & .22^{* *} & .03 & .04\end{array}$ coworkers

a Variables $3-5$ are proximal, variables 6-14 are distal to behavior and intention.

$\mathrm{p}<.01 ;$ ** $\mathrm{p}<.001$

Having negative beliefs about ETS was associated with hindrance from ETS ( $\beta$ $=.50)$, not having smoked in the past $(B=-.11)$ and a higher educational level ( $B$ $=.09)\left(\mathrm{R}^{2}=.28\right)$. Hindrance from ETS was related to having more smoking colleagues $\left(\mathrm{R}^{2}=.06 ; B=.22\right)$. To examine the relationship between hindrance and the proportion of smoking colleagues further, the answers to the question measuring hindrance were categorized into three categories: 'never', 'sometimes' and 'often' 
(regularly - always). It was found that if the proportion of smokers among colleagues is around $30 \%$ or less, most nonsmokers were sometimes or never bothered by tobacco smoke at work. The percentage of nonsmokers who said they were often bothered by ETS was at a low $20 \%$. If the proportion of smokers among colleagues increases to around $40 \%$, the percentage of nonsmokers who are often bothered by ETS increases sharply to around $50 \%$.

\subsection{Discussion}

This study found that $51 \%$ of nonsmoking employees in eight large Dutch worksites at least sometimes asked coworkers not to smoke. This finding supports studies from the United States reporting that about half the employees sometimes behave assertively (Biener, Abrams, Emmons \& Follick, 1989; Gottlieb \& Nelson, 1990). A comparison with public places where assertive behavior is rare (Davis et al., 1990; Schofield et al., 1993), suggests that nonsmokers are more willing to do something about tobacco smoke at their own workplace than in public places. However, not all employees were assertive when confronted with tobacco smoke. The present study examined the question why some employees behave assertively, whereas others never do so.

Among the strengths of the study were the inclusion of employees from several worksites from various work sectors, making the generalizibility of conclusions to other Dutch worksites possible, and the usage of an explicitly stated theoretical model to examine assertive behavior. A limitation of the study was that only cross-sectional data were used, making it impossible to draw firm conclusions regarding the causality of the observed relations. Assertive behavior occurred over a period before the survey and the intention and attitudes were those at the time of the survey. Therefore, it is possible that intention is produced by the behavior instead of the other way around. The logistic regression analysis showed that the influence of attitude, social influence, and self-efficacy was only partially accounted for by intention. This suggests that our assessment of behavior was maybe not so much of future behavior but indeed past behavior. Despite this limitation, tentative conclusions can be drawn about possible determinants of assertive behavior and intention, and subsequent implications for educational interventions can be suggested. 
As expected, both assertive behavior and intention were significantly 'explained' by the ASE variables. This suggests that each of these three 'routes of influences' was important. In other words, assertive behavior and intention to ask colleagues to refrain from smoking depend on how one feells about behaving assertively (attitude), what colleagues in the same situation might do (social influence or modeling), and - although to a lesser extent - one's expectation of how difficult it would be to ask colleagues not to smoke (self-efficacy). However, since $23 \%$ of the variance in intention was accounted for by the ASE variables, a fair amount of variance in intention was still not explained. One way of improving predictive power is to elaborate on the attitude measure. The variable measuring beliefs about ETS is conceptually closely related to attitude. Addition of this variable to the model resulted in an additional $9 \%$ of the variance in intention explained. In accordance with the ASE model, other distal variables had little direct impact on intention and behavior. Only hindrance from ETS and number of subordinates exerted some influence on behavior and intention, which could not be accounted for by the proximal variables. Another means of increasing predictive power could be to measure past experience with succes and failure with asking colleagues not to smoke in various contexts or situations, since we only measured assertive behavior in general. For example, the kind of smoking policy that exists in the worksite, the presence of non-smoking sings, or the situation when a smoker enters a nonsmokers" office could be important.

Gottlieb and Nelson (1990) could explain 12\% of the variance in assertiveness. This may have been caused by the fact that they only measured factors more distall to behavior (educational level, amount of workstress, support for worksite policy, and support for worksite cessation programs). These variables may not have a large direct influence on the behavior in question. Still, these factors may affect attitude, social influence and self-efficacy. Therefore, the development and testing of a more elaborate model to explain assertiveness towards ETS, using a longitudinal research design, is recommended.

The relations between the demographic and other distal variables with the ASE variables were not very strong. Of some interest was the finding that education (higher) and sex (being male) were related to self-efficacy expectations. Thus, it may be that lower status, lower educated employees are reluctant to make assertive requests to their boss and that female workers fear negative reactions from insensi- 
tive smokers. The positive association between assertiveness and education was also found by others (Elder et al., 1992).

Hindrance from ETS was closely related to the number of smoking colleagues one had, and those who experienced more hindrance from ETS had more negative beliefs about ETS, which in turn was related to attitude, intention and behavior. The fact that we also ascertained that the proportion of smokers among colleagues was not directly related to assertive behavior, suggests that what matters is not how many colleagues smoke, but whether their smoke is actually perceived as bothersome (hindrance) and harmful (beliefs about ETS). It is likely that both conditions must be met for nonsmokers to behave assertively. This may imply that an educational campaign to increase nonsmoking employees' awareness that ETS can be directly harmful to their health, could help increase the social pressure on smoking employees to smoke less during worktime. However, little is known about the possible effectiveness of such interventions. How many smokers will meekly refrain when asked not to smoke? This might strongly depend on the situation. For example, one study found that an assertive request was positively complied with more often in nonrecreational areas compared with recreational areas (Leedom et al., 1986). This is an area worth further studying.

The present study contributes to the understanding of social control processes that regulate smoking in worksites. Health education strategies to make the harmfulness of ETS more salient and to make assertive behavior more 'normal' might be important additions to smoking control strategies to decrease smoking prevalence in worksites. However, research is needed about the effectiveness of such strategies. 


\title{
6
}

\section{Evaluation of a pilot program: The PTT-Telecom study ${ }^{1}$}

\begin{abstract}
Background This study was the first evaluation of a worksite smoking cessation intervention in the Netherlands.

Method A quasi-experimental design was used to study program effectiveness. The program was implemented in one site of a large Dutch telecommunications company, and compared with a no-intervention control site of the same company. Subjects were smoking employees who wanted to quit smoking. The intervention consisted of a questionnaire assessing quitting motivation and barriers to quit, a tailored letter of advice, an offer of a self-help guide, a group program, and a telephone quit line. Main outcome measures were point prevalence smoking status at three and 12 months post-intervention, daily smoking rate, and observed movement in stage of change.

Results There were significant differences on all outcome measures at threemonths follow-up between the conditions, but these differences were not sustained at 12 months.

Conclusions In the Netherlands, comprehensive multi-component programs may be needed to achieve a sustained impact on worksite smoking prevalence.
\end{abstract}

"Three-months results published as:

Willemsen, M.C. \& De Vries, H (1993). Stoppen met roken via de werkplek: Een onderzoek bij PTT-Telecom. Tidschrift woor Saciale Gezondbeidszorg, 71, 25ע-257.

12-months results published as:

Willemsen, M.C. \& De Vries, H. (1995). Evaluation of a smoking cessation intervention for Dutch employees consisting of self-help methods and a group program. Tobacco Cantrol, 4, 351-354. 


\subsection{Introduction}

The annual mortality attributed to smoking has been estimated at 29,900 for 1995 in the Netherlands (Peto et al., 1992) The prevalence of daily smoking in the Netherlands appears to have stabilized at approximately $34 \%$ of the adult population, after a steady decline from the 1950s to the beginning of the 1990s (Dutch Foundation on Smoking and Health, 1996a). Smokers move through a series of motivational stages in their efforts to quit (Prochaska \& DiClemente, 1983, 1991; Prochaska et al., 1988). A telephone survey of 931 randomly selected smokers in a national survey showed that at the end of $1990,70 \%$ of Dutch smokers were precontemplators (that is, reporting no intention to quit within the next six months), $23 \%$ were contemplating quitting within the next six months, and only $7 \%$ were in the preparation stage (planning to quit within the next 30 days) (Mudde, Dolders \& De Vries, 1994). Smoking cessation efforts therefore remain a high priority in the Nerherlands. One of the intervention challenges is to stimulate contemplators and those in the preparation stage to make a successful quit attempt. The worksite is one setting in which smokers can be reached.

The impact of a smoking cessation method can best be conceptualized as the recruitment rate multiplied by the quit rate (Velicer et al., 1994). With a self-help approach, company-wide participation of smoking employees would be relatively high, but the quit rate would be relatively low, in the range of 5-15\% (Davis, Faust \& Ordentlich, 1984). With a group program, participation would be much lower, but success rates would be higher, in the range of 20-30\% (Klesges et al., 1987). Presenting programs in a manner consistent with smokers' preferences may improve program efficacy. Allowing smokers to choose the modality of intervention may contribute to a program's attractiveness and therefore to the participation rate (US Department of Health and Human Services, 1985). However, this assumption has not yet been examined extensively (Spoth, 1991). Our intervention allowed smoking employees to choose between a group program and a self-help method (or both). It is expected that both methods will contribute equally to the impact of the intervention.

This is the first known study about the effectiveness of smoking cessation programs in Dutch worksites. Our program was developed as part of a larger cancer prevention research program (De Vries, 1989). Participant ratings of the various program components are also presented. 


\subsection{Method}

\subsubsection{Recruitment procedure}

A quasi-experimental design was used to study the effectiveness of a worksite smoking cessation program in PTT-Telecom, which is a large company responsible for the management and implementation of Dutch telecommunications infrastructure. Two districts of the company were involved in the study. The experimental district consisted of 1735 employees, the control district of 2800 employees. Each district included one headquarters, five to eight large sites, and several small sites. The company indicated that both districts had the same very liberal smoking policy with hardly any restrictions. Both districts had the same percentage of male employees. Univariate comparisons showed that the control district had more employees in the age category of 25-35 years, and fewer aged 45-55 years. In each district, smokers were recruited by an announcement in the district's bulletin and an introduction letter with an entry form. Smokers could select a self-help guide, a group program, or both. Participation in the program was voluntary and free of charge.

In the experimental district, 155 smokers enrolled in the program ${ }^{2}$. Fifty two applicants (33\%) requested the group program, $92(59 \%)$ preferred self-help, and 11 $(8 \%)$ did not indicate a preference. Of those who stated their interest in the group program, 23 actually joined one of two group courses. The others received a selfhelp manual by default. The 11 smokers who did not indicate a preference for a specific quit mode received a self-help manual. All 155 applicants were invited to call the project's telephone quit line.

In the control district, 239 smokers enrolled, of whom $38 \%$ preferred the group program, $57 \%$ preferred the self-help manual and $5 \%$ had no preference. Applicants were informed that the company was considering future action, but that no immediate activities were planned, creating a 'waiting list' control group.

2 By comparing data on national tobacco consumption specified for age and sex (DFSH, 1996a) with the sex and age distribution of the PTT-Telecom workforce, we estimated the number of smoking employees between $35 \%$ and $37 \%$ ( 642 to 677 smokers). Hundred and fifty five applicants represented between $23 \%$ and $26 \%$ of all smoking employees. 


\subsubsection{Intervention}

The intervention was prepared and executed by a small project team consisting of a worksite physician, a nurse, a district manager and one member of the research team. All smokers in the experimental condition were offered the following program components.

Self-belp method: manual and tailored letters. The Dutch self-help guide is partly based on the American Lung Association's "Freedom From Smoking" guide (Strecher et al., 1984). The guide was pretested and evaluated in other projects (Mudde, De Vries, et al., 1994). A short questionnaire assessing quitting motivation and barriers, and level of nicotine dependence, was included in the entry form. Results were used to tailor a letter to the individual's concerns. Tailored letters were generated with help of computer algorithms and laser printed by the research team. About 150 combinations of advice were possible. Advice was tailored to motivational level (high or low), expected barriers to quit (for example, gaining weight, stress, withdrawal symptoms, social pressure, and problems in maintaining abstinence), and nicotine dependence (those who smoked more than 16 cigarettes per day were advised to consider using nicotine replacement therapy). The objective of the tailored letter was to help make the information in the manual more personally relevant.

Group program The group program was the standard smoking cessation program offered by the Dutch Foundation on Smoking and Health. The courses were conducted outside working time, but within company facilities. One course was led by an experienced counsellor from outside the company, the other by an in-house educator who received special instruction and training for this task. Participation costs (equivalent of US\$50) were paid for by the company. The group program consisted of eight 90 minute meetings, spread over three weeks. In the first session, participants were prepared for quitting in the second meeting. The following sessions emphasized the participants' own potential to fight addiction, and focused on preparing for nicotine withdrawal symptoms and relapse prevention by exchanging experiences and discussing the difficulties and risk situations encountered by the participants. Suggestions on how to cope with these difficulties were presented such as the use of rewards and nicotine replacement methods - and relaxation techniques were practiced.

Quit line. During working hours, smokers could call a telephone quit line, which was operated by the worksite physician or nurse. 


\subsubsection{Questionnaire and outcome measures}

The baseline questionnaire assessed smoking behavior, number of previous quit attempts and sociodemographics (age, sex, education). Various three months and 12 months follow up measures were used to evaluate program effectiveness, including movement through the stages of change (Velicer et al.s 1992), daily cigarette consumption, and point prevalence abstinence ("Have you smoked in the past seven days, even if just one puff?"). Self reports were used because biochemical validation was not possible due to restraints by the company management. At three months follow up, the questionnaire also assessed the awareness of, use of, and evaluation of the different program components.

\subsubsection{Subjects and data collection}

All data were collected through telephone interviews conducted by trained students. Baseline data were collected from 127 of 155 applicants in the experimental district ( $82 \%$ response rate) and from 187 of 239 applicants in the control condition (78\% response rate). Follow up surveys were conducted at three and 12 months after the program. Response rates at three months follow up were $90 \%$ for the experimental condition and $82 \%$ for the control group. At one year follow up, response rates were $85 \%$ in the experimental condition and $62 \%$ in the control group. Attrition between pretest and first posttest was mainly due to incorrect telephone numbers. At second follow up, the main reason was refusal to take part in the survey.

At the 12 months follow up, 35 control subjects indicated having read the selfhelp manual. Because these subjects did not differ significantly from the other control subjects on any of the demographic or smoking history variables (including stage of change), they were excluded from the analyses concerning 12 months results. Exclusion of these control subjects did not affect the comparability of the experimental to the control group.

\subsection{Results}

At baseline, the control group was younger than the experimental group ( 37 versus 40 years; $\mathrm{F}(1,277)=6.05 ; \mathrm{p}<.05)$, reflecting a difference in age distribution between the control and experimental districts. No significant differences were found with respect to cigarette consumption, number of previous quit attempts, gender, educa- 
tional level, and stage of change, in either the pretest or the first posttest. On average, the respondents in both conditions smoked 18 cigarettes per day and had made two previous quit attempts. In comparison, the Dutch smoking population in 1990 smoked 16.6 cigarettes per day and has had an average of 2.7 quit attempts (Mudde, 1994). There were more males ( $80 \%$ ) in our sample of smokers than in the overall Dutch smoking population (69\%) (Mudde, 1994). Fifty seven percent of the smokers in our sample smoked only roll-your-own cigarettes, $27 \%$ smoked only factory made cigarettes, while the remainder smoked a combination of tobacco products (hand-rolled, factory made or pipe and cigars). At baseline, 18\% were in the precontemplation stage, $60 \%$ were in the contemplation stage and $22 \%$ were in the preparation stage.

\subsubsection{Program evaluation}

Table 6.1 presents the awareness, utilization and participant evaluation of the various program components. The self-help manual was read by $90 \%$ of the respondents, and $18 \%$ had participated in a group course. The majority $(64 \%)$ could not recall having read the tailored letter. Process analysis showed that smokers confused the tailored letter with a formal introduction letter that went with the package. Fifty percent of the respondents knew of the existence of the telephone quit line, but only $2 \%$ actually used it. Participants were asked to rate the self-help manual, the group program, the tailored letter, and the quit line on an evaluation scale from 1 (bad) to 10 (excellent). All program components were given an average score higher than 7, which is an overall positive evaluation.

We examined the characteristics of respondents who applied for a group program and for a self-help manual. Respondents with no preference for a quit method were excluded in these comparisons. Self-help applicants were slightly more often male compared to group applicants $\left(\chi^{2}(1)=3.07 ; p=.08\right)$. Compared to respondents who were interested in the group program, applicants for the self-help manual were lighter smokers $(\mathrm{F}(1,118)=15.8 ; \mathrm{p}<.0011)$. One-way analyses of variance (Tukey

contrasts) showed that, compared with contemplating smokers, those in the precontemplation stage more often prefered the self-help manual and significantly less often preferred the group course $(p<.01)$. 
Table 6.1: Evaluation of the program components $(\mathrm{N}=114)$.

\begin{tabular}{llll}
\hline $\begin{array}{l}\text { Program } \\
\text { component }\end{array}$ & Awareness & Utilization & Evalustion a \\
\hline Posters & $85 \%$ & - & 7.3 \\
Self-help manual & $98 \%$ & $90 \%$ & 7.7 \\
Group program & $97 \%$ & $18 \%$ & 7.5 \\
Telephone quit line & $50 \%$ & $2 \%$ & $\ldots$ \\
Tailored letter & $36 \%$ & $14 \%$ & 7.1 \\
\hline
\end{tabular}

$1=$ very bad, 10 = very good

b The number of respondents who used the quit line was too small to permit conclusions about evaluation.

\subsubsection{Behavioral outcomes}

Following established guidelines, all individuals who could not be contacted at follow up were counted as smokers (Lando, 1989). The initial quit rate at the end of the group program was $43 \%(10 / 23)$ and the seven day point prevalence quit rates were $26 \%(6 / 23)$ at three months and $22 \%(5 / 23)$ at 12 months. Quit rates for the self-help participants were $8 \%(8 / 104)$ at three months and $7 \%(7 / 104)$ at the one year follow up.

To compare the intervention district with the control district, the group program participants and the self-help participants were pooled. Overall, in the experimental district the seven day point prevalence quit rate at three months was $11 \%(14 / 127)$ compared with $2 \%$ in the control group (3/152); the difference was significant $\left(\chi^{2}(1)=11.33 ; \mathrm{p}<.001\right.$, using Yates correction). At one year follow up, in the experimental condition the quit rate had decreased to $9 \%(12 / 127)$, whereas it had increased in the control condition to $8 \%(12 / 152)$; the difference among conditions was no longer significant.

In both conditions the smokers who did not quit reduced their daily consumption from baseline to the three months follow up. This reduction was greater in the experimental condition (from 18.2 to 14.2 cigarettes) than in the control 
condition (from 19.0 to 17.8$)(F(1,239)=16.81 ; \mathrm{p}<.001)$. This difference disappeared at the one year follow up.

\subsubsection{Stages of change movement}

By the three months follow up, $36 \%$ of respondents in the intervention condition advanced at least one step through the stages of change, $34 \%$ stayed in the same stage, and $30 \%$ fell back one or more stages. The controls progressed in $17 \%$ of the cases, $62 \%$ remained stable, and $21 \%$ fell back one or more stages. The changes were significantly more often positive in the experimental group compared with the control group $\left(\chi^{2}=20.21 ; \mathrm{df}=2 ; \mathrm{p}<.001\right)$. From baseline to one year follow up, $26 \%$ of the respondents in the intervention condition had advanced at least one step through the stages of change, $37 \%$ stayed in the same phase, and $37 \%$ fell back one or more stages. These percentages did not differ significantly from those observed in the control group using $\chi^{2}$ test.

In the intervention group at three months follow up, $26 \%$ of precontemplators (5/19), $50 \%$ of contemplators (33/66), and $75 \%$ of those in the preparation stage $(18 / 24)$ had attempted to quit, whereas $5 \%$ of precontemplators, $14 \%$ of contemplators and $17 \%$ of those in the preparation stage had successfully stopped smoking.

\subsection{Discussion}

This is the first quasi-experimental study conducted in the Netherlands to evaluate the effectiveness of a worksite smoking cessation program. The intervention had a significant effect on smoking cessation at three months follow up. Twice as many intervention subjects improved in stage compared with the controls (36\% versus $17 \%)$. This coincided with the observed improvements on the two other smoking cessation outcomes: three month point prevalence abstinence and daily cigarette consumption among continuing smokers.

Prochaska and colleagues reported cross sectional data suggesting that an increase of one stage of change doubles the percentage of smokers taking action (Prochaska et al., 1992). Our results show that contemplators have indeed twice as much chance of making an attempt to quit compared with precontemplators. How- 
ever, the increase from contemplation to preparation was accompanied by an increase from 50 to $75 \%$, less than double. Still, observed movement through the stages of change can be a useful method to detect initial program impact, which cannot be detected by only measuring smoking status. It should be noted that stage of change is a self reported measure and is sensitive to demand characteristics, especially with respondents who had already stated their interest in participating in a smoking cessation program. These smokers might be reluctant to acknowledge that they have no intention to stop smoking in the near future.

The addition of a telephone quit line to the intervention was not very successful. Very few smokers made use of the quit line, and only $50 \%$ recalled its existence. One reason might be that the line was only available during working hours, often the time when it is easiest for employees to refrain from smoking. We would not recommend future programs to include a telephone quit line. Brown et al. (1992) also found no significant effect of the addition of a telephone contact to self-instructed smoking cessation materials. Others also reported that telephone counseling appeals to very few smoking employees (Amos et al., 1995; Kinne et al., 1991). The low awareness level and poor utilisation of the tailored letters suggest that this method was not optimally implemented. As a result, program impact at three months follow up should thus be attributed mainly to the self-help manuals and the group courses.

The finding that there were no sustained differences between the intervention group and the control group after three months points to the need for continuation of the intervention. We suggest that smokers who did not reach the action stage be offered new assistance to capitalize on the progress that occurred in the initial period of three months. For example, direct follow-up contact to offer them support and new quitting opportunities have been recommended (Lichtenstein \& Glasgow, 1992).

Our program was successful in attracting between $23 \%$ and $26 \%$ of all smoking employees, causing about $9 \%$ of all smokers to make an attempt to quit smoking. This is assumed to be a high participation rate for large companies (Omenn et al., 1988). Five percent of all smokers signing up for a smoking cessation program is a common finding (Prochaska et al., 1992). Explanations for this high rate might be the high smoking prevalence in the PTT-Telecom district, and the fact the we offered smokers a choice between self-help and group therapy, both free of charge. 
Applicants who did not enroll in the group program automatically received a selfhelp treatment.

Of the 14 initial quitters, 6 were group participants and 8 were self-help participants. The self-help strategy and the group program both added to the impact of the program, suggesting that this combination of strategies is succesful. The two strategies attract different 'types' of smokers. Others have reported that group participants more often are female (Bertera et al., 1990; Owen \& Davies, 1990), are heavier smokers, and have more previous quit attempts (Davis, Jackson, et al., 1984; Hallet \& Sutton, 1987). The present study confirms two of these findings: compared to self-help participants, group participants were more often female and smoked more cigarettes per day. We also found that group applicants were more motivated to stop smoking.

Our study has some methodological and logistical limitations. First, the unit of analysis (subjects) was different from the unit of assignment (worksites). Efforts were undertaken to include more districts of the company in the study, but this was not feasible because the company management was not convinced of the need to include more districts in this pilot study. We would recommend replication of the findings from our study by a study involving more worksites.

Second, the observed increase in point prevalence quit rate in the control group between the first and second follow up measurements makes the interpretation of the long term effects of the program difficult. This increase in the control group might have resulted from the waiting list status of the control subjects, causing them to delay stopping smoking until after the first posttest. Furthermore, it is possible that waiting list control subjects especially were triggered to stop smoking by a national antismoking campaign involving frequent media coverage conducted in the Netherlands during December 1990 (soon after the three months follow up).

Another limitation of the study is that it relied on self reported smoking status. However, misreporting rates are usually very low, except in situations that explicitly elicit socially desirable reports of smoking status, such as when outcomes are connected to incentives (Velicer et al., 1992). The subjects in this study wrere interviewed under conditions of strict confidentiality to reduce the chance of misreporting.

The results of this intervention can be used as an effectiveness benchmark for more intensive multicomponent programs such as proposed by Abrams et al. (1994), 
targeted not only at the individual smoker, but also at the social environment and the organization as a whole. Such a broad program could include restrictive smoking policies and an educational and publicity campaign to motivate precontemplators to participate in the program and to consider quitting. 


\title{
7
}

\section{Comparison of a comprehensive with a minimal program ${ }^{1}$}

\begin{abstract}
Background Following the results of the PTT-Telecom pilot program, massmedia activities and continuation strategies were added to a core program consisting of self-belp manuals and group courses. This study examines in eight companies whether this comprebensive program is more effective than a minimal intervention.

Method One program consisted of self-belp manuals (minimal program), the other program consisted of self-belp manuals, group courses, a mass-media campaign, smoking policies, and program continuation strategies (comprebensive program).

Results At 14 months follow up, $16 \%$ of the participants in the comprehensive program had quit smoking, compared to $12 \%$ in the minimal program condition (biochemically validated). The effect of treatment on smoking cessation depended on nicotine dependency levels as measured with the Fagerström Test for Nicotine Dependence (FTND). Smokers with bigh FTND scores ( $\geq 3$ ) bad a substantially bigher chance of success with the comprebensive smoking cessation program. The mass-media campaign and group courses belped initial quitters to maintain their non-smoking status (sustained quitting).

Conclusions The results suggest that from a public bealth perspective a minimal program can be most cost effective, but that medium to beavy smokers benefit from more comprehensive programs.
\end{abstract}

"Submitted for publication as:

Willemsen, M.C., De Vries, H., \& Genders, R. Long-term effectiveness of two Dutch worksite smoking cessation programs. 


\subsection{Introduction}

Most adults spend one third of their average day in a worksite environment. For this reason, the worksite has the potential of being a setting through which large groups of smokers can be reached with health promotional efforts against smoking. Nevertheless, up to now this potential has hardly been exploited in European countries. For example, in the Netherlands only $25 \%$ of worksites pay attention to smoking among employees (Dutch Foundation on Smoking and Health, 1990). Activities are mostly limited to briefly informing employees about the health effects of smoking or passive smoking. In private companies, smoking bans are still the exception rather than the rule. Most of the research on the effectiveness of health education and health promotion aimed at reducing smoking prevalence among workers, has been conducted in the United States (US). However, programs that have been found effective in the US, need not automatically be effective in European countries where large variations in cultural values and customs exist (Pucci \& Haglund, 1994). The need for effective smoking cessation programs that can be used with working populations is urgent in Europe (European Bureau for Action on Smoking Prevention, 1994) where smoking prevalence is still much higher than the US, Canada and Australia (Fiore et al., 1995). This chapter reports on the effectiveness of a smoking cessation program that was developed for worksites in the Netherlands, where smoking prevalence among adults is still at a high 37\% (Dutch Foundation for Smoking and Health, 1996a).

In a previous study the effectiveness of a smoking cessation program in a large decentralized Dutch organization was examined. In one district of this organization smoking employees could participate in a program consisting of self-help methods and a group program. A comparison group of smoking employees received no treatment. Although the program effectiveness was limited to short term follow up ( $14 \%$ quit rate compared to $3 \%$ in the control district after three months), the results were promising and justified further research (Willemsen \& De Vries, 1995). For the present study, the following program adjustments were made to try to improve long-term quit rates: addition of a mass-media component, implementation of smoking policies and continuation strategies. We will refer to this new program as the comprehensive program. This program was comprehensive in the sense that the mass-media program was expected to influence all employees in the worksite, not only smokers who take part in the cessation program. The comprehensive 
program was aimed at three levels in the organization (Abrams et al., 1994). First, at the individual level strategies aimed at smokers were differentiated to their stage of change: smokers who were ready to quit were offered cessation methods, smokers who were comtemplating to quit were stimulated through mass-media to sign up for the program, and smokers who had no intention to quit smoking were motivated by mass-media messages. The program was expected to accelerate the "natural' transition from the precontemplation stage to the maintainence stage. By continuing the program over several years, smokers could recycle back into the program. Moreover, in the second year of the program in each worksite, smokers would be offered personalized advice, tailored to their stage of change. Second, at the social level, mass-media methods were expected to make the social environment more supportive of quit attempts. Third, at the organizational level, smoking policies and other structural improvements were realized. The impact of the comprehensive program on the social and organizational levels will be discussed in Chapter 8.

This chapter examines the effectiveness of the comprehensive program on smokers who want to quit smoking, by comparing program effects with those obtained in a 'minimal' program consisting only of self-help treatment. This will provide a rigorous test of program effectiveness, because it must be demonstrated that the comprehensive program can out-perform a reasonable comparison condition rather than a no-treatment control (Biener et al., 1994). Many smokers prefer selfhelp smoking cessation methods to more intensive and face to face approaches (Hallet, 1986; Gruman \& Lynn, 1993). Many worksites already provide self-help quit methods to employees (Gruman \& Lynn, 1993). Another important feature of a minimal program is that it is easy to implement in worksites at relatively low costs. The challenge is to develop smoking cessation programs for worksites that are substantially better than self-help programs.

Program results will be related to data about program exposure (process evaluation). Data on exact program exposure are important for three reasons. First, they provide information about whether the program was implemented as intended. Second, in a field experiment such as this, researchers have no control over sources outside the worksetting from which respondents can get information about smoking cessation (e.g., general practitioners, friends and mass-media). Process data will help to assess the impact of such influences. Third, smokers exposed to the comprehensive program receive a variety of interventions. Data about program exposure 
are needed to determine which program components contributed to observed program effects.

\subsection{Method}

\subsubsection{Setting and subjects}

Only worksites with more than 250 employees were considered for inclusion in the study. With less employees, participation in the group course would be insufficient to warrant effective group sessions. The research team contacted several large worksites through company physicians. Eight worksites agreed to participate in the study. These included chemical industry, telecommunication, public transport and local government. Four worksites were assigned to receiving the comprehensive program, while the other worksites were assigned to the minimal program. These worksites were matched according to worksite type, size and smoking policy. An effort was made to include more large worksites in the study, to be able to use worksites as unit of analyses, but it became clear that this was not feasible. A total of 10,704 employees were employed at the worksites, the largest had some 3,500 employees, the smallest had 303.

Worksite smoking prevalence was estimated, based on data collected from representative samples of all employees (Willemsen, De Vries \& Genders, 1996). Smoking prevalence was $40 \%$ in comprehensive intervention worksites and $42 \%$ in minimal intervention worksites (not significant). On average, 15\% of smoking employees participated in the quit smoking program (range 12\% - 29\%). Subjects were 498 smoking employees who enrolled in the quit smoking program offered at their worksite and who completed the baseline questionnaire. All measurements were done by means of computer assisted telephonic interviewing and included a pretest, a four months follow up and a 14 months follow up.

\subsubsection{Recruitment procedures}

Recruitment procedures in both treatment conditions were an announcement in company newsletters and a letter sent to all employees. In this letter, smokers were offered a self-help manual and a chance to participate in a smoking cessation group. Nicotine-addicted smokers were also advised to use nicotine replacement therapy if they smoked more than 25 cigarettes per day. These smokers were advised to 
contact their general practitioner or company physician for instructions on how to use nicotine patches or nicotine chewing gum. If smokers were interested in the group program they could indicate this on an enrollment form. Subjects in both treatment groups were then sent a self-help manual. Subjects interested in the group program received an invitation for a group course (comprehensive treatment) or they received a letter saying that due to insufficient interest no group program could be realized (minimal treatment).

\subsubsection{Minimal intervention}

The minimal program only consisted of self-help manuals "Ex-smokers talk about quitting smoking" (Mudde, 1993). These were the same as those used in the comprehensive program. A previous version of the manual had been thoroughly pretested. Abstinence rates with this manual have been reported to be between $8 \%$ and $18 \%$ (Mudde, De Vries, et al., 1994).

\subsubsection{Comprehensive intervention}

At each comprehensive intervention worksite, a work group was organized with representatives from the University, the Dutch Comprehensive Cancer Centers and company representatives. Each group met frequently (on average 12 meetings) to fit the program to the resources and characteristics of the worksite. This included developing a detailed communication plan, based on the same protocol to ensure standardization of treatments across worksites. The comprehensive program consisted of the following components.

Smoking cessation program Participants received the self-help manual and an opportunity to enroll in a smoking cessation group course. The group course was the standard smoking cessation course by the Dutch Foundation on Smoking and Health free and was offered free of charge. The courses were conducted outside work time, but on company premises using company facilities, led by experienced external counselors. The group program consisted of eight meetings of ninety minutes, spread over three weeks. The program used theoretical principles such as counter conditioning, stimulus control and reinforcement management. Other important ingredients were social commitment, teaching about addiction leading to cognitive restructuring and information about health aspects of smoking to strengthen motivation. 
Mass-media component An important component of the comprehensive program was an educational exhibition at strategic locations in the worksites. These exhibitions were installed for about three months and provided up-to-date information on the ongoing program, and gave information about the health risks of smoking and passive smoking. Employees could also pick up hand-outs and brochures with further information on smoking and smoking cessation. Important elements of the exhibitions were interactive sessions in which employees were invited to measure the carbon monoxide content of expired breath along with their lung capacity, supervised by a company physician or nurse. Smokers could compare their 'score' with those of nonsmokers. Company newsletters were used to focus monthly attention on unhealthy aspects of smoking, passive smoking and on the ongoing cessation program. A no-smoking day was organized in each 'comprehensive' worksite. This was announced through various mass-media channels in each company.

Smoking policy A baseline survey assessed employee support for smoking policy options. Based on these data, a report was written for each comprehensive treatment worksite to stimulate management to implement restrictive smoking policies. Although none of these worksites implemented a strict smoking ban, smoking restrictions were realized for specific areas, such as canteens and meetings rooms and general usage areas and all tobacco-selling points on the premises were removed. Furthermore, renewed attention was given in company newsletters to restrictions that were already in place.

Program continuation The cessation program and mass-media program were repeated after one year. This included offering new group courses, organizing a nosmoking day, and focusing attention on the program in company news letters in all companies. In addition, all respondents at the comprehensive program worksites were offered tailored letters that gave smokers advice on how to quit smoking: respondents' answers to the telephonic interview were automatically processed by the computer to produce a laser printed personalized letter. The contents of the letter were tailored to demographic variables, nicotine dependency level, socialpsychological determinants of smoking cessation (attitudinal beliefs, social influences and self-efficacy beliefs) and stages-of-change. In total there were 32 questions. Computer algorithms combined 97 different pieces of text to more then one million theoretically different output-letters. Tailoring smoking cessation messages by means of computer technology is a new and promising strategy to help smokers quit 
smoking (Rimer et al., 1994; Strecher et al., 1994; Velicer et al., 1993). To our knowledge this has not been used before as a maintenance strategy.

\subsubsection{Questionnaire and outcome measures}

Education was measured by asking respondents to choose between six types of education, which were categorized according to Dutch standards as $1=10 \mathrm{w}, 2=\mathrm{m}$ ediate, 3 = high. Questions about the work situation were: having subordinates (yes/no), working in shifts (yes/no), and self-reported type of work, measured by making respondents choose between the following options: 1 = "my work primarily consists of desk work" (white-collar workers), 2 = "my work consists of both desk work and manual labor," 3 = "my work primarily consists of manual labor" (blue-collar workers).

Nicotine dependence was measured using the Fagerström Test for Nicotine Dependence (FTND), comprised of six items, such as time between waking up and first cigarette and daily number of smoked cigarettes (Heatherton et al., 1991). FTND scores range from $O$ (no physical addiction) to 10 (highly addicted). Cronbach"s $\alpha$ was 0.58 , which is similar to coefficient alpha's reported by others (Heatherton et al., 1991; Pommerleau et al., 1994). The FTND scale is a valid measure of heaviness of smoking as measured by biochemical indices (Heatherton et al., 1991; Pommerleau et al., 1994).

Behavioral variables were number of cigarettes smoked per day and past cessation behavior. Past cessation behavior was measured with the question "How many times have you seriously tried to quit smoking in the past?" $(0,1,2,3,4,5$, and 6 or more).

Two measures were used to assess program effectiveness: 4 months and 14 months point prevalence abstinence ("Have you smoked in the past seven days, even just one cigarette?"), and sustained abstinence (i.e., point-prevalence abstinence at both follow up measures). Owing to their potential impact on smoking cessation, intention to quit smoking (Hallet \& Sutton, 1987; Hellman et al., 1991) and selfefficacy (Kavanagh et al., 1993; Lichtenstein \& Cohen, 1990; Stuart et al., 1994; Sussman et al., 1989) were included in the analyses of treatment effect as confounders. Intention to quit was operationalized as "Do you intend to quit smoking within six months?" followed by a five-point Likert scale ranging from "Definitely yes" to "Definitely not". Self-efficacy was measured as a single summation across situations. The questions measured whether respondents found it difficult $(+3)$ or easy $(-3)$ to 
avoid smoking in 9 different situations, for example, being offered a cigarette and feeling tense. Five-point Likert scales were used. Cronbach's $\alpha$ was 0.88 .

Exposure to health education program modalities was measured by asking respondents if they had seen the health education exhibition, if they had noticed the no-smoking day, if they had read leaflets, and if they had read articles in the company newsletter about smoking or smoking cessation (all dichotomous variables). The last two variables were summed to one measure of exposure to written mass-media methods. Furthermore, respondents were asked it they had used various quit methods (i.e., self-help manuals, group program, nicotine replacement therapy and tailored letters). At posttests, respondents were asked if the smoking policy at their work station had been restricted since the first interview.

\subsubsection{Statistical analyses}

The effect of treatment on smoking cessation was examined by logistic regression analyses in which the effect of treatment was controlled for baseline variables and interactions between baseline variables and treatment. The main effects were entered first as one block, followed by the interaction terms. Interaction terms were then removed using a backward elimination procedure. If any significant interactions remained between a baseline variable and treatment, the effect of treatment was then stratified to this variable. Possible confounding effects of company type were accommodated by including the fixed factor 'company type' as main effect in the regression analyses. Company type was one variable with four values (chemical industry, Telecommunications, transport, and local government). The effectiveness of continuation strategies will be examined by looking at quit rates and relapse rates occurring after continuation strategies had been implemented.

\subsection{Results}

Baseline characteristics of subjects in both conditions are shown in Table 7.1. Univariate analyses revealed that, although subjects from individual worksites differed on sex distribution, proportion of blue-collar workers, educational level and proportion of respondents working in shifts, the two treatment groups did not differ significantly on any of these variables. 
Table 7.1: Baseline characteristics of subjects by worksite and by treatment condition.

\begin{tabular}{|c|c|c|c|c|c|c|c|c|c|c|}
\hline \multirow[b]{2}{*}{ Worksite ${ }^{a}$ : } & \multicolumn{4}{|c|}{$\begin{array}{c}\text { Comprehensive program } \\
\text { worksites }\end{array}$} & \multicolumn{4}{|c|}{$\begin{array}{c}\text { Mlinimal treatment } \\
\text { worksites }\end{array}$} & \multicolumn{2}{|c|}{$\begin{array}{c}\text { Total } \\
\text { Compr. Mini- } \\
\text { mal }\end{array}$} \\
\hline & 1 & 2 & 3 & 4 & 5 & 6 & 7 & 8 & $1-4$ & $5-8$ \\
\hline Employees $(N)$ : & 125 & 56 & 43 & 40 & 145 & 40 & 18 & 31 & 264 & 234 \\
\hline Male $\{\%\}$ & 66 & 71 & 100 & $88^{* *}$ & 68 & 70 & 94 & $100^{* *}$ & 76 & 74 \\
\hline Age (mean) & 39 & 40 & 39 & 42 & 41 & 41 & 45 & 44 & 40 & 42 \\
\hline Blue-collars $(\%)$ & 14 & 11 & 23 & $57^{* *}$ & 15 & 0 & 28 & $74^{\cdots}$ & 22 & 21 \\
\hline \multicolumn{11}{|l|}{ Educational level $(\%)$} \\
\hline low & 31 & 13 & 16 & 72 & 33 & 12 & 11 & 84 & 31 & 35 \\
\hline medium & 57 & 41 & 56 & $23^{* *}$ & 55 & 38 & 72 & $16^{* *}$ & 48 & 48 \\
\hline high & 12 & 46 & 28 & 5 & 12 & 50 & 17 & 0 & 21 & 17 \\
\hline Shift workers $(\%)$ & 18 & 9 & 56 & $88^{* *}$ & 21 & 5 & 72 & $94^{* *}$ & 33 & 32 \\
\hline FTND score (mean) & 3.4 & 3.5 & 3.6 & 3.6 & 3.6 & 2.7 & 4.4 & $4.0^{*}$ & 3.5 & 3.5 \\
\hline $\begin{array}{l}\text { Cigarettes / day } \\
\text { (mean) }\end{array}$ & 19.8 & 19.2 & 16.9 & 18.9 & 20.0 & 16.7 & 21.8 & 19.0 & 19.0 & 19.7 \\
\hline $\begin{array}{l}\text { Prewious quit } \\
\text { attempts (mean) }\end{array}$ & 2.6 & 3.0 & 2.0 & 2.1 & 3.5 & 2.4 & 1.9 & 3.3 & 2.5 & 3.1 \\
\hline Intention (mean) & 1.7 & 1.6 & 1.8 & 1.9 & 1.5 & 1.8 & 1.9 & 1.8 & 1.7 & 1.6 \\
\hline Self-efficacy (mean) & .60 & .62 & .98 & $.66^{*}$ & .56 & .80 & .57 & .51 & .67 & .59 \\
\hline
\end{tabular}

2 Type of worksites: 1 and $5=$ Telecommunications; 2 and $6=$ Local government; $\mathrm{p}<.01_{\mathrm{i}}^{* \text { *nt }} \mathrm{p}<.001$

3 and $7=$ Chemical industry; 4 and $8=$ Transport.

\subsubsection{Response}

Response rates did not differ between comprehensive program and self-help program subjects: $92 \%$ at 4 months follow up and $83 \%$ at 14 months. Analyses were conducted to examine if losses to follow up would threaten internal validity. Logistic regres- 
sion analysis revealed that none of the demographics or social-psychological variables was related to attrition, but that the interaction. Type of company $x$ Treatment was a significant predictor: employees in the chemical company who were assigned to the comprehensive treatment were more likely to drop out than respondents from other worksites. The reason was that half way through the research period, an international crisis in the chemical industry caused this company to make about one fifth of their labor force redundant.

\subsubsection{Smoking cessation}

The effect of treatment program on smoking cessation was examined using logistic regression analyses. Because of the clear one-sided hypothesis that the comprehensive program would be superior to the minimal program, one-sided test statistics were used. Baseline characteristics and interactions between treatment and baseline variables were included as confounders. The Treatment $x$ FTND score interaction was found to be significant at 4 months follow up $(O R=1.45, p<.005)$, meaning that the effect of treatment on smoking cessation was confounded by nicotine dependency levels. Therefore, all further analyses had to be done separately for smokers with a low and smokers with a high FTND score. Secondary analyses revealed that the ideal cut-off point was at a FTND score of 3 . Furthermore, smokers with a score higher than 3 smoked more cigarettes per day $(23$ versus $13 ; \mathrm{F}(1,505)=178 ; \mathrm{p}<$ $.001)$ and had lower self-efficacy levels $(F(1,505)=5.7 ; \mathrm{p}<.05)$ than the other smokers. We will refer to smokers with a FTND score $<3$ as 'light smokers', whereas the other smokers are called 'medium to heavy smokers' (see also Killen et al., 1988).

After stratification to FTND scores, participation in the comprehensive program treatment was found to have an Odds Ratio of $0.48(\mathrm{p}<.05)$ for light smokers, and an OR of $4.68(\mathrm{p}<.005)$ for medium to heavy smokers, after correction for baseline variables. This indicated that medium to heavy smokers benefitted most from participating in the comprehensive program (more than 4 times higher probability of success), whereas light smokers doubled their chances of quitting smoking by taking part in the self-help treatment instead of the comprehensive program. At 14 months follow up, the comprehensive program still showed a positive trend for medium to heavy smokers $(\mathrm{OR}=1.93$; $\mathrm{p}<.05$ ), but not for light smokers. 


\subsubsection{Quit rates}

We examined the effectiveness of the smoking cessation group course as part of the comprehensive program. Of 45 respondents who attended the first session of the group course, 37 completed their course ( $82 \%$ ). Fifty-three percent of participants (24/45) were still not smoking at the end of the program, according to information from the group trainers. Self-reported quit rates at 4 months follow up and biochemically validated 14 months follow up quit rates were $38 \%(17 / 45)$ and $18 \%$ (8/45) respectively. Non-responders were counted as smokers. Among participants in the comprehensive program who received the self-help manual but did not participate in the group program, quit rates were $16 \%(35 / 219)$ at 4 months and $17 \%(37 / 219)$ at 14 months follow up.

At 4 month follow up, the bogus-pipeline procedure (Murray et al., 1987) was used to improve validity of self-reports of smoking status, that is, before asking their current smoking status, respondents were told they could be asked to provide saliva assays to control for smoking status. The 79 respondents who claimed they were nonsmoker at 14 months follow up were asked to cooperate with biochemical validation of their smoking status. Collection of saliva was organized at central locations at each worksite several weeks after completion of the interview. Nine respondents refused to cooperate. The company physician could confirm the nonsmoking status of one respondent; the other eight were counted as smokers. Thirtyseven could not be contacted by the research assistant because they worked in shifts, were ill or were on leave. With 41 respondents saliva assays were collected. Saliva samples were analyzed at a university hospital. Five of $41(12 \%)$ were found to be false positive (i.e., cotinine levels higher than $50 \mu \mathrm{gram} / \mathrm{liter}$ ) and were counted as smokers.

Table 7.2 shows quit rates and sustained abstinence rates, both stratified for light and medium to heavy smokers and for the whole group. The results are corrected for $12 \%$ false positive; all non-respondents were counted as smokers. Overall quit rates at 4 months follow up were $20 \%$ in the comprehensive worksites and $12 \%$ in the minimal treatment worksites. At 14 months follow up they were $16 \%$ and $12 \%$, respectively.

\subsubsection{Sustained abstinence}

Logistic regression analysis controlling for baseline variables, showed that among medium to heavy smokers exposure to the comprehensive program strongly predict- 
ed sustained abstinence ( $O R=5.74 ; \mathrm{p}<.001)$. As can be seen in Table 7.2, among medium to heavy smokers, sustained abstinence rates were $12 \%$ for the comprehensive program and $3 \%$ for the minimal program.

Table 7.2: Point prevalence quit rates and sustained quit rates per treatment, by FTND score.

\begin{tabular}{|c|c|c|c|c|c|}
\hline \multicolumn{2}{|c|}{ FTND $<3$} & \multicolumn{2}{|c|}{ FTND $\geq 3$} & \multicolumn{2}{|c|}{ Total } \\
\hline inim & $\begin{array}{l}\text { Comprehen- } \\
\text { sive }\end{array}$ & Minimal & $\begin{array}{l}\text { Comprehen- } \\
\text { sive }\end{array}$ & Minimal & $\begin{array}{l}\text { Compre- } \\
\text { hensive }\end{array}$ \\
\hline
\end{tabular}

$\begin{array}{lcccccc}4 \text { months } & 22 \% & 17 \% & 6 \% & 21 \% & 12 \% & 20 \% \\ \text { quit rate } & (19 / 85) & (18 / 104) & (9 / 149) & (37 / 175) & (28 / 234) & (55 / 279) \\ 14 \text { months } & 18 \% & 17 \% & 8 \% & 15 \% & 12 \% & 16 \% \\ \text { quit rate } & (15 / 85) & (18 / 104) & (12 / 149) & (26 / 175) & (27 / 234) & (44 / 279) \\ \text { Sustained } & 13 \% & 9 \% & 3 \% & 12 \% & 6 \% & 11 \% \\ \text { abstinence } & (11 / 85) & (9 / 104) & (4 / 149) & (21 / 175) & (15 / 234) & (30 / 279)\end{array}$

\subsubsection{Program exposure}

At 14 month follow up, participants in both treatment conditions were asked which program modalities they had been exposed to, since the pretest. The results are graphically displayed in Figure 7.1. Participants in both conditions had been exposed to brochures and articles in the company newsletter, but significantly more intense at the comprehensive program worksites. Twenty-one percent of respondents at the comprehensive worksites ( 43 subjects) had participated in the group program, compared to $1 \%$ (two subjects) at the control worksites. Participation of control subjects in the group course was caused by courses offered by local health authorities outside the worksite. Furthermore, the comprehensive program differed significantly from the self-help treatment in tailored advice ( $89 \%$ exposure), health education exhibitions ( $79 \%$ exposure) and the no-smoking day ( $40 \%$ exposed). These activities were not featured in the minimal treatment worksites. Compared to the 
self-help condition (22\%), smokers in the comprehensive program condition (48\%) more often noticed that smoking regulations had been strengthened $(\mathrm{p}<.001)$. Treatment conditions did not differ with respect to exposure to self-help manuals and usage of nicotine replacement strategies (NRT) (either nicotine gum or nicotine patches), which was used by about one fifth of participants.

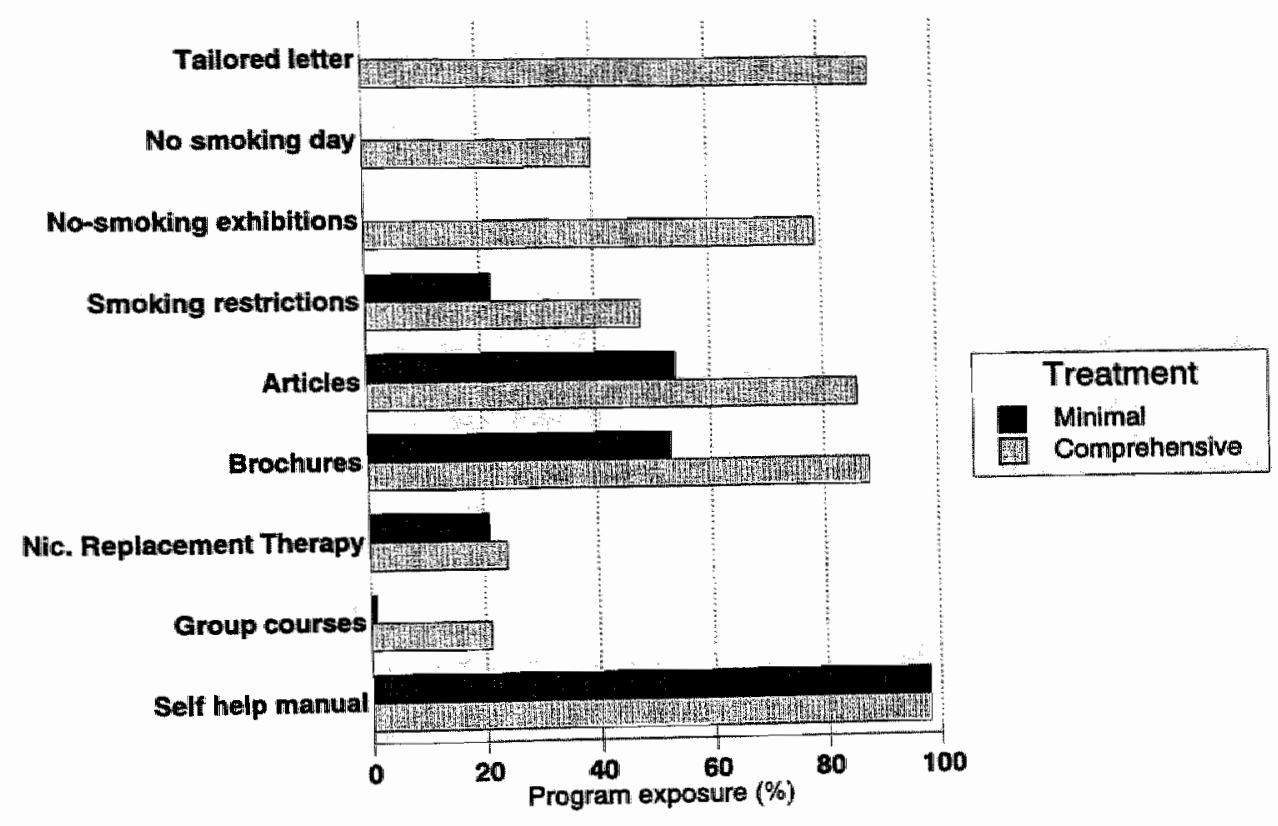

Figure 7.1: Exposure to program components $(\mathrm{N}=374)$.

Logistic regression was used to relate data on program exposure to 4 and 14 months point-prevalence quit rates and sustained abstinence rates. First, the effect of exposure to a group course and/or NRT was examined. For light smokers, participation in the group course and usage of NRT were not significantly associated with any of the three outcome measures. For medium to heavy smokers, participation in the group course was positively associated with 4 months abstinence $(O R=4.12$; $\mathrm{p}<.01)$ and with sustained abstinence (OR $=3.16$; $\mathrm{p}<.05)$, but not with 14 month point prevalence quit rates. Usage of NRT only had a beneficial effect on 4 month cessation $(\mathrm{OR}=2.86 ; \mathrm{p}<.05)$. 
The effects of health educational strategies (educational exhibition, brochures and articles in company newsletter, no-smoking day, and no-smoking policy) was also examined. After controlling for exposure to group courses and NRT, only one significant model improvement was found: stronger addicted smokers had a greater chance of sustained abstinence if they had been exposed to the health education exhibition ( $\mathrm{OR}=2.99 ; \mathrm{p}<.05 ; \chi^{2}$ improvement of fit $\left.=5.04 ; \mathrm{p}<.05\right)$.

\subsubsection{Effectiveness of continuation strategies}

The effects that repetition of the program may have on quitting smoking and preventing relapse between first and second follow up, was examined by means of $\chi^{2}$ analyses. This revealed that the percentage of respondents who were smoking at 4 months follow up and who had successfully quit smoking at 14 months follow up, was $7 \%$ in both treatment groups. Furthermore, respondents who had quit smoking at 4 months follow up showed comparable relapse rates: $55 \%$ in the comprehensive treatment group and 54\% in the minimal treatment group had relapsed (not significant).

\subsection{Discussion}

The overall 14 months quit rate of $16 \%$ compares favorably with previous Dutch research in which a long-term quit rate of $9 \%$ was reported with a program consisting of group courses and a self-help method (Willemsen $\&$ De Vries, 1995) and with an average 12 -month quit rate of $13 \%$ that was found in a meta-analysis of 20 worksite smoking cessation programs (Fisher et al., 1994). Furthermore, sustained abstinence rates (quitter at both follow up measurement points) were higher in worksites receiving the comprehensive program (11\% versus $6 \%$ ). In absolute terms these results are encouraging. However, the difference between comprehensive and minimal treatment, which produced $12 \%$ quit rate, was only $4 \%$ after 14 months. This finding is important in light of the low cost of delivering minimal interventions and smokers' preferences for self-help approaches. From a public health perspective, it might indeed be more fruitful to diffuse minimal self-help type of worksite programs to worksites than to stimulate them to implement more comprehensive programs. 
A remarkable result of the study was that the effect of treatment on smoking cessation differed for light and medium to heavy smokers. For smokers who had a score above 3 on the FTND scale, the comprehensive program was superior at both follow up measures. For light smokers, the minimal treatment was at least as good as the comprehensive program. A 'stepped-care' approach has been proposed in which lighter smokers might be treated with self-help methods and heavier smokers with more intensive methods (Klesges et al., 1988; Orleans, 1993). Our results suggest that the cut-off point for this might be at a FTND score of 3 . One third of the participants had a FTND score $<3$. This proportion has also been found in population-based samples in France (Fagerström et al., 1996) and Austria (Schoberger et al., 1996).

Recently, an improvement in the FTND was proposed by adding items assessing inhalation habits (Tate \& Schmitz, 1993). This Revised Tolerance Questionnaire (RTQ) was shown to possess a higher internal consistency than the FTND that was used for the present study. We therefore recommend replicating the current findings in a study using the RTQ.

The results of the logistics regression analyses suggest that group courses and health educational exhibitions help medium to heavy smokers who quit to sustain their nonsmoking status. Thus, these methods seem to have an additional impact over and above self-help manuals. Others have also reported that smoking cessation group programs provide an important backup to minimal contact and self-help approaches (Gruman \& Lynn, 1993).

Disappointing findings, however, were that overall relapse rates between 4 months and 14 months follow up were comparable in both treatment groups, despite the fact that $89 \%$ of participants in the comprehensive treatment had received tailored letters as a maintenance strategy. McFall et al. (1993) also report on the failure of a maintenance strategy that was designed to prevent relapse among participants in a self-help smoking cessation program (McFall et al., 1993). Their maintenance program consisted of mailing 10 newsletters with information and support addressing different stages in the cessation process over a 6 months period. Given such failures, we must conclude that either these maintenance strategies have not been powerful enough, and/or that other components are also necessary to produce long-term effects. One alternative avenue could be to provide more personal contacts (McFall et al., 1993), for example, a member of medical staff checking on one's progress. Moreover, one recent study found that management support was 
related to program cessation rates (Fisher et al, 1994). Another avenue is to reduce exposure to environmental smoking cues (Abrams et al., 1994). In the present program, we tried to do this by implementing restrictive smoking policies, but we did not succeed in bringing about substantial improvements such as general smoking bans.

Positive aspects of the present study were the collection of longer term follow up data, assessment of the effectiveness of second-year continuation strategies, biochemical validation of longer term selfreported outcome measures, and the comparison with a minimal treatment program providing a rigorous test of program effectiveness.

The current study must also be viewed with some caution, because worksites were assigned to treatment conditions in a non-random manner. In light of the relatively small number of worksites, a matching procedure was preferred in stead of randomization, because matching would ensure that both treatment groups were comparable on a number of important criteria (type of worksite, size of worksite and smoking policy). No pre-intervention differences were found on any of the baseline variables, suggesting that the matching procedure worked very well. However, it can not be ruled out that worksites in the experimental condition differed systematically from the control condition in other ways.

The results of this study suggest that a minimal worksite program consisting solely of self-help manuals is effective and would be the first choice if worksite smoking cessation programs are going to be diffused on a national basis in the Netherlands. Minimal interventions can be implemented at low costs and with minimum time required of company staff. As a second option, worksites that have more resources could be advised to implement a more comprehensive program that meets the needs of more heavily addicted smokers. Our study suggests that the addition of a health educational campaign consisting of group courses and exhibitions to a basic program consisting of self-help manuals, helps medium to heavy smokers who quit to maintain their non-smoking status. 


\title{
8
}

\section{Impact on employees not participating in the cessation program ${ }^{1}$}

\begin{abstract}
Background Smoking cessation programs at worksites often combine quit smoking methods with mass-media and policy changes. These latter strategies provide cessation programs with an 'enriched environment' in which quitting may be more easy. This paper examines whether such an enriched environment has a spin-off effect on smokers who do not participate in smoking cessation programs and whether it affects nonsmokers' assertiveness and supportive behavior.

Method Random samples were draven from eight large worksites, resulting in 1730 respondents (smokers and nonsmokers). Changes from baseline to 18 montbs follow-up were analyzed with logistic regression analysis.

Results The results failed to support the bypotheses with regard to smoking cessation, and changes in cognitions among smakers. However, two positive findings emerged from this study: a. smoking cessation exhibitions may bave a beneficial effect on participation in the cessation program and b. smoking restrictions were found to bave an impact on nonsmokers' assertiveness and intolerance. Of additional interest was the finding that exposure to smoking cessation exhibitions, leaflets, and newsletters was less optimal among bluecollar workers.

Conclusions This study suggests that an 'enriched milieu' might improve participation in worksite cessation programs, but is unlikely to bave additional impact on nonparticipating smokers. The challenge remains bow the potential of worksites as a setting to reach and influence many smokers, especially blue-collar workers, can best be realized.
\end{abstract}




\subsection{Introduction}

A meta-analysis of the effectiveness of worksite smoking cessation programs revealed that, on average, such programs produce a $13 \%$ long-term quit rate among participants (Fisher et al., 1990). This is not better than smoking cessation programs conducted outside work settings (Glasgow \& Terborg, 1988; Hymowitz et al., 1991; Schwarz, 1987), despite the fact that many worksite programs include mass-media methods and smoking policy changes to promote a supportive environment for quitting. One study failed to demonstrate the advantage of such an 'enriched milieu' on program quit rates (Hymowitz et al., 1991). Another study found evidence that exposure to exhibitions about smoking cessation situated at strategic locations in a worksite, improved sustained abstinence of participants in a smoking cessation program, but not quit rates (Willemsen, De Vries \& Genders, submitted). Several studies failed to find evidence that improvements in smoking policy result in smoking cessation among employees (reviewed in Brenner \& Mielck, 1992; see also Jeffery et al., 1994). Thus, the effect of an enriched environment on the effectiveness of quit smoking programs in worksites seems quite modest. However, an enriched environment may have other advantages. First, mass-media programs and smoking policies might increase participation in a quit smoking program. Second, an enriched environment might influence those smokers who do not participate in formal quit smoking programs offered at their workplace. Information campaigns generally produce changes in awareness, knowledge, and attitudes (Flay, 1987a,b). This might eventually result in smoking cessation. Some evidence for effects on behavior change exists. In a recent study it was found that a smoking cessation program using a community organization approach to promote worksite support for smoking cessation, affected cessation among non-program participants (Fisher et al., 1994). However, due to the lack of a comparison group, this finding was preliminary. Third, the fact that a cessation program is being conducted in a worksite, might have a direct spin-off effect on nonparticipants. When many smoking employees participate in a cessation program at their worksite, this might be a cue to action for other smoking employees to stop smoking as wrell. A Dutch study reported such a spin-off effect in the context of smoking cessation group courses (Van der Rijt et al., 1993). For every two successful quitters there was one smoker in the direct sacial environment who had quit smoking also. Fourth, one might expect that mass-media could influence the social environment at worksites in such a way that nonsmokers 
become more supportive of employees who attempt to quit smoking and less tolerant towards employees who smoke at work.

In this paper, the attitude-social influence-efficacy model or ASE model (De Vries, Backbier et al., 1995; De Vries et al., 1988) is used as a theoretical framework for choosing cognitive outcome measures. In a previous study we showed that attitude and social influences from people outside the work setting (notably the partner) were most strongly associated with employees' intentions to quit smoking (Willemsen, De Vries, Van Breukelen \& Oldenburg, 1996). Other studies showed that smokers with high self-efficacy beliefs about stopping smoking have a greater chance of long-term success (reviewed by Strecher et al., 1986). This has allso been found to be true for employees (Gottlieb \& Nelson, 1990; Harris et al., 1994).

This paper reports on a mass-media campaign and improvements in smoking policy that accompanied a worksite smoking cessation program. With regard to smoking employees, we hypothesized that this enriched environment would result in a. increased participation in the cessation program, b. more favorable cognitions towards quitting smoking among nonprogram participants (i.e., more pros of quitting smoking and less cons, higher self-efficacy levels, more positive perceptions of social influences, and increased intention to quit smoking), and c. higher quit rates among nonparticipants. With regard to nonsmokers, we expected that an enriched environment would: a. reduce tolerance towards smoking at work, $b$. increase assertiveness, and c. make nonsmokers more supportive of quitters. The hypotheses were tested by comparing changes observed among employees of enriched environment worksites and comparison worksites.

\subsection{Method}

\subsubsection{Study design}

Only worksites with more than 250 employees were considered for inclusion in the study. The research team contacted several worksites through company physicians or human resource managers. Eight worksites agreed to participate. These included chemical industry, telecommunications, public transport, and local government. Four worksites were assigned to receive a comprehensive smoking cessation program, a mass-media program and smoking policy changes (enriched environment condition), while the other worksites only received a minimal cessation program 
and no mass-media and policy changes. The latter worksites were matched to the 'enriched environment condition' worksites according to type of worksite and size. While the 'enriched environment worksites' implemented a smoking cessation program basically consisting of self-help manuals and group courses ('comprehensive cessation program'), the comparison worksites offered a smoking cessation program consisting of only a self-help manual ('minimal cessation program'). The effectiveness of the comprehensive versus the minimal cessation program has been reported elsewhere (Willemsen, De Vries \& Genders, submitted), showing that the comprehensive cessation program resulted in a $16 \%$ quit rate and the minimal program in $12 \%$ quitters at 14 months follow-up. In the 'enriched environment worksites', mass-media activities were conducted and smoking restrictions were realized, while comparison worksite signed a contract stating that they would refrain from massmedia campaigns aimed at smoking discouragement and that they would not pay extra attention to smoking policies during the research period than they would normally do (i.e., 'usual care' treatment condition).

\subsubsection{Linkage groups}

In each 'enriched environment worksite', a work group was organized using the socalled linkage approach (Orlandi et al., 1990). Representatives from the resource system (the University, the Foundation on Smoking and Health, and the Dutch Comprehensive Cancer Centers, who collaborated in developing the program) and representatives of the user system (departments of health services, human resource, work councils, and public relations) met frequently over a 6 months period, with an average of 12 meetings. The aims was to fit the program to resources and characteristics of the worksite, using a protocol to ensure standardization across worksites. Support from management was assured by representatives from the working group, who reported directly to management about the project.

\subsubsection{Mass-media campaign}

The mass-media campaign lasted three months. An important feature was an exhibition at strategic locations in the worksites. These exhibitions provided up to date information about the ongoing program, provided education about health risks of smoking and passive smoking, and information about smoking cessation. Employees could take away leaflets with more information on these topics. Also, smoking employees were invited to measure the CO-content of expired breath and their lung 
capacity at the exhibition sites. They could compare their 'scores' with those of nonsmokers. Furthermore, in 'enriched environment worksites', company newsletters gave frequent attention to (passive) smoking and to the ongoing cessation program. Also, a no-smoking day was organized, which was announced through various mass-media channels. The mass-media campaign was repeated after one year. This included organizing a worksite-wide no-smoking day and frequent attention in company newsletters to smoking cessation and smoking policies.

\subsubsection{Smoking restrictions}

At each worksite, a baseline survey provided data on support for worksite smoking policy options (Willemsen, De Vries \& Genders, 1996). Based on these data, the researchers wrote a report for each 'enriched enwironment worksite' to stimulate management to implement restrictive smoking policies. Although none of these worksites implemented a strict smoking ban, smoking restrictions were imposed for specific areas, such as canteens, meetings rooms, and general usage areas. Furthermore, renewed attention was given in company newsletters to restrictions that were already in place and all tobacco selling points on the premises were removed.

\subsubsection{Subjects}

In the eight worksites, 10,687 employees were employed. Of these, 1730 wrere randomly selected for an interview. This baseline survey was conducted six months prior to the start of the mass-media campaign, and the sample was interviewed again eighteen months after the first campaign (i.e., six months after completion of continuation activities). All measurements were done by means of computer assisted telephonic interviewing. The overall response rate to the baseline survey was 87 percent $(N=885)$ at 'enriched milieu worksites' and 84 percent $(N=595)$ at comparison worksites.

\subsubsection{Questionnaire}

The questionnaire was based on previous research (Mudde et al., 1995) and was adapted for the present study by means of qualitative interviews with employees.

Outcome measures in smokers. At baseline measurement, respondents were counted as smokers if they gave an affirmative answer to the question: "Do you smoke?". At post test, seven day point prevalence abstinence was measured (i.e., "Have you smoked in the past seven days, even if just one cigarette?"). The bogus 
pipeline procedure (Murray et al., 1987) was used to improve validity of self-reports; that is, before being asked about their current smoking status, respondents were told they might be asked to provide saliva samples to check their smoking status. Smokers were also asked about the number of cigarettes and other tobacco products they smoked each day and about their past quitting behavior ("How often have you seriously tried to quit smoking in the past?").

The following psychological outcomes were measured: pros of quitting smoking ( 3 items; $\alpha=70$ ), social pressure to quit smoking from people at work (2 items) and from people outside work ( 4 items, $\alpha=.66$ ), perceived smoking behavior of people, both at work ("how many of your colleagues smoke?") and outside work ( 4 items forming an index of the number of important others who smoke), self-efficacy (4 items, alpha $=.73$ ), and intention to quit smoking ("Do you intend to quit smoking within six months?"). Further details about these items can be found in Willemsen, De Vries, Van Breukelen \& Oldenburg (1996).

Outcome measures in nonsmokers. The mass-media campaign was expected to decrease nonsmokers' tolerance towards smoking at work. Tolerance was assessed with six 5-point Likert scale items $(\alpha=.78)$, partly based on a measure developed by Stephens et al. (1989). Examples of items are: "It must be left entirely to the employees' own discretion whether and where they smoke" and "A smoky work environment is harmful to my health". Another indication of intolerance was assertive behavior (Willemsen $\&$ De Vries, 1996), which was measured by asking nonsmokers how often they asked smoking colleagues not to smoke. A six-point scale was used with answers ranging from never $(0)$ to always $(+5)$. Coworker support - or at least the absence of coworker discouragement - seems to be related to abstinence from smoking (Sorensen, Lando \& Pechacek, 1993). Supportive behavior was measured by asking how often respondents supported smoking colleagues in a quit attempt. A 6-point scale was used, with answers ranging from $O$ (never) to 5 (always).

Socio-demographic and worksite variables. Socio-demographics (age, sex, and education) and questions about the work situation were assessed for all respondents. Education was measured by asking respondents to choose between six types of education, which could be categorized according to Dutch standards as $1=10 \mathrm{w}, 2$ $=$ medium, and $3=$ high. Questions about the work situation were: having subordinates (yes/no), working in shifts (yes/no), and self-reported type of work, measured by making respondents choose between the following options: 1 = "my work 
primarily consists of desk work" (white-collar workers), 2 = "my work consists of both desk-work, and manual labor," 3 = "my work primarily consists of manual labor" (blue-collar workers). Company type was a categorical variable (chemical industry, telecommunications, transport or local government).

Exposure variables. At posttest, exposure to mass-media was measured by a series of yes/no questions, asking respondents if they had seen the smoking cessation exhibition, if they had read leaflets about smoking (-cessation), if they had read articles in the company newsletter about smoking or smoking cessation, and if they had noticed the no-smoking day. Furthermore, two questions were asked to assess exposure to changes in smoking policy. First, respondents were asked - on a 4-point scale - to indicate to what extent the smoking policy at their work station had been restricted since the first interview $(3=$ very much restricted, $0=$ not restricted). Second, they were asked whether the number of places where smoking was allowed had changed $(-1=$ more places, $0=$ no change $+1=$ fewer places $)$.

\subsubsection{Statistical analyses}

We examined the effect of the mass-media campaign and smoking policy changes on various outcome measures by means of regression analyses. Each time a model was used consisting of exposure variables, treatment condition ("enriched environment" versus comparison worksites) and potential confounders (socio-demographics, worksite variables, and baseline scores of outcome variables). Potential interactions between treatment and pretest scores of the dependent variable were also examined. An alpha level of .05 was used for all statistical test.

\subsection{Results}

The response to the follow-up interview was 73\% (644/885) in the 'enriched environment worksites' and $78 \%(463 / 595)$ in the comparison worksites. Smoking prevalence was 32\% (285/885) in the 'enriched environment worksites' and 38\% $(224 / 595)$ in the comparison worksites $\left(\chi^{2}(1)=2.11\right.$, NS). Of all the smokers in our sample, $71(14 \%)$ had enrolled in the smoking cessation program conducted at their workplace, while 438 ( $84 \%$ ) were nonparticipants. Among program participants, the 
response to the posttest questionnaire was $93 \%$ (66/71), while among non-program participants this was $68 \%(296 / 438)$, and among nonsmokers $76 \%$ (745/971).

In order to examine whether loss to follow-up could threaten internal and external validity, logistic regression analyses were performed in which attrition was predicted from baseline characteristics and treatment condition. Enriched environment and comparison worksites did not show different attrition rates for program participants. The single predictor of attrition for non-program participating smokers and nonsmokers was being an employee in the chemical industry: the odds ratio for non-program participants was $5.2(95 \% \mathrm{CI}=2.69-10.20)$, while that for nonsmokers was $2.75(95 \% \mathrm{CI}=1.77-4.26)$. The reason was that halfway through the research period, an international crisis in the chemical industry led to the discharge of about one fifth of employees.

Baseline characteristics of smokers (program participants and non-program participants) and nonsmokers are shown in Table 8.1. Some significant baseline differences were identified between the 'enriched environment' and comparison worksites: non-program participants and nonsmoking respondents in the 'enriched environment worksites' were less often white-collar workers, worked in shifts more often, and less often had subordinates. Respondents in the 'enriched environment worksites' more often worked in the telecommunication sector and less often in the chemical industry. These variables were included as confounders in the regression analyses.

\subsubsection{Program exposure}

Smokers in both treatment conditions were asked which program modalities they had been exposed to in the previous 18 months. The results are shown in Figure 8.1. The smoking cessation exhibition and the no-smoking day were not featured in the comparison worksites. Although $\chi^{2}$ analysis showed that 'enriched environment' and comparison worksites differed on all exposure variables $(p<.0001)$, not all respondents in the 'enriched environment' worksites said they had been exposed to mass-media messages. Because exposure to various mass-media activities in the 'enriched environment' worksites was not optimal, we examined whether employees who were exposed, had specific baseline characteristics. To this end, logistic regression analyses were conducted in which exposure was regressed on baseline variables. This revealed that smokers who read articles about smoking in company newsletters were more often higher educated $(\mathrm{OR}=3.68 ; 95 \% \mathrm{CI}=1.53-8.87 ; \mathrm{p}<.01)$ and 
had made more quit attempts in the past $(\mathrm{OR}=1.75 ; 95 \% \mathrm{CI}=1.17-2.61 ; \mathrm{p}<$ .01). Moreover, education level was also positively associated with picking up leaflets ( $\mathrm{OR}=2.76 ; 95 \% \mathrm{CI}=1.16-6.52)$ and with having been exposed to smoking cessation exhibitions $(\mathrm{OR}=2.78 ; 95 \% \mathrm{CI}=1.25-6.17)$.

Table 8.1: Baseline comparison of 'enriched environment" and comparison terksites, for smokers (program participants and nonparticipants) and nonsmokers.

\begin{tabular}{|c|c|c|c|c|c|c|}
\hline \multirow[b]{2}{*}{ Variables } & \multicolumn{2}{|c|}{$\begin{array}{c}\text { Smokers } \\
\text { (Program participants) }\end{array}$} & \multicolumn{2}{|c|}{$\begin{array}{c}\text { Smokers } \\
\text { (Nonparticipants) }\end{array}$} & \multicolumn{2}{|c|}{ Nonsmokers } \\
\hline & $\begin{array}{l}\text { Comprehensive } \\
\text { program + } \\
\text { Enriched envi- } \\
\text { ronment } \\
|N-46| \\
\end{array}$ & $\begin{array}{l}\text { Minimal } \\
\text { program } \\
+ \\
\text { Usual care } \\
(\mathbb{N}-25) \\
\end{array}$ & $\begin{array}{l}\text { Enriched } \\
\text { environ- } \\
\text { ment } \\
(\mathrm{N}=239) \\
\end{array}$ & $\begin{array}{l}\text { Usual cere } \\
(N-199 \mid\end{array}$ & $\begin{array}{l}\text { Enriched } \\
\text { environ- } \\
\text { ment } \\
(\mathrm{N}-599)\end{array}$ & $\begin{array}{l}\text { Usual } \\
\text { care } \\
(N-370)\end{array}$ \\
\hline Male $(\%)$ & 78 & 84 & 78 & 75 & 81 & 80 \\
\hline Age (mean) & 41 & 42 & 40 & 41 & 40 & 41 \\
\hline White-collar worker $(\%)$ & 44 & 52 & 41 & $60^{\cdots *}$ & 54 & $63^{* *}$ \\
\hline $\begin{array}{l}\text { Educationall level } \\
\% \text { low } \\
\% \text { medium } \\
\% \text { high }\end{array}$ & $\begin{array}{l}28 \\
48 \\
24\end{array}$ & $\begin{array}{l}32 \\
56 \\
12\end{array}$ & $\begin{array}{l}31 \\
50 \\
19\end{array}$ & $\begin{array}{l}26 \\
48 \\
26\end{array}$ & $\begin{array}{l}21 \\
52 \\
27\end{array}$ & $\begin{array}{l}22 \\
49 \\
29\end{array}$ \\
\hline Shift workers $(\%)$ & 46 & 40 & 34 & $23^{* *}$ & 30 & $24^{*}$ \\
\hline Having subordinates $(\%)$ & 32 & 40 & 33 & $44^{\circ}$ & 34 & $48^{\cdots}$ \\
\hline $\begin{array}{l}\text { Company type } \\
\text { Telecommunication } \\
\text { Locial government } \\
\text { Chemical industry } \\
\text { Public transport }\end{array}$ & $\begin{array}{l}36 \\
20 \\
20 \\
24\end{array}$ & $\begin{array}{c}24 \\
8 \\
36 \\
32\end{array}$ & $\begin{array}{l}29 \\
24 \\
34 \\
14\end{array}$ & $\begin{array}{l}14^{* * *} \\
31 \\
45^{*} \\
11\end{array}$ & $\begin{array}{l}36 \\
23 \\
29 \\
12\end{array}$ & $\begin{array}{l}16 \cdots \\
31 * * \\
39^{* *} \\
14\end{array}$ \\
\hline
\end{tabular}

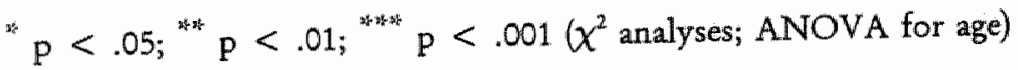

\subsubsection{Participation}

Participation rates did not differ significantly between 'enriched environment' worksites (16\% of smokers) and comparison worksites (11\%). Table 8.2 presents the results of a logistic regression analysis to predict participation in the quit smoking program from exposure to the smoking cessation exhibition and exposure to articles in company newsletters, since these two methods were partly used to attract attention to the 


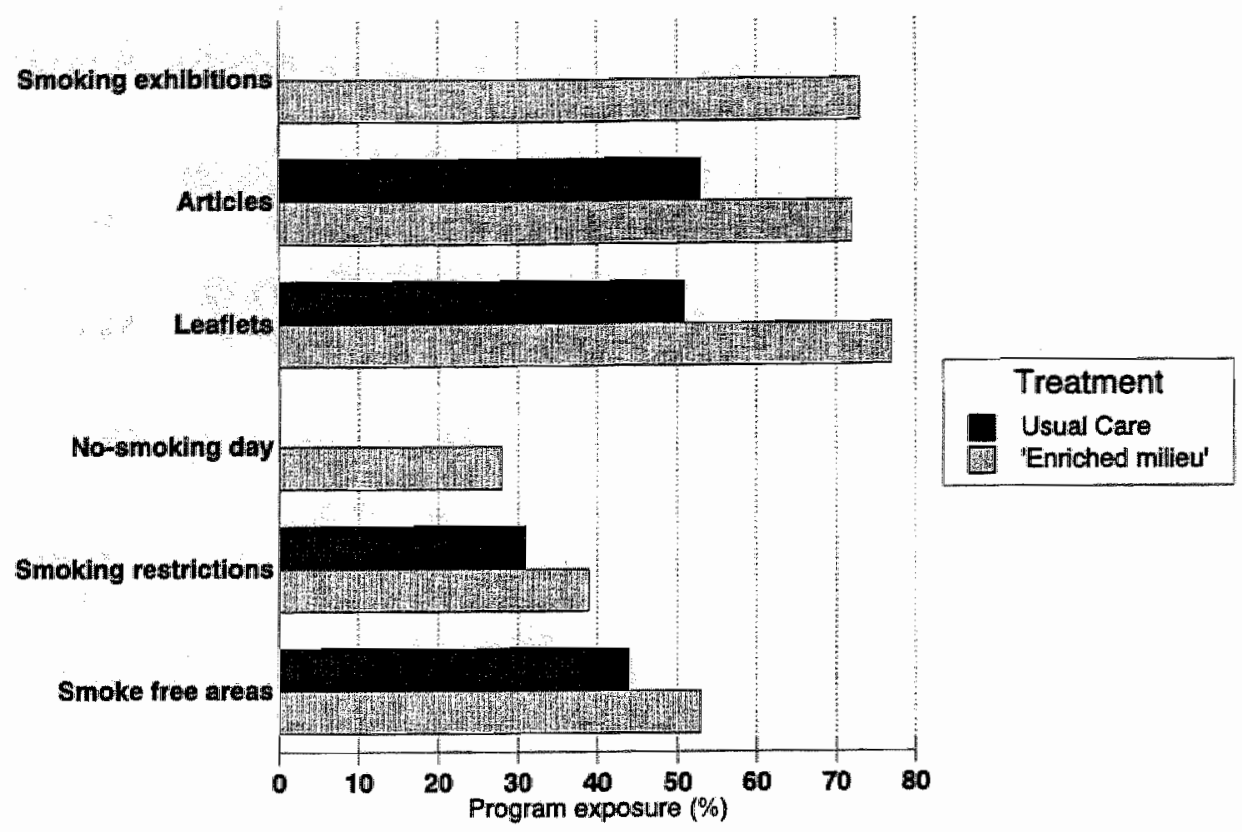

Figure 8.1: Smokers' exposure to program components ( $\mathrm{N}=296)$.

smoking cessation program. It was found that significant predictors of participation were: having been exposed to the smoking cessation exhibitions, having made more previous quit attempts, and working in a bus company or a telecommunications company. No significant interactions were found between exposure variables and treatment condition ("enriched environment" worksite versus 'usual care' worksite).

\subsubsection{Impact on non-program participants}

The effect of mass-media and smoking policy on various changes in cognitive variables (between pre- and posttest) was examined with a series of multiple regression analyses. No overall-effect was found from treatment (i.e., 'enriched environment' worksites versus comparison worksites) on any of the cognitive variables, with the exception of perceived social pressure to quit smoking from people outside the work setting (friends, family). This variable had increased more strongly in the comparison worksites $(B=-$ $.24, \mathrm{r}=-.16 ; \mathrm{p}<.01)$. Furthermore, regression analyses revealed that two exposure variables were related to changes in psychological variables: exposure to leaflets and 
Table 8.2: Prediction of smokers' participation in the cessation program from baseline characteristics (logistic regression analysis).

\begin{tabular}{|c|c|c|}
\hline Sex (male) & 0.98 & $10.47-2.071$ \\
\hline Age & 1.01 & $10.98-1.051$ \\
\hline White-collar worker (blue-collar is reference category) & 2.14 & $(0.95-4.81)$ \\
\hline \multicolumn{3}{|l|}{ Educational Level (low is reference category) } \\
\hline Middle & 0.90 & $(0.54-1.50)$ \\
\hline High & 1.12 & $(0.76-1.65)$ \\
\hline Shift worker & 1.33 & $10.60-2.941$ \\
\hline Having subordinates & 1.06 & $10.55-2.05\}$ \\
\hline \multicolumn{3}{|l|}{ Type of company (Chemical Industry is reference category) } \\
\hline Governmental & 0.81 & $(0.53-1.89)$ \\
\hline Telecommunications: & 3.77 & $(1.63-8.74)^{\cdots}$ \\
\hline Transport & 3.44 & $|1.31-9.86|$ \\
\hline Number of cigarettes per day & 1.02 & $(0.99-1.12)$ \\
\hline Number of previous quit attempts & 1.19 & $(1.02-1.40)^{*}$ \\
\hline Exposure to articles in compiary newsletter & 1.63 & $(0.86-16.49)$ \\
\hline Exposure to smoking cessation exhibitions & 4.48 & $(1.77-11.34)^{*}$ \\
\hline Treatment ('enriched environment' versus 'usual care') & 0.46 & $10.19-1.121$ \\
\hline
\end{tabular}

$\mathrm{p}<.05{ }^{* * 4} \mathrm{p}<.01$

exposure to improvements in the number of places in which it was allowed to smoke. One regression analysis showed that exposure to leaflets was positively associated with an increase in perceived social pressure from people outside the work setting $(B=.16$, $r=.11, \mathrm{p}<.05)$. Another regression analysis showed that exposure to leaflets was associated with a decrease in the number of smokers outside the work setting (friends, family) $(B=.14, r=.11 ; p<.05)$. These two results suggest that smokers take leaflets home and stimulate others to quit smoking. Respondents who indicated that, since the baseline measurement, the number of places where it was not allowed to smoke had increased, more often reported increases in intention to quit smoking $(B=.14 ; \mathrm{r}=.15$, $\mathrm{P}<.05)$. Furthermore, reductions in the perceived smoking behavior of colleagues were more often observed when smoking was restricted $(\mathbb{B}=-.13, \mathrm{r}=-.12, \mathrm{p}<.05)$. 
Point prevalence quit rates were $8 \%(13 / 158)$ in the 'enriched environment' condition and $11 \%(15 / 138)$ in the comparison worksites. Nonresponders were counted as smokers. Logistic regression analysis revealed no effect of treatment ('enriched environment' versus 'usual care' worksite) on pasttest smoking status, controlling for baseline differences. Regression analyses revealed no significant effects of specific exposure variables on posttest smoking cessation either.

\subsubsection{Impact on nonsmokers}

Multiple regression analyses controlling for baseline differences showed no overall effect of treatment on nonsmokers. However, two effects were found resulting from exposure to specific program elements. Increases in nonsmokers' assertiveness were positively associated with increased restrictiveness of smoking policy $(B=.10, r=.08$; $\mathrm{p}<.05$ ). Intolerance towards smoking at work increased when the number of places where it was allowed to smoke decreased $(B=.08, \mathrm{r}=.05, \mathrm{p}<.05)$.

\subsection{Discussion}

An intensive mass-media campaign and improvements in smoking policy accompanied a worksite smoking cessation program. This 'enriched environment' was expected to increase participation in the cessation program and to produce spin-off effects, both on smokers who did not enroll in the cessation program and on nonsmokers. We wrell first discuss our findings with respect to program participation, followed by spin-off effects on smokers and nonsmokers.

Although participation rates were not significantly higher in "enriched environment' worksites than in comparison worksites, program participation was more frequent among smokers who had been exposed to the smoking cessation exhibition at their workplace. This might point to a strong positive effect of mass-media strategies on participation rates. However, this conclusion should be interpreted with caution, since no firm causal conclusions can be drawn from these observations. The program participants may also have been more sensitive to anti-smoking information, resulting in greater awareness of the existence of the smoking cessation exhibitions. Replication of our findings by other studies can show that mass-media strategies can be effective in increasing participation in worksite smoking cessation program. This is important since high program participation is essential for substantial impact on worksite-wide smoking prevalence to occur.

The results did not support our hypotheses with respect to smokers who did not take part in the cessation program. Point prevalence quit rates among non-program participants did not differ significantly between 'enriched environment' and comparison 
worksites, averaging $9 \%$. This percentage falls just within the range of quit rates that could be expected in no-treatment or usual care conditions, which has been estimated to be between 5.6 and 9.1 per cent $(95 \%$ Cl) (Baillie et al., 1995). Neither was any effect of treatment found with regard to attitudes, intention, and other psychological variables. Furthermore, exposure to specific mass-media methods was unrelated to outcomes in smokers, including most psychological measures. An analysis of exposure to various intervention components (leaflets, articles in company bulletins, no-smoking day, smoking cessation exhibition) showed that, although program exposure was for from optimal, respondents in the 'enriched environment" worksites still had a significantly higher exposure to these methods. This suggests that the absence of positive treatment effects might only partly be explained by implementation failures. Another explanation is that the lower baseline smoking rate in 'enriched environment' worksites (32\% versus $38 \%$ ) might have worked against the effectiveness of the mass-media program. However, such a bias should have been disclosed by any significant interactions between treatment and baseline scores on our outcome variables, which we did not find. Moreover, the finding that individual exposure to specific mass-media components was both unrelated to smoking cessation and to changes in psychological determinants of cessation, leads us to conclude that a comprehensive smoking cessation program in large Dutch worksites did have little spin-off effect on those smokers who did not take part in the cessation program. We found that smokers who visited the smoking cessation exhibitions and who read leaflets about smoking were the more highly educated employees. An explanation for this finding is that the exhibitions were lacated in the main buildings and offices, where mostly white-collar workers were located. We also found that employees who read messages in the company newsletters about smoking were the more highly educated workers. These findings thus point to the need to develop separate strategies with which less educated blue-collar workers can be reached.

An unexpected finding was that perceived social pressure from family and friends, which is an important determinant of employees' intention to quit smoking (Willemsen, De Vries, Van Breukelen \& Oldenburg, 1996), had increased more strongly in the comparison worksites. It is difficult to see how this might have resulted from differences between the 'enriched environment' and comparison worksites. It was discovered that respondents who were exposed to leaflets about smoking cessation, both in the 'enriched environment' and in the 'usual care' worksites, more often experienced positive changes in social influences from family and friends. This suggests that they exposed family and friends to these materials.

The present findings regarding the non-program participating smokers must be interpreted against the background of the fact that all worksites were medium-sized to large (ranging from 295 to 3,500 employees). In large worksites it may be more difficult 
to change the social climate, especially in a relatively short time. This may be more feasible in medium sized and small worksites. Fisher et al. (1994) reported that 10 to $25 \%$ of nonparticipants in two worksites with fewer than 200 employees had successfully quit smoking.

To our knowledge, the present study is the first attempt to examine the impact of mass-media and smoking policy on nonsmoking employees. Previous research in the field of health psychology and smoking has been directed at smokers only. We expected to see a positive effect of mass-media intervention and smoking policy on nonsmokers' $^{3}$ assertiveness, supportive behavior, and intolerance towards smoking during working hours. We found evidence for effects resulting from smoking policy changes, but not from mass-media. The mass-media intervention was not specifically designed to affect nonsmokers" attitudes and behaviors (but instead was targeted at smokers), but intuitively it seemed reasonable to expect to see positive effects among nonsmokers as well. This makes clear that for a worksite campaign to have an impact on nonsmokers, specific health education messages, and strategies need to be developed first. These should be grounded on knowledge about psychological determinants of nonsmokers' supportiveness and assertiveness. Improvements in smoking policy were associated with nonsmokers becoming more assertive and less tolerant towards smoking colleagues. This suggests that policy changes may have a positive influence not only on smoking behavior, but on nonsmokers' behavior as well, most likely because nonsmokers see that their claims for a smoke-free environment are supported by clear no-smoking signs.

To summarize, the failure to find evidence of a spin-off effects of a smoking cessation program in an enriched environment on nonparticipating smokers' cognitions and behavior, is disappointing. This is especially so in light of the intensive nature of the mass-media campaign that was examined in this study. However, two positive findings emerged from this study. First, smoking cessation exhibitions may have a beneficial effect on participation in the cessation program. Second, smoking restrictions were found to have an impact on nonsmokers' assertiveness and intolerance. Of additional interest was the finding that exposure to exhibitions, leaflets, and newsletters was less optimal among blue-collar workers. The challenge remains how the potential of worksites as a setting to reach and influence many smokers, especially blue-collar workers, can best be realized. 


\section{9}

\section{Main conclusions and general discussion}

The objective of this thesis was to examine whether the wrorksite could be an effective channel through which adult Dutch smokers could be reached and encouraged to quit smoking. To this end, quantitative data were collected from employees in several large worksites in the Netherlands. Employees who participated in smoking cessation programs provided research data as well as employees who chose not to participare and nonsmokers.

Chapter 1 presented data showing that national smoking prevalence in the Netherlands is high in comparison to many other European countries, and that this has stabilized in the past 5 years, instead of declining. A review of governmental policies led to the conclusion that these have been quite limited. Political efforts are needed to speed up and extend governmental regulations. Another strategy to bring down national smoking rates is to increase health education efforts, both aimed at the general population and at specific target groups. One of these target groups is the working population, which comprises $63 \%$ of the adult population. However, in the Netherlands there are still very few worksites that offer smoking cessation programs to their employees. 
Chapter 2 presented data showing that smoking prevalence among workers was higher than in the general adult population ( $42 \%$ compared to $36 \%$ in 1993). Most smokers can be found among blue-collar workers, especially in the catering industry and among construction workers. Smokers who are regularly exposed to coal, grain, silica, asbestos, and several other hazardous substances are at an increased risk of illness due to additive or synergistic effects of tobacco smoke in combination with these substances. However, Dutch legislation on national labor conditions does not list environmental tobacco smoke (ETS) as a hazardous occupational agent. It is up to the individual occupational physician to interpret this legislation as including ETS exposure and to act accordingly. This could be by, for example, encouraging smoking employees who work in high-risk professions to quit smoking and by protecting nonsmokers from ETS exposure.

At the start of our research, it was unclear whether special programs would be needed to reach and influence Dutch blue-collar workers as opposed to white-collar workers. It was decided to develop and pilot-test a smoking cessation program based on state-of-the-art knowledge about the effectiveness of smoking cessation methods in worksites (Chapter 6), and then evaluate this program in large worksites that include blue and white collar workers (Chapter 7 and Chapter 8). Special attention was then paid to whether the program had different effects on blue and white-collar workers.

One important issue that emerged from the problem analysis in Chapter 2, is the difference in perspective between public health advocates and employers. For health educators, smoking is an important target behavior, because it is the single most important cause of premature illness and death. For employers, passive smoking seems more important, due to the social problems that are associated with passive smoking at the workplace. If smoking and nonsmoking employees cannot come to satisfactory agreements, management may regard the irritation caused by passive smoking as a problem that requires concrete and rapid solutions. In such cases, smoking policies are the first priority and smoking cessation programs may be offered in addition to policy changes. ${ }^{1}$

"From a public health perspective, it must be noted that passive smoking is much less harmful than active smoking, but that it nevertheless contributes to morbidity and mortality. It has been estimated that each year, in the Netherlands, between 110 and 270 people who have never smoked themselves, die of lung cancer resulting from frequent exposure to ETS (Jansen et al., 1993). Moreover, passive smoking has been shown to cause respirato- 
In this final chapter, the results from the individual studies are summarized and discussed. The findings will be integrated within the broader perspective of what has been learned about the potential of Dutch worksites to reach adult smokers (9.1). This will be followed by suggestions for future research (9.2), a discussion of methodological limitations (9.3), and main conclusions (9.4).

\subsection{Summary and discussion of major findings}

Three types of studies were conducted. First, baseline data were used in a descriptive study in which employees' positions with respect to smoking at work and to smoking policies were examined (9.1.1). Second, baseline data were also used in exploratory studies in which we examined psychological determinants of smoking employees' intentions to quit smoking (9.1.2), and determinants of nonsmokers" assertiveness (9.1.3). Based on these two determinant studies, the usefulness of the ASE model to predict intention and behavior will be discussed (9.1.4). Third, longitudinal data were used to test hypotheses with regard to the effectiveness of smoking cessation programs in Dutch worksites (9.1.5).

\subsubsection{Smoking as a social problem}

The fact that passive smoking causes social problems at the workplace is a legitimate reason for employers to try to reduce smoking among their employees. It is therefore important that managers are aware of this issue. The study presented in Chapter 3 was carried out to collect descriptive data about the magnitude of this social problem. Another objective was to assess employee support for various smoking policy options. The results could be used to boost employers" awareness of the smoking problem and to recommend feasible smoking policies to them. A representative sample of smoking and nonsmoking employees $(N=1480)$ was drawn from eight large companies in four sectors of Dutch industry. The main finding was that about two-thirds of nonsmokers were "sometimes" to "often" bothered by ETS at

ry as well as other diseases (US Department of Health and Human Services, 1986). An unknown number of these might be attributable to ETS exposure in worksites. 
their company. ${ }^{2}$ Passive smoking was most often encountered in work offices, meeting rooms and canteens. A striking finding was that the "common courtesy" approach (no smoking restrictions), endorsed by the tobacco industry, was rejected by most nonsmokers and by many smokers. Instead, in three sectors of industry, employees supported a general smoking ban, under the condition that there would be designated smoking areas. Support for a complete smoking ban was very low. Thus, as long as support for complete smoking bans does not increase substantially, companies will have to be prepared to pay the costs of creating designated smoking areas.

\subsubsection{Smokers' intention to quit}

The study reported in Chapter 4 used a representative cross-section of smoking employees in eight worksites. We found that $66 \%$ of smoking employees had no intention to quit smoking within six months. This means that Dutch worksite smoking cessation programs will only reach a small proportion of smoking employees. Interventions should, therefore, be targeted at all smokers in a worksite population, not only at those who are already prepared to quit (Abrams et al., 1994). The question remains how these smokers may be encouraged to contemplate quitting smoking and eventually make a quit attempt. In this context, an important finding was that beliefs about the outcomes of smoking cessation (the attitude component in the ASE model) were the strongest predictors of intention to quit, suggesting that attitudinal information may increase employees' intention to quit smoking. In the determinant study presented in Chapter 4, special attention was paid to examining social influences in the worksite, because international literature reported contradictory findings with respect to the influence colleagues may have on a smoker's decision to quit smoking. The results from our study suggested that colleagues in eight large Dutch worksites have little influence on a smoker's intention to quit smoking. In contrast, family and friends were much more important. One explanation is that employees see smoking primarily as a private behavior that falls outside the influence of the work setting. Maybe this is more so in the Netherlands than in, for example, the US. Nevertheless, while the opinion of co-workers may be not very

${ }^{2}$ A comparable figure was recently reported in a study among the population of Rotterdam in the Netherlands, where it was found that $66.2 \%$ of nonsmokers said they were sometimes or often bothered by smoking at work (Van de Goor et al., 1996). 
important with respect to a worker's initial decision to quit smoking, a supportive work environment may still be very important to help employees who quit to stay off the cigarettes.

The results of the determinant study suggested that smokers who failed after a quit attempt do not automatically become de-motivated to quit again in the near future. Therefore, smokers who relapse should be encouraged to make a new quit attempt by enrolling them in a worksite smoking cessation program which offers various cessation options. However, the time that elapsed between this determinant study and the effectiveness studies that were presented in Chapters 7 and 8, was too short to implement this recommendation.

\subsubsection{Passive smoking and assertiveness}

Chapter 5 described a study examining how nonsmokers reacted to smoking in their workplace. Nonsmokers" attitudes and behavior towards smokers may be important for at least two reasons. First, in situations where there are smoking bans, smokers may not comply with the smoking restrictions. Compliance may then depend on how nonsmokers react to smokers who violate these bans: will they be assertive or will they keep quiet? Second, in cases where there are smoking bans, these are very often not indicated properly, as was shown in an inspection carried out for the Dutch government revealing that in $59 \%$ of public health care institutions, only some nonsmoking signs were put up or none were at all (Ministry of Public Health, Welfare and Sports, 1994). In such cases, nonsmokers' assertiveness is the only means of keeping communal spaces free from cigarette smoke. This study examined the extent to which Dutch employees were assertive towards smoking colleagues, and - if health education interventions needed to be developed to increase nonsmokers' assertiveness - which psychological determinants would be targets for such interventions.

We found that $51 \%$ of nonsmokers sometimes asked colleagues to refrain from smoking at their workplace, which was comparable to findings from the United States and is much higher than percentages found outside work settings (Davis et al., 1990; Schofield et al., 1993). Thus, nonsmokers are more willing to do something about tobacco smoke at their own workplace than in public places, suggesting that there is no urgent need for interventions that attempt to further increase nonsmokers' assertiveness in Dutch worksites. Such interventions are probably more relevant if targeted to the general public. 


\subsubsection{Tests of the ASE model}

Both determinant studies in Chapters 4 and 5 used the ASE model to predict behavioral intention and/or behavior itself. This model makes a distinction between distal - or descriptive - predictors (demographics, behavioral variables and environmental variables) and proximal - or mediating - predictors (attitudinal, normative and selfefficacy beliefs). For health educators, the latter type of variables are important because they can be influenced through educational interventions, while the former type of variables serve to identify specific target groups for interventions. By means of a series of regression analyses we tested the model's assumption that distal variables, such as smoking frequency, past behavior and demographics only have an indirect impact on intention, through their influence on the direct predictors attitude, social influence and self-efficacy. Several conclusions may be drawn from the two studies. First, the predictive power of the model was higher than in studies using no explicit theoretical model (see Chapter 4). The model explained 29\% of variance in employees' intention to quit smoking and $34 \%$ of variance in nonsmokers' intentions to behave assertively. Second, the assumption that the ASE variables would mediate all possible effects of variables that were theoretically more distal from the behavior, was rejected with regard to two variables: past behavior (which was measured in Chapter 4) and beliefs about the consequences of exposure to ETS (Chapter 5). These variables had a substantial additional predictive power. Below we will briefly discuss the implications of these two findings.

Past behavior. The addition of past behavior increased the ASE model's power to predict smokers' intentions to quit from $23 \%$ to $29 \%$. This is in line with other studies reporting an impact of previous behavior that was not mediated by cognitions (Budd, North \& Spencer, 1984; De Vries, Backbier et al., 1995; Fredericks \& Dossett, 1983). Ajzen (1991) stated that if one finds a significant effect of past behavior, this means that intention is not predicted well enough from the mediating variables. This argues against including a measure of past behavior as a proximal factor in the ASE model, as long as specific attitudinal, normative or self-efficacy beliefs might be found that can further improve the model. Because we used a small number of beliefs in our study, it is possible that a more extensive operationalization of the ASE concepts would result in a model in which past behavior had no additional power. However, a recent study in which the ASE model was used to predict smoking onset found that the effect of previous behavior was too large to be attributable to method variance (De Vries, Backbier et al., 1995). Another reason 
why one should be cautious about including previous behavior in the ASE model, is that previous behavior is in itself not a cognitive factor that can be modified or changed through health education. In other words: past behavior might improve the predictive power of the model, without improving the model's value to practitioners.

Our results did suggest that past behavior impacted on attitude and perceived social pressure. Smokers who had made more quit attempts in the past had a more positive attitude towards quitting smoking and experienced more pressure from people outside work to quit. Thus, current beliefs about quitting smoking partly reflect past experiences with quit attempts (Flay \& Petraitis, 1994). Fishbein \& Ajzen recommended a feedback-loop from behavior back to the cognitive variables. Indeed, "performance of a particular behavior may lead to new beliefs about the object, which may in turn influence the attitude" (Fishbein \& Ajzen, 1975; p 15).

Very repetitive behaviors seem to be an exception to the above. In cases such as driving a car or smoking a cigarette, past behavior produces strong habits, which drive current behavior largely automatically, with cognitions playing only a subordinate role. As habit increases, behavior becomes less rational and more of a learned response (Bagozzi, 1981). However, making an attempt to quit smoking can hardly be regarded as a repetitive behavior. For example, in our sample, the average number of past quit attempts was 2.8. Thus, smoking can be considered a habit, but smoking cessation certainly cannot.

Beliefs about exposure to ETS. According to the theory of reasoned action, behavioral intention is determined by beliefs about the desired behavior itself (for example, assertiveness), not by beliefs about the object of the behavior (for example, exposure to ETS) (Fishbein \& Ajzen, 1975). However, in Chapter 5 we found that a variable measuring beliefs about ETS could explain an additional $9 \%$ of the variance in nonsmokers' intention to behave assertively, over and above the ASE variables. This suggests that one way of improving the ASE model's predictive power is to elaborate on the attitude measure, by including beliefs about the object. Our operationalization of this variable closely resembles the concept of 'perceived susceptibility', that is, one's perception of the risk of being affected by a condition, in our case exposure to ETS. This variable has been shown to be an important predictor of preventive actions in the health belief model (Janz $8 x$ Becker, 1984). Our results suggest that in instances where susceptibility to disease is uncertain, such as with exposure to environmental tobacco smoke, the attitude component in the 
ASE model might be extended with items measuring perceived susceptibility to the disease.

\subsubsection{Program effectiveness}

The results from the three Dutch effectiveness studies will be discussed below.

The PTT-Telecom pilot. Chapter 6 reports on the first known Dutch study evaluating a smoking cessation program in worksites. When developing the program, an important starting point was that the program should be presented to the employees in a manner consistent with their preferences. Allowing smokers to choose their own smoking cessation method may contribute to a program's attractiveness, resulting in high participation rates (US Department of Health and Human Services, 1985). Smokers who fail with one method may be encouraged to 'recycle' in a program by trying another method. For the pilot program we chose to offer a self-help method and a group program, because we were most familiar with these two methods and the effectiveness of these methods was well known (Schwarz, 1987). Moreover, an American program had shown that the largest number of participants could be reached by offering a choice between a self-help and a clinical approach (e.g., Bertera et al., 1990). The self-help manual was developed at our department, modeled after the American Lung Association's manual, and adapted to Dutch smokers (Mudde, De Vries, et al., 1994). The pilot study revealed that both methods contributed about equally to the impact of the intervention, and that they attracted different 'types' of smokers. This made clear that the combination of selfhelp methods and group programs was a good starting point for more elaborate and comprehensive programs. Another important finding from the pilot study was that the program's effects were not sustained over a period of one year. Thus, continuation of the intervention was important to obtain long-term impact.

There were two additional program components that did not work out as expected: a telephone quit line and tailored letters. Because others also reported negative experiences with telephone quit lines in worksites, we decided not to continue with this method. It was unclear to what extent the tailored letters suffered from implementation failures. Because other studies reported positive results with computer algorithms that provided smokers with personalized feedback about smoking and smoking cessation (De Vries, Willemsen, et al., 1995; Prochaska et al., 1993; Strecher et al., 1994), we decided to further improve the tailored letters and to incorporate them into the continuation strategy of our future program. 
Following the results from the PTT pilot study, mass-media activities, smoking policies, and continuation strategies were added to a core program consisting of selfhelp manuals and group courses. Following recommendations that were considered state-of-the art at the time of program development, an intervention protocol was developed in which intervention strategies were differentiated to the individual, social, and company level. The results with regard to the individual level were presented in Chapter 7 , while the results with regard to the social and organizational level were presented in Chapter 8.

Effects of the comprebensive program at the individual level. The research conducted in this thesis is basically a replication of studies conducted outside the Netherlands, notably in the United States. The study presented in Chapter 7 revealed that the comprehensive cessation program was more effective than the PTT-Telecom pilot program. Furthermore, the 14-months quit rate of $16 \%$ is much in line with international experimental studies examining the effectiveness of worksite smoking cessation programs involving combinations of self-help and group programs. An average 12 -month quit rate of $13 \%$ was reported in a meta-analysis of 20 worksite smoking cessation programs (Fisher et al., 1994). The recently publicized results of the large-scale Working Well Trial, which included a comprehensive worksite smoking cessation program quite similar to ours, produced a 6-months quit rate of $14 \%$ (Sorensen et al, 1996). Hymowitz et al. (1991) reported an average quit 12months rate of $18 \%$ from a similar program which was examined in a study involving six US companies. Our results thus seem to confirm effect sizes found in the United States. However, one recent large-scale study produced substantially higher quit rates. Salina et al. (1994) randomly assigned 38 US companies to either a selfhelp condition consisting of a self-help manual and a 20-day video program or a very intensive group program. This included the self-help manual, the 20-day video program, six group sessions and monthly peer-led support groups and incentives. After two years, the intensive program produced $30 \%$ quitters, compared to $19 \%$ in the 'minimal' program. Thus, one possible way to increase quit rates is to further intensify the program, especially paying attention to follow-up counseling (see also 9.2; suggestions for further research). A disadvantage is that such programs may be difficult to implement and to maintain and therefore less suitable for wide-scale dissemination.

The $16 \%$ quit rate was not much higher than the $12 \%$ quit rate observed in the minimal intervention worksites in our study. Our main conclusion was that, from 
a public health perspective, minimal programs are promising, because they may be relatively easy to diffuse to worksites. Moreover, their effectiveness seems almost as good as that of more comprehensive programs. This emphasis on interventions that appeal to a broad population of smokers corresponds to a public health perspective as opposed to a clinical perspective on smoking interventions (Epstein et al., 1989). While quit rates are modest, more smokers can be reached, resulting in a larger impact on general smoking prevalence (Epstein et al., 1989).

An unexpected finding was that the effectiveness of the intervention depended on the heaviness of smoking as measured with the Fagerström Test for Nicotine Dependence (FTND). Heavier smokers (a FTND score $\geq 3$ ) were almost twice as likely to successfully quit smoking by taking part in the comprehensive program compared to the minimal program. Group courses were largely responsible for the superiority of the comprehensive program. Few other studies have reported interactions between treatment effect and heaviness of smoking. One study reported that computer-tailored cessation messages only worked for moderate to light smokers, but not for heavily addicted smokers (Strecher et al. (1994). We recommend that future effectiveness studies in the field of smoking cessation routinely examine interactions between treatment method and measures of heaviness of smoking. This type of research adds to knowledge about how various treatments can be matched to smokers' characteristics (Digiusto \& Bird, 1995).

In Chapter 7, a stepwise approach was proposed in which lighter smokers might be treated with self-help methods and heavier smokers with more intensive methods. Such an approach might also be used as a diffusion strategy in which first easy-to-implement minimal programs are marketed to worksites. Minimal interventions can be implemented at low costs and with minimum time required of company staff. In a second effort, more comprehensive programs can be disseminated that might appeal to employers wanting to offer their more heavily addicted smokers intensive treatment.

Effects of a comprebensive program at social and organizational levels. In Chapter 8, we examined whether mass media strategies and policies affect smokers who do not participate in smoking cessation programs and whether they affect nonsmokers' assertiveness and supportive behavior. Eleven percent of smokers who did not take part in the cessation program in the 'comprehensive worksites' were abstinent at follow-up, but this did not differ significantly from the comparison worksites. It was concluded that worksite smoking cessation programs that include a mass-media 
campaign are unlikely to have a large impact on employees other than those taking part in the smoking cessation program. A recent preliminary qualitative study conducted in the US, examining a comparable cessation program as ours, found that 10 to $25 \%$ of nonparticipants were abstinent at 1 year follow-up (Fisher et al., 1994). In that study, about one third of all smoking employees participated in the smoking cessation program, compared to about one sixth in our program, suggesting that higher participation rates might result in more nomparticipants who quit. In our study, we found that anti-smoking exhibitions seemed to increase participation in the cessation program (an odds ratio of 4.48). This suggests that, although mass media strategies seem to have no direct influence on non-participants, they might have an indirect effect by increasing participation in the cessation program. Furthermore, we found some evidence that health educational exhibitions could help initial quitters to remain nonsmoker.

The assumption in international literature (see Chapter 1) is that worksite smoking cessation programs can change social norms in worksite and can mobilize social support to help smoking employees quit smoking. This may not be easy to realize in Dutch worksites, as demonstrated by the failure of the mass media pro gram to bring about cognitive changes among non-program participants and nonsmokers. Directly changing social norms may be very difficult to accomplish in a small period of time (18 months). This may take much longer. Furthermore, it cannot be ruled out that other strategies aimed at the social environment, such as incentives or competitions, may be successful in Dutch worksites, or that the present strategies may be successful under specific conditions, for example in combination with stricter smoking policies or in specific occupational groups.

Several other findings emerged from the study presented in Chapter 8. First, it was of special interest that improvements in smoking policy were associated with nonsmokers becoming more assertive and less tolerant towards smoking colleagues. This suggests that policy changes may have a positive influence not only on smoking behavior, but on nonsmokers' behavior as well. Second, exposure to exhibitions, leaflets, and newsletters was less satisfactory among blue-collar workers. This finding points to the need for separate strategies to reach blue-collar workers. 


\subsection{Suggestions for future research}

In various recent large-scale studies, considerable variability in effect-sizes has been observed across worksites: some worksites produced substantial effects with respect to smoking cessation, whereas others did poorly, despite standardization of program content (Glasgow et al., 1995; Jeffery et al., 1993; Sorensen et al., 1996). This variability has also been noted in a meta-analysis of 20 worksite smoking cessation programs (Fisher et al., 1990). Fisher et al. (1990) suggest that such variability may partly originate from a good or bad 'fit' between organizational characteristics and treatment. Glasgow et al. (1995) recommended that future research examines how worksite and employee characteristics determine program success. Our experience with implementing the program in different worksites suggests that such organizational variables are indeed important. For example, in one of the companies it was very difficult to get things done, while this was relatively easy in the other companies. We attributed this to differences in organizational culture and organizational structure, such as company size. Literature is scarce on how worksite characteristics affect smoking cessation programs in worksites (Fielding, 1991). To date, only two studies have explicitly addressed this issue (Crump et al., 1996; Emont \& Cummings, 1990). Clearly, more research is needed to examine how factors such as organizational structure, company culture, and management style influence the adoption, implementation and effectiveness of worksite smoking control programs.

More research is needed on the effectiveness of the current minimal and comprehensive program in small worksites. Small worksites are interesting, because they have been found to produce larger effects, at least in the United States (Fisher et al., 1990). A large proportion of Dutch workers can be found in small worksites. Moreover, smoking prevalence in smaller worksites is comparable to larger worksites. Unpublished data from the CBS Health Survey indicated that in 1993, Dutch worksites with < 10 employees had $43 \%$ smokers, companies with 10 to $50 \mathrm{em}$ ployees had $41 \%$ smokers, companies with 50 to 100 employees had $44 \%$ smokers, while companies with more than 100 workers also have $44 \%$ smokers among their work force. Since an important conclusion from our study was that minimal programs are very promising, future research should focus on how best to deliver and disseminate minimal programs to as many Dutch worksites as possible, especially small and medium-sized worksites. Furthermore, research on the cost-effectiveness 
(costs per successful quitter) of minimal versus more comprehensive smoking cessation programs in worksites is needed.

No research has been conducted in the Netherlands on smoking cessation programs aimed at workers in sectors that have a special responsibility for health, such as health care (hospitals, home care, psychiatry) and the educational system (schools). Furthermore, separate programs are needed for blue-collar workers, since our study showed that blue-collar workers were underexposed to various program components. It is advisable that such research uses an overall planning model to guide research, such as the $\mathrm{ABC}$ model. One important step is to conduct analyses of psychological determinants of smoking cessation among workers in these sectors, for which the theoretical model outlined in Chapters 2, 4 and 5 could be used as a starting point. Subsequent research should concentrate on developing and testing interventions.

In Chapter 5, it was found that reported hindrance from ETS was higher when a nonsmoker had negative beliefs about ETS. We also found that assertive behavior was quite strongly related to whether a nonsmoker was regularly bothered by ETS at work, but was not related to how many smoking colleagues he or she had. This suggests that what matters is whether colleagues' smoke is perceived as bothersome and harmful. An interesting research issue is the extent to which inconvenience is related to health damage. For employers this is probably less relevant, because for them reports of frequent annoyance are sufficient to try to eliminate exposure to ETS, but from a public health perspective this is highly relevant, because employees who say they are not bothered by smoking at their workplace, might be exposed to high daily levels of ETS. Research is thus needed to validate self-reports of daily exposure to tobacco smoke in worksites. One recent study in the Netherlands reported a pearson correlation of 0.65 between a self-report measure of exposure to ETS and area samples of nicotine in indoor air (Willemsen, Brug, et al., 1997).

An important issue is the effectiveness of continuation strategies. In the second year of the program, smoking employees were offered new quitting opportunities (self-help manuals, group courses). Smokers who were not motivated to quit in the first year, might be interested in enrolling in the program in the second year. Moreover, smokers who failed in the first year could enroll in the program and try another cessation method. However, there seemed to be very little interest from employees for this second-year program. A new group course was only organized in the two largest worksites. Very few additional smokers were interested in receiv- 
ing a tailored letter, apart from the smokers who had already participated in the program, and very few requested self-help manuals. It thus seems that most smokers who are willing to quit smoking with help from the company, sign up at the first opportunity. It may take several years before a large enough new group of interested smokers has emerged in a worksite to legitimate the same program being offered again. It is, therefore, recommended that smokers enrolling in the first year should be worked with more intensively. Follow-up counseling has been found to improve the effectiveness of health education and smoking cessation classes in worksites (Erfurt, Foote \& Heirich, 1991). This recommendation is in line with recent results from the 38-worksite study by Saline et al (1994) showing that intensive follow-up counseling results in quit rates up to $30 \%$.

\subsection{Methodological considerations}

The studies in this thesis may be subject to a number of methodological deficiencies. The potential for problems with internal validity was greatest in the longitudinal experimental studies (Chapters 6 to 8), while limitations regarding external validity or generalizibility of the research findings were possible in the descriptive and correlational studies (Chapters 3 to 5 ) as well as the experimental studies.

Internal validity is the degree to which changes in dependent variables can be confidently attributed to the experimental manipulations and not to uncontrolled factors. First, the observed effects of treatment on smoking cessation may be confounded by differences in baseline factors between treatment conditions. Our effectiveness studies used a quasi-experimental research design in which worksites were assigned to treatment groups according to company size, type of company and current smoking policy. This matching procedure leaves open the possibility that treatment groups differ on relevant baseline characteristics, notably the dependent variable. However, in the PTT-Telecom pilot study the groups differed only with respect to age, which was not related to smoking cessation. In the two subsequent studies, smoking prevalence was slightly lower in the comprehensive treatment worksites. This might have worked against finding larger differences between comprehensive and minimal programs due to a ceiling-effect. Future studies should make use of a randomized design, possibly in combination with matching so as to achieve optimal balanced treatment groups (Koepsell et al., 1992). 
Another threat to internal validity is the effect that exposure to the pretest questionnaire might have on changes in dependent variables (test effect). The quasiexperimental design controlled for this as long as both experimental and control respondents reacted equally to the survey. Pretests were exactly the same for both treatment groups, but posttest questionnaires differed somewhat, because experimental subjects received more questions concerning process evaluation of their program. However, response rates between treatment groups at the posttests did not differ much, as was shown in Chapters 7 and 8. Thus, possible test effects were probably for the greater part canceled out in the analyses between experimental and control groups, but they might have had a general beneficial effect on treatment outcomes.

The failure to find an effect of treatment on changes in cognitive variables (Chapter 8) might be attributable to general reactive effects of respondents to the questionnaire or to the intervention, resulting in changes in the respondents' interpretations of the concepts that were measured. This response shift could have been prevented by including retrospective pretest questions in the posttest (Sprangers, 1988).

Another reactive effect can occur when respondents are aware of the experimental manipulations. We prevented this by trying to keep the interviewers blind to the treatment assignment of respondents. Only company representatives who worked with us to implement the programs knew about the respondents' experimental status. Company representatives who were responsible for the program in the control worksites assured ws that they did not initiate anti-smoking activities during the research period.

A potential weakness of our study was that the unit of analysis (subjects) was different from the unit of assignment to treatment (worksites) (Lichtenstein \& Glasgow, 1992; Koepsell et al., 1992). This may result in a failure to account for variance in outcomes due to worksites (Kelder et al., 1993). Any within-worksite homogeneity with respect to the dependent variable may produce lower estimates of standard errors and hence more statistically significant differences than are actually present (Kelder et al., 1993). Efforts were undertaken to include more worksites in our study, but because some very large worksites were involved, budget limitations prevented inclusion of more than eight worksites in the effect study. In Chapter 4, a multi-level analysis procedure was used to account for these intraclass correlations, but the results were comparable to analyses that were done solely at the level of the individual, suggesting that analyses at the level of individuals were not strongly 
affected by type of worksite. As an additional safeguard, a variable measuring 'type of company' was included as a confounder in all analyses.

An important question regarding the descriptive and correlational studies (Chapters 3 to 5 ) is the generalizibility of findings across populations. It could be regarded as a strength of our study that worksites from different sectors of industry were included, but this may also be seen as a weakness, because only four sectors were involved. Moreover, only relatively large worksites (at least 250 employees) were included. Thus, the generalizibility across worksites is limited and further research is recommended, especially in small and medium-sized worksites (see paragraph 9.4).

Another issue is whether the conclusions drawn from our studies can be generalized to non-research settings. The research setting was an impediment to some of the worksite committees that coordinated the implementation. They had to wait until surveys were carried out, before they could continue to implement the program in their worksite. In day-to-day practice, programs could be implemented more efficiently than in our research setting, so that better results might be obtained. Other differences between a research setting and non-research setrings are the number and the intensity of questionnaires. Smoking cessation programs in nonresearch settings usually employ written questionnaires as a baseline measure of employee needs and to assess support for smoking policies (Willemsen, Haartsen, et al., 1996). Exposure to questionnaires might be regarded as an intervention in itself, especially with telephone interviews that are more intimate than written questionnaires. We chose telephone interviewing instead of written questionnaires, because of the higher response rate and the speed of data processing. Recently, a beneficial test-effect of telephone interviewing was observed in a study examining the effectiveness of a smoking cessation mass media campaign (Mudde, 1994). It might very well be that telephone interviews resulted in higher outcomes in our study as well.

\subsection{Main conclusions}

Three main conclusions can be drawn from the research in this thesis. First, comprehensive worksite smoking cessation programs are more effective in helping Dutch employees quit smoking than no intervention or minimal interventions, as far as moderate and heavy smokers are concerned. Second, the difference in overall 
effectiveness between the minimal program (self-help manuals) and the comprehensive program was not very large. Due to their greater ease of implementation, minimal programs seem more suitable for nation-wide diffusion. Finally, more research is needed on how the adoption, implementation and effectiveness of smoking control programs in worksites are affected by contingency factors such as organizational structure and decision making style in organizations. 


\section{References}

Abrams, D.B., \& Biener, L. (1992). Motivational characteristics of smokers at the workplace: A public health challenge. Preventive Medicine, 21,679-687.

Abrams, D.B., Emmons, K.M., Linnan, L., \& Biener, L. (1994). Smoking cessation at the workplace: Conceptual and practical considerations. In R. Richmond (Ed.), Interventions for smokers. An intermational perspective (pp. 137-169). Baltimore: Williams \& Wilkins.

Ajzen, I. (1985). From intentions to actions: a theory of planned behawior. In: J. Kuhl \& J. Beckmann (Eds.). Action-control: From cognition to behavior. Heidelberg: Springer (p11-39).

Ajzen, I. (1991). The theory of planned behavior. Organizational Behatior and Humun Decision Processes, 50, 179-211.

Ajzen, I, \& Fishbein, M. (1980). Understanding Attitwdes and Predicting Social Behavior. Englewrood Cliffs: Prentice Hall.

Ajzen, I., \& Madden, T.J. (1986). Prediction of goal-directed behavior: attitudes, intentions and perceived behavioral control. Joumal of Experimental Social Psycbology, 20, 453-474.

American Psychiatric Association (1987). Diagnistic and statistical manual of mental disorders: DSM. III.R, 3rd ed., rev. Washington: APA.

Amos, A., White, D.A., \& Elton, R.A. (1995). Is a telephone helpline of value to the workplace smoker? Occupational Medicine Oxford, 45, 234-238.

Andrews, J.L. (1983). Reducing smoking in the hospital: An effective model program. Chest, 84, 206-209.

Bagozzi, R.P. (1981). Atritudes, intentions, and behavior: A test of some key hypotheses. Jowtnal of Personality and Sacial Psycbology, 41, 607-627.

Baillie, A.J., Martick, R.P., \& Hall, W. (1995). Quitting smoking: Estimation by meta-analysis of the rate of unaided smoking cessation. Australian Jourmal of Public Health, 19, 129-131.

Bandura, A. (1977). Self-efficacy: Toward a unifying theory of behavioral change. Psychological Review, 84, 191-215.

Bandura, A. (1986). Social Foundations of Thought and Action: A Social Cognitive Theory. New York: Prentice-Hall.

Bertera, R.L. (1991). The effects of behavioral risks on absenteeism and health-care costs in the workplace. fournal of Occupational Medicine, 33, 1119-1124.

Bertera, R.L., Oehl, L.K., \& Telepchak, J.M. (1990). Self-help versus group approaches to smoking cessation in the workplace: Eighteen-month follow-up and cost-analysis. American Journal of Health Promotion, 4, 187-192.

Bibeau, D.L., Mullen, K.D., McLeroy, K.R., Green, I.W., \& Foshee, V. (1988). Evaluations of workplace smoking cessation programs: A critique. American foumal for Preventive Medicine, 4, $87-95$.

Biener, L, \& Abrams, D.B. (1991). The contemplation ladder: validation of a measure of readiness to consider smoking cessation. Health Psycbology, 10, 306-365.

Biener, L., Abrams, D.B., Emmons, K., \& Follick, M.J. (1989). Evaluating worksite smoking policies: Methodological issues. New York State Joumal of Medicine, 89, 5-10.

Biener, L., Abrams, D.B., Follick, M.J., \& Dean, L. (1989). A comparative evaluation of a restrictive smoking policy in a general hospital. American Journal of Public Health, 79, 192-195. 
Biener, L., DePue, J.D., Emmons, L., \& Abrams, D.B. (1994). Recruitment of work sites to a health promotion research trial Journal of Occupational Medicine, 36, 631-636.

Borland, R., Chaprian, S, Owen, N., 2 Hill, D. (1990b). Effects of workplace smoking bans on cigarette consumption. American Journal of Public Health, 80, 178-180.

Borland, R., Owen, N., Hill, D., \& Chapman, S. (1990a). Changes in acceptance of workplace smoking bans following their implementation: a prospective study. Preventive Medecine, 19, $314-322$.

Borland, R., Owen, N., Hill, D., \& Schofield, P. (1991). Predicting attempts and sustained cessation of smoking after the introduction of workplace smoking bans. Health Psychology, 10, 336-342.

Borland, R., Owen, N., \& Hocking, B. (1991). Changes in smoking behavior after a total workplace smoking ban. Australian Journal of Public Health, 15, 130134.

Borland, R., Pierce, J.P., Burns, D.M., Gilpin, E., Johnson, M., \& Bal, D. (1992). Protection from environmental tobacco smoke in California: The case for a smoke-free workplace. JAMA, $268,749-752$.

Bosanquet, N. (1992). Comparison of the position in different member states on price, taxation and consumption. In: Reducing smoking throwgh price and otber means. Procedings of the UK presidency seminat. London: Department of Health. (pp. 90-98).

Brenner, H., \& Fleischle, B.M.M. (1994). Social acceptance of smoking regulations in the workplace. European Joumal of Public Health, 4, 17-21.

Brenner, H., \& Mielck, A. (1992). Einschränkungen des Rauchens am Arbeidsplatz und Rauchgewohnheiten: ein Literaturreview. Sozial Prätentivmedizine, 37, 162-167.

Breteler, M.H.M. (1988). Smoking cessation: Some determinants of motivation and success [PhD thesis]. Nijmegen: University of Nijmegen.

Breteler, M.H.M., \& Rombouts, R. (1986). Meningen over een rookverbod in de werksituatie: een inventarisatie [Opinions about smoking bans at the workplace: a review]. Tijdscbrift voor Sociale Gezondbeidszorg, 64, 790-793.

Brigham, J., Gross, J., Stitzer, M.L., \& Felch, L.J. (1994). Effects of a restricted work-site smoking policy on employees who smoke. American Jaumal of Public Health, 84, 773-738.

Brown, S.L., Hunt, G., \& Owen, N. (1992). The effect of adding telephone contact to the use of self-instructional smoking cessation materials. Bebavior Change, 9, 216-222.

Brown, E.R., McCarthy, W.I., Marcus, A., Baker, D., Froines, J.R., Dellenbaugh, C., \& McQuiston, T. (1988). Workplace smoking policies: Attitudes of union members in a high risk industry. Joumal of Occupational Medicine, 30, 312-320.

Brownson, R.C., Dawis, J.R., Jackson-Thompson, J., \& Wilkerson, J.C. (1995). Environmental tobacco smoke awareness and exposure: impact of a statewide clean indoor air law and the report of the US Environmental Protection Agency. Tobacco Control, 4, 132-138.

Brownson, R.C., Koffman, D.M., Nowotny, T.E., Hughes, TR.G., \& Eriksen, M.P. (1995). Environmental and policy interventions to control tobacco use and prevent cardiovascular disease. Health Education Quarerly, 22, 478-498.

Bryk, A.S., \& Raudenbusch, S.W. (1992). Hierarchical Linear Models: Applications and data analysis methods. Newbury Park: Sage Publications.

Budd, R.J., North, D. \& Spencer, C. (1984). Understanding seat-belt use: a test of Bentler and Speckart's extension of the 'theory of reasoned action'. European Josmal of Sacial Psychology, 14, 69-78. 
Burns, D.M. (1991). The scientific rationale for comprehensive, community-based, smoking control strategies. In D.R. Shopland. (Ed), Strategies to control tobacco the Untited States: A bluprint for public bealth action in the 1990's (pp. 1-31). Washington: U.S. Government printing office. NIH Publication No. 92-3316.

Bush, R., \& Wooden, M. (1995). Smoking and abscence from work: Australian evidence. Social Science and Medicine, $41,437-446$.

Caplan, R.D., Cobb, S., \& French, J.R.P. (1976). Relationships of cessation of smoking with job stress, personality and social support. Joumal of Applied Social Psychology, 60, 211-219.

Carey, M.P., Snel, D.L., Carey, K.B., \& Richards, C.S. (1989). Self-initiated smoking cessation: A review of the empirical literature from a stress and coping perspective. Cognitive Therapy and Researcb, 13, 323-341.

Carmody, T.P. (1992). Preventing relapse in the treatment of nicotine addiction: Current issues and future directions. Joumal of Psychoactive Drugs, 24, 131-158.

Chapman, S. (1996). Smoking in public places: Self regulation of businesses is not working. British Medical Jormal, 312, 1051-1052.

Christen, A.G., \& Christen, J.A. (1994). Why is cigarette smoking so addicting? An overview of smoking as a chemical and process addiction. Healuh Values, 18, 17-24.

Cohen, S., Lichtenstein, E., Prochaska, J.O., Rossi, J.S., Gritz, E.R., Carr, C.R., Orleans, C.T., Schoenbach, V.J., Biener, L., Abrams, D., DiClemente, C., Curry, S., Marlatt, G.A., Cummings, K.M., Emont, S.L., Giovino, G., \& Ossip-Klein, D. (1989). Debunking myths about self-quitting: Evidence from 10 prospective studies of persons who attempt to quit smolking by themselves. American Psychologist, 44, 1355-1365.

Covey, L.S., \& Wynder, E.L. (1981). Smoking habits and occupational status. Journal of Occupational Medicine, 23, 537-542.

Crump, C.A., Earl, J.L., Kozma, C.M., \& Hertz-Picciotto, I. (1996). Effect of organizational-level variables on differential employee participation in 10 federal worksite health promotion programs. Health Education Quarterly, 23, 204-223.

Cummings, K.M., Emons, S.I., Jaén, C., \& Sciandra, R. (1988). Format and quitting instructions as factors influencing the impact of a self-administered quit smoking program. Health Education Quarterly, 15, 199-216.

Cummings, K.M., Hellmann, R., \& Emons, S.L. (1988). Correlates of participation in a worksite stop-smoking contest. Journal of Behavioral Medicine, 11, 267-277.

Daughton, D.M., Andrews, C.E., Orona, C.P., Kashinath, D., \& Rennard, S.I. (1992). Total indoor smoking ban and smoking behavior. Preventive Medicine, 21, 670-676.

Daughton, D.M. Roberts, D., Patil, K.D., \& Rennard, S.I. (1990). Smoking cessation in the workplace: Evaluation of relapse factors. Preventive Medicine, 19, 227-230.

Davis, A.L., Faust, $\mathbb{R}_{\text {, \& }}$ Ordentlich, M. (1984). Self-help smoking cessation and maintenance programs: A comparative study with 12-month follow-up by the American Lung Association. American Joumal of Public Healtb, 4, 1212-1217.

Davis, K.E. Jackson, K.L., Kronenfeld, J.J. \& Blair, S.N. (1984). Intent to participate in worksite health promotion activities: A model of risk factors and psychosocial variables, Health Education Quarterly, 11, 361-377.

Davis, R.M. (1993). The delivery of smoking cessation services: Current status and future needs. Tobacco Control, 2 (suppl), S63-578. 
Davis, R.M., Boyd, G.M., \& Schoenborn, C.H. (1990). 'Common courtesy' and the elimination of passive smoking. Results of the 1987 National Health Interview Survey. JAMA, 263, 22082210.

Dawley, L.T., Dawley, H.H., Glasgow, R.E., Rice, J., \& Correa, P. (1993). Worksite smoking control, discouragement, and cessation. The International Joumal of whe Addictions, 28, 719 733.

Dawley, H.H., Fleischer, B.J., \& Dawley, L.T. (1984). Smoking cessation with hospital employees: An example of worksite smoking cessation. The International Jowmal of the Addictions, 19, 327.334.

De Volkskrant (1995). Rokendie GAK-medewerkers moeten tijd inhalen [Smoking GAK-employees must catch up worktime]. De Volkskrant, actober 30, 1995.

De Vries, H. (1988). De effectiviteit van rookpreventie. In R. Jonkers, P.C. Liederkerken, W.F.M. de Haes, G.J. Kok, J.A.M. Saan, Effectiviteit wan gezondheidsvoorlichting en -opvoeding (GVO) (pp. 149 - 163). Rijswijk: Uitgeverij voor Gezondheidsbevordering.

De Vries, H. (1989). Prevention of cancer: Towards a national ABC Framework. European Joumal of Cancer and Clinical Oncology, 25, 1025-1033.

De Vries, H., \& Backbier, E. (1994). Self-efficacy as an important determinant of quitting among pregnant women who smoke: the $\varnothing$-pattern. Preventive Medicine, 23, 167-174.

De Vries, H., Backbier, E., Dijkstra, M., Van Breukelen, G., Parcel, G., \& Kok, G. (1994). A Dutch social influence smoking prevention approach for vocational school students. Health Education Research, 9, 365-374.

De Vries, H., Backbier, E., Kok, G., \& Dijkstra, M. (1995). The impact of social influences in the context of attitude, self-efficacy, intention and previous behavior as predictors of smoking onset. Joumal of Applied Social Psychology, 25, 237-257.

De Vries, H., Dijkstra, M., \& Kuhlman P. (1988). Self-efficacy: The third factor besides attitude and subjective norm as a predictor of behavioral intentions. Health Education Research, 3, 273-282.

De Vries, Mudde, A.N., Willemsen, M.C., Dijkstra, A., \& Peters, L. (1996). Attitudes, social influences, self-efficacy and the stages of change: A replication of the $\varnothing$-pattern among smokers. Manuscript submitted for publication.

De Vries, H., \& WilJemsen, M.C. (1996). Planmatige gezondheidswoorlichting in de arbeidssituatie [Systematic health education in worksites]. In P. Baart, G. Roerink \& M. Selie, Gezondheidsbewordering op de werkplek. Amsterdam: NLA.

De Vries, H., Willemsen, M.C., Brug, H., Dijkstra, A., \& Berben, J. (1995). Voorlichting op maat: Een niewwe interactiewe voorlichtingsmethode. Tijdschrift Gezondbeidsbevordering, 16, 59-70.

DiCLemente, C.C., Prochaska, J.O., Fairhurst, S.K., Velicer, W.F., Velasquez, M.M., \& Rossi, J.S. (1991). The process of smoking cessation: An analysis of precontemplation, contemplation, and preparation stages of change. Jowmal of Consulting and Clinical Psychology, 59, 295-304.

DiFranza, J.R., \& Brown, I.J. (1992). The Tobacco Institute"s "It's the law" campaign: Has it halted illegal sales of tobacco to children? American Joumal of Public Health, 82, 1271-1273.

Digiusto, E., \& Bird, K.D. (1995). Matching smokers to treatment: Self-control versus social support. Journal of Constalting and Clinical Psychology, 63, 290-295.

Dijkstra, M. (1995). Development, implementation and evaluation of two Dutch smoking prevention programs. [PhD thesis]. Maastricht: University Press. 
Doll, R., \& Hill, A.B. (1950). Smoking and carcinoma of the lung: Preliminary report. British Medical Joumal, 2, 739-748.

Doll, R., \& Hill, A.B. (1956). Lung cancer and other causes of death in relation to smoking: A second report on the mortality of British doctors. British Medical Joutrual, 2, 1071-1081.

Doll, R., Peto, R., Wheatley, K., Gray, R., \& Sutherland, I. (1994). Mortality in relation to smoking: 40 years' observations on male British doctors. British Medical Jowrnal, 309, $901-911$.

Dutch Central Bureau for Statistics (1995). Statistisch Jaarboek 1995 [Statistical Annual 1995]. The Hague: SDU.

Durch Foundation on Smoking and Health. (1990). Voormeting rookverboden bedrifsleven. een telefonisch onderzoek [Pretest smoking bans in worksites: a telephonic survey]. Den Haag: Stichting Volksgezondheid en Roken.

Dutch Foundation on Smoking and Health (1996a) Jaarverslag 1995 [Annual Report 1996]. Den Haag: Stichting Volksgezondheid en Roken.

Dutch Foundation on Smoking and Health (1996b). Rokem: De barde feiten. [Smoking: the facts]. Den Haag: Stichting Volksgezondheid en Roken.

Eiser, J.R. (1983). Smoking, addiction and decision-making. International Review of Applied Psychology, 32, 11-28.

Eiser, J.R., Van der Pligt, J., Raw, M., \& Sutton, S.R. (1985). Trying to stop smoking: Effects of perceived addiction, attributions for failure and expectancy of success. Journal of Beharvioral Medicine, 8, 321-341.

Elder, J., Rosbrook, B., Choi, W., Johnson, M., Bal, D., Pierce, J.P. (1992). Public objections to environmental tobacco smoke. Preventive Medicinem $x_{x}$ 21, 701-70\%.

Emont, S.L., \& Cummings, K.M. (1990). Organizational factors affecting participation in a smoking cessation program and abstinence among 68 auto dealerships. American Journal of Health Promotion, S, 102-114.

Environmental Protection Agency. (1992). Respiratory health effects of passive smoking: lung cancer and other disorders. Washington: Office of Health and Environmental Assessment.

Epstein, L.H., Grunberg, N.E., Lichtenstein, E.y \& Evans, R.I. (1989). Smoking research: basic research, intervention, prevention, and new trends. Health Psychalogy, 8, 705-721.

Eriksen, M.P. (1986). Workplace smoking control: Rational and approaches. In W.B. Ward (Ed). Advances in Health Education and Health Promotion, Vol 1a. Greenwich: JAI Press. (pp 65. 103).

European Bureau for Action on Smoking and Health. (1993). Results of the survey on passive smoking in the EC. Neresletter, 20, 10-11.

European Bureau for Action on Smoking and Health. (1994). Tobacco and bealth in the European Union: An overview. Brussels: European Bureau for Action on Smoking Prevention.

Evans, R.I., Dratt, L.M., Raines, B.E., \& Rosenberg, S. (1988). Social influences on smoking initiation: Importance of distinguishing descriptive versus mediating process variables. Journal of Applied Social Psychology, 18, 925-943.

Fagerström, K.O., Kunze, M., Schoberger, R., Breslau, N., Hughes, J.R., Hurt, R.D., Puska, P., Ramström, L, \& Zatonski, W. (1996). Nicotine dependence versus smoking prevalence: comparisons among countries and caregories of smokers. Tobacco Control, 5, 52-56.

Fielding, J.E. (1984). Health promotion and disease prevention at the worksite. Annual Review of Public Healtb, 5, 237-65. 
Fielding, J.E. (1990). Worksite health promotion survey: Smoking control activities. Preventive Medicine, 19, 402-413.

Fielding, J.E. (1991). Smoking control at the workplace. Annwal Review of Public Health, 12, 209243.

Fiore, M.C., Newcomb, P, \& McBride, P. (1993). Natural history and epidemiology of tobacco use and addiction. In C.T. Orleans \&. J. Slade, Nicotine Addiction: Principles and management. (pp. 89-104). New York: Oxford Univ. Press.

Fiore, M.C., Piasecki, T.M, Baker, T.B. (1995). Signal and noise in minimal interventions for smoking cessation (Editorial). Tobacco Control, 4, 114-116.

Fishbein, M.; \& Ajzen, I. (1975). Belief, attitude, intention, and bebavior: An introduction to theory and research. Reading, MA: Addison-Wesley.

Fisher, E.B., Bishop, D.B., Levitt-Gilmour, T., Cappello, M.T., Ashenberg, Z.S., \& Newman, E. (1994). Social support in worksite smoking cessation: Qualitative analysis of the EASE project. American Jow of Heal h Promotion, 9, 39-47.

Fisher, K.J., Glasgow, R.E., Terborg, J.R. (1990). Work-site smoking cessation: A meta-analysis of long-term quit rates from controlled studies. Jowmal of Occupational Medicine, 32, 429-439.

Fisher, E.B., Lichtenstein, E., \&c Haire-Joshu, D. (1993). Multiple determinants of tobacco use and cessation. In C.T. Orleans \& J. Slade. Nicotine Addiction: Principles and management. New York: Oxford Univ. Press. (pp. 59-88).

Flay, B.R. (1987a). Selling the smokeless socieny: Fifty-six evaluated mass media programs and campaigns worldnvide. Washington: American Public Health Association.

Flay, B.R. (1987b). Mass media and smoking cessation: A critical review. American Joumal of Public Health, 77, 153-160.

Flay, B.R., \& Petraitis, J. (1994). The theory of triadic influence: A new theory of health behavior with implications for preventive interventions. Advances in Medical Sociology, 4, 19-44.

Forster, J.L., Hourigan, M., \& McGovern, P.. (1992). Availlability of cigarettes to underage youth in three communities. Preventive Medicine, 21, 320-328.

Fredericks, A.J., \& Dossett, D.L. (1983). Atritude-behavior relations: A comparison of the FishbeinAjzen and the Bentler-Speckart models. Joumal of Personality and Sacial Psychology, 45, 501512 .

Freund, K.M., D"Agustino, R.B., Belanger, A.J., Kannel, W.B., \& Ill, J.S. (1992). Predictors of smoking cessation: The Framingham study. American Joumal of Epidemiology, 135, 957-964.

Fries, J.F., Green, L.W., \& Levine, S. (1989). Health promotion and the compression of morbidity. The Lancet, 1989 (1), $481-483$.

Gadourek, I. (1963). Riskante gewoontem en zorg voor eigen welzijn [Hazardous habits and human well-being]. Groningen: Wolters.

Gallup Poll (1985). Survey of attitudes toterard smoking. Princeton, New Jersey: Gallop Organization.

GBW-NIPO (1996). Gezondheidsbevordering op de werkplek: GBW-NIPO enquête [Worksite Health Promotion: GBW-NIPO Survey]. Den Hag: Centrum GBW.

Glanz, S.A. \& Parmley, W.W. (1991). Passive smoking and heart disease: Epidemiology, physiology, and biochemistry. Circulation, 83, 1-12. 
Glasgow, R.E., Klesges, R.C., Klesges, L.M., \& Somes, G.R. (1988). Variables associated with participation and outcome in a worksite smoking control program. Jokmal of Consulting and Clinical Psychology, 56, 617-620.

Glasgow, R.E., \& Terborg, J.R. (1988). Occupational health promotion programs to redice cardiovascular risk. Joumal of Consulting and Clinical Pychology, 56, 365-373.

Glasgow, R.E., Terborg, J.R., Hollis, J.F., Severson, H.H., \& Boles, S.M. (1995). Take Heart: Results from the initial phase of a work-site wellness program. American Joumal of Public Health, 85, 209-216.

Godin, G., Valois, P., Lepage, L., \& Desharnais, R. (1992). Predictors of smoking behavior: An application of Ajzen's theory of planned behavior. British Joumal of Addictions, 87, 1335 1343 .

Gottlieb, N.H., Eriksen, M.P., Lovato, C.Y., Weinstein, R.P., \& Green, L.W. (1990). Impact of a restrictive worksite smoking policy on smoking behavior, attitudes and norms. fournal of Occupational Medicine, 32, 16-23.

Gottlieb, N.H., Galavotti, C., McCuan, R.A., \& McAllister, A.L. (1990). Specification of a socialcognitive model predicting cessation in a Mexican-American population: A prospective study. Cognitive Therapy and Research, 14, 529-542.

Gottlieb, N..H., \& Nelson, A. (1990), A systematic effort to reduce smoking at the worksite. Health Education Quarterly, 17, 99-118.

Green, K.L. (1988). Issues of control and responsibility in workers" health. Health Education Quarterly, 15, 473-486.

Green, K.L., $8 x$ Johnson, J.V. (1990). The effects of psychosocial work organization on patterns of cigarette smoking among male chemical plant employees. American Joumal of Health Promotion, 80, 1368-1371.

Green, L.W., \& Kreuter, M.W. (1991). Health promotion planning: An educational and environ* mental approach. Mountain View: Mayfield.

Greenberg, J. (1994). Using socially fair treatment to promote acceptance of a worksite smoking ban. Jourral of Applied Psychology, 79, 288-297.

Grosfeld, J.A.M. (1988). De voorspelbadrbeid van individuele verzuimdun [Predictability of individuall absenteeism]. (Amsterdam: Swets \& Zeitlinger.

Grube, J.W., Morgan, M., \& McGree, S.T. (1986). Attitudes and normative beliefs as predictors of smoking intentions and behaviors: A test of three models. British Joumal of Psychology, 25, $81-93$.

Gruman, J., \& Lynn, W. (1993). Worksite and Community intervention for tobacco control. In C.T. Orleans \& J. Slade (Eds.), Nicotine addiction: Principles and management (pp. 396-411). New York: Oxford Univ. Press.

Gulliver, S.B., Hughes, J.R., Solomon, L्L.J., \&. Dey, A.N. (1995). An investigation of selfiefficacy, partner support and daily stresses as predictors of relapse to smoking in self-quitters. Addiction, 90, 767-772.

Hajek, P. (1996). Current issues in behavioral and pharmacological approaches to smoking cessation. Addictive Bebaviors, 21, 669-707.

Hallet, R. (1986). Smoking intervention in the workplace: review and recommendations. Preventive Medicine, 15, 213-231. 
Hallett, R, \& Sutton, S.R. (1987). Predicting participation and outcome in four workplace smoking intervention programmes. Health Educational Research, 2, 257-266.

Hallett, R., \& Suttom, S.R. (1988). Intervening against smoking in the workplace. Psychology \& Health, 2, 13im 29 .

Hammond, E.C., \& Horn, D. (1954). The relationship between smoking habits and death rates. A follow-up study of 187,766 men. $/ A M A, 155,1316-1328$.

Hanson, B.S., Isacsson, S., Janzon, L., \& Lindell, S. (1990). Social support and quitting smoking for good: Is there an association? Addictive Behaviors, 15, 221-233.

Hartis, K., Richmond, R. \& De Almeida Neto, A. (1994). Multiple group programs conducted at the hospital clinic and worksite: Cessation rates and predictors of outcome. In R. Richmond (Ed), Intervertions for smokers: An international perspective (pp. 171-194). Baltimore: Williams \& Wilkins.

Haynes, S.G., Odenkirchen, J., \& Heimendinger, J. (1990). Worksite health promotion for cancer control. Seminars in Oncology, 17, 463-484.

Health Council. (1990). Passief roken: beoordeling wan de schadelijkbeid van omgevingstabaksroak voor de gezondheid [Passive smoking: Review of the harmful aspects of environmental tobacco smoke for public health]. The Hague: De Gezondheidsraad.

Heatherton, T.F., Kozlowski, L.T., Frecker, R.C., \& Fagerström, K.O. (1991). The Fagerström test for nicotine dependence: A revision of the Fagerström Tolerance Questionnaire. British Journal of Addicion, 86, 119-127.

Hellman, R., Cummings, K.M., Haughey, B.P., Zielezny, M.A., \& O'Shea, R.M.O. (1991). Predictors of attempting and succeeding at smoking cessation. Health Education Research, 6, 77-86.

Henningfield, J.E., Cohen, C., \& Pickworth, W.B. (1993). Psychopharmacology of nicotine. In C.T. Orleans \& J. Slade, Nicotine Addiction: Principles and management (pp. 24-45). New York: Oxford Univ. Press.

Hennrikus, D.J., Jeffery, R.W., \& Lando, H.A. (1995). The smoking cessation process: Longitudinal observations in a working population. Preventive Medicine, 24, 235-244.

Hughes, J.R., Keenan, R.M., \& Yellin, A. (1989). Effect of tobacco withdrawal on sustained attention. Addictive Behawiors, 14,577-580.

Hymowitz, N., Campbell, K., 8x Feuerman, M. (1991). Long-term smoking intervention at the worksite: Effects of quit-smoking groups and an "Enriched Milieu" on smoking cessation in adult white-collar employees. Health Pyychology, 10, 366-369.

Jansen, D.F., Van Barneveld, T.A., \& Van Leeuwen, F.E. (1993). Passief roken en longkanker: bet EPA rapport [Passiwe smoking: The EPA report]. Amsterdam: Het Nederlands Kankerinstituut.

Janz, N.K., \& Becker, M.H. (1984). The health belief model: A decade later. Health Edwcation Quarterly, 11,1-47.

Jarvik, M.E. (1991). Beneficial effects of nicotine. British Jowmal of Addiction, 86, 571-575.

Jeffery, R.W., Forster, J.L. French, S.A., Kelder, S.H., Lando, H.A., MeGovern, P.G., Jacobs, D.R., \& Baxter, J.E. (1993). The Healthy Worker Project: A worksite intervention for weight control and smoking cessation. American Journal of Public Health, 83, 395-401.

Jeffery, R.W., Kelder, S.H., Forster, J.L., French, A.S., Lando, H.A., \& Baxter, J.E. (1994). Restrictive smoking policies in the workplace: effects on smoking prevalence and cigarette consumption. Preventive Medicine, 23, 78-82. 
Johansson, G., Johnson, J.V., \& Hall, E.M. (1991). Smoking and sedentary behavior as related to work organization. Social Science and Medicine, 7, 837-846.

Jones, R.C., Bly, J.L., \& Richardson, J.F. (1990). A study of worksite health promotion program and absenteeism. Joumal of Occupational Medicine, 32, 95-99.

Joossens, L. (1990). Smoking policy in the workplace and other public places. Luing, Suppl, $437-44$. Joossens, L., Naett, C., \& Howie, C. (1992). Taxes on tobacco products: A bealth isstie. Brussels: European Bureau for Action on Smoking Prevention.

Joossens, L., Naet, C., \& Howie, C. (1994). Een rapport over passief roken. Brussels: European Bureau for Action on Smoking Prevention.

Joossens, L., Naet, C., Howie, C., \& Muldoon, A. (1994). Tobacco and bealth in the European Union: An overview. Brussels: European Bureau for Acrion on Smoking Prevention.

Kabat, G.C., \& Wynder, E.L. (1987). Determinants of quitting smoking. American Joumal of Public Health, $77,1301-1305$.

Kavanagh, D.J., Pierce, J., Lo, S.K., \& Shelley, J. (1993). Self-efficacy and social support as predictors of smoking after a quit attempt. Psychology and Healtb, 8, 231-242.

Kelder, S.H., Jacobs, D.R., Jeffery, R.W., McGovern, P.G., \& Forster, J.L. (1993). The worksite component of variance: design effects and the Healthy Worker Project. Health Edscation Research, 8, 555-566.

Killen, J.D., Fortmann, S.P., Telch, M.J., \& Newman, B. (1988). Are heavy smokers different from light smokers? A comparison after 48 hours without cigarettes. JAMA, 260, 1581-1585.

Kinne, S., Thompson, B., \& Wooldridge, J.A. (1991). Response to a telephone smoking information line. American Joumal of Health Promotion, S, 410-413.

Klesges, R.C., Brown, K., Pascale, R.W., Murphy, M., Williams, E., \& Cigrang, J.A. (1988). Factors associated with participation, attrition, and outcome in a smoking cessation program at the workplace. Health Psychology, 7, 575-589.

Klesges, R.C., Cigrang, J., \& Glasgow, R.E. (1987). Worksite smoking modification programs: A state-of-the-art review and directions for future research. Current Psychological Research and Revieves, 6, 26-56.

Kluger, R. (1996). Ashes to ashes: America's bundred-yeat cigarette war, the public bealth, and the unabashed triumph of Plilip Morris. New York: Alfred A. Knopt.

Koepsell, T.D., Wagner, E.H., Cheadle, A.C., Patrick, D.L., Martin, D.C., Diehr, P.H., Perrin, E.B., Kristal, A.R., Allan-Andrilla, C.H., \& Dey, L.J. (1992). Selected methodological issues in evaluating community-based health promotion and disease prevention programs. Anrual Reviere of Public Health, 13, 31-57.

Kok, F.J., Matroos, A.W., Van den Ban, A.W., \& Hautwast, G.A.J. (1982). Roken: Wat onderscheidr de falende van de succesvolle stopper? [Smoking: what distinguishes the unsuccessful from the successfu] quitter?】 Tijdschrift voor Sociale Geneeskunde, $60,405-410$.

Kok, G.J. (1992). Quality of planning as decisive determinant of health education effectiveness. Hygie, 11, 5-8.

Kortewreg, R. (1958). Huisarts, roken en de preventie van longkanker [General practitioner, smoking, and prevention of lung cancer]. Verslagen en Mededelingen betreffende de Volksgezondheid, $8 / 9,805-858$.

Kreft, I.G.G., De Leeuw, J., Van der Leeden, R. (1994). Review of five multilevel analysis programs: BMDP-5V, GENMOD, HIM, ML3, VARCL. American Statistician, 48, 324-335. 
Kristein, M.M. (1983). How much can business expect to profit from smoking cessation? Preventive Medicine, $12,358-381$.

Lamberts, H. (1989). Eindelijk actie tegen passief roken [Finally action against passive smoking]. Nederlands Tijdschrift woor de Geneeskunde, 133, 2157-2160.

Lando, H.A. (1993). Formal quit smoking treatments. In C.T. Orleans \& J. Slade, Nicotine Addiction: Principles and management (pp. 221-224). New York: Oxford Univ. Press.

Landrine, H., Klonoff, E.A., \& Fritz, J.M. (1994). Prewenting cigarette sales to minors: The need for contextual sociocultural analysis. Preventive Medicine, 23, 322-327.

Law, M.R., \& Hacksaw, A.K. (1996). Environmental tobacco smoke. British Medical Journal, 52 (1), $22-34$

Leedom, C., Persaud, D., \& Shovein, J. (1986). The effect on smoking behavior of an assertive request to refrain from smoking. Internation Joumal of Addictions, 21, 1113-1117.

Lichtenstein, E, \& Cohen, S. (1990). Prospective analysis of two modes of unaided smoking cessation. Health Education Research, 5, 6472.

Lichtenstein, E., \& Glasgow, R.E. (1992). Smoking cessation: What have we learned over the past decade? Joumal of Consulting and Clinical Psychology, 60, 518-527.

Lichtenstein, E., Glasgow, R.E., \& Abrams, D.B. (1986). Social support in smoking cessation: In search of effective interventions. Behavior Therapy, 17, 607-619.

Lininan, L.A., Emmons, K.M., Galuska, E.C., $8 x$ Abrams, D.B. (1993). Smoking control at the workplace: Current status and emerging issues. Rbode Island Medicine, 76, 510-514.

Longford, N.T. (1986). VARCL: Interactive software for variance component Analysis. Applications for surwey data. Profesional Statistician, 5, 28-32.

Marlatt., G.A., \& Gordon, I.R. (1985). Relapse prewention: Maintenance strategies in the treatment of addictive bebaviors. New York: Guilford Press.

Marsh, A., \& McKay, S. (1994). Poor smokers. London: Policy Studies Institute.

Matson, D.M., Lee, J.W., \& Hopp, J.W. (1993). The impact of incentives and competitions on participation and quit rates in worksite smoking cessation programs. American foumal of Health Promation, 7, 270-280.

McFall, S.L., Michener, A., Rubin, D., Flay, B.R., Mermelstein, R.J., Burton, D., Jelen, P., \& Warnecke, R.B. (1993). The effects and use of maintenance newsletrers in a smoking cessation intervention. Addictive Behaviors, 18, 151-158.

Mermelstein, R., Cohen, S., Lichtenstein, E., Baer, J.S., \& Kamarck, T. (1986). Social support and smoking cessation and maintenance. Joumal of Consulting and Clinical Psycbology, 54, 447453.

Millar, W. J. (1988). Evaluation of the impact of smoking restrictions in a government work setting. Canadian Joumal of Public Health, 79, 379-82.

Ministry of Public and Environmental Health. (1975). Maatregelen tot beperking van bet roken: Adries wan de Gezondbeidstaad [Measures to reduce smoking: Advice from the Health Council]. Leidschendam: Ministerie van Volksgezondheid en Milieuhygiëne.

Ministry of Public Health, Welfare and Sports. (1994). Rookrapport [Report on smoking]. Alkmaar: Keuringsdienst van Waren.

Ministry of Public Health, Welfare and Sports. (1996). Nota 'Tabaksontmoedigingsbeleid' [Memorial on smoking discouragement policy]. Rijswijk: Ministerie van Volksgezondheid, Welzijn en Sport (VWS). 
Mudde, A.N. (1993). Ex-rokers wertellen over stoppen met roken: Stoppen met roken bp bet werk [Exsmokers talk about quitting smoking: Smoking cessation at the workplace]. Den Haag: Stichting Volksgezondheid en Roken.

Mudde, A.N. (1994). The development and evaluation of a community and a mass media approach to smoking cessation. [PhD thesis]. Maastricht: Maastricht University.

Mudde, A.N., \& De Vries, H. (in press). The reach and effectiveness of a national mass media-led smoking cessation campaign in the Netherlands. American Joumal of Public Health.

Mudde, A.N., De Vries, H., Willemsen, M.C., \& Van Assema, P. (1994). Development and utilization of a self-help manual for community smoking cessation interventions. In $\mathrm{R}$. Richmond (Ed), Interventions for smokers: An intemational perspective (pp. 293-322). Baltimore, Williams $\&$ Wilkins.

Mudde, A., Dolders, M., \& De Vries, H. (1994). Publieksevaluatie van de actie: Volwassen bevolking [Evaluation of the intervention: the adult population.]. In B. Baan, H.M.H. Breteler, \& G.A.J. Van der Rijt (Eds.), Evaluatie van de actie 'Samen stoppen mer roken' (pp. 22-44). Den Haag: Stichting Volksgezondheid en Roken.

Mudde, A.N., Kok, G \& Strecher, V.J. (1995). Self-efficacy as a predictor for the cessation of smoking: Methodological issues and implications for smoking cessation programs. Psychology and Health, 10, 353-367.

Mudde, A.N., Willemsen , M.C., Gerards, F.M., \& Dubois, V.E. (1989) Stoppen met roken: Een patiëntgerichte benadering. Medisch Contact, 44, 1456-1458.

Mullen, P.D., Green, L.W., \& Persinger, G. (1985). Clinical trials for patient education for chronic conditions: A comparative meta-analysis of intervention types. Preventive Medicine, 14, 753 . 781.

Murray, D.M., O'Connell, C.M., Schmid, L.A., \& Perry, C.I. (1987). The validity of smoking selfreports by adolescents: A reexamination of the bogus-pipeline procedure. Addictive Bebaviors, 12, 7-15.

Nelson, D.E., Emont, S.L., Brackbill, R.M., Cameron, L.L., Peddicord, J., \& Fiore, M.C. (1994). Cigarette smoking prevalence by accupation in the United States. Joumal of Occupational Medicine, 36, 516-525.

Ockene, J.K., Benfari, R.C., Nuttall, R.L., Hurwitz, I., \& Ockene, I.S. (1982). Relationship of psychosocial factors to smoking behavior change in an intervention program. Preventive Medicine, 11, 13-28.

Oldenburg, B. (in press). Promotion of a healthy lifestyle: Integrating the clinical and public health approaches. Intermational Review of Health Psychology.

Omenn, G.S., Thompson, B., Sexton, M., Hessol, N., Breitenstein, B., Curry, S., Michnich, M. \& Peterson, A. (1988). A randomized comparision of worksite-sponsored smoking cessation programs. American Joumal of Preventive Medicine, 4, 261- 267.

Owen, N. \& Davies, M.J. (1990). Smokers" preferences for assistance with cessation. Preventive Medicine, 19, 424-431.

Orlandi, M.A., Landers, C., Weston, R., \& Haley, N. (1990). Diffusion of health promotion innovations. In K. Glanz, F.M. Lewis, \& B. Rimer. (Eds.), Health behavior and bealth education: Theory, research and practice (pp 288-313). San Fransisco: Jossey-Bass. 
Orleans, C. T* (1993). Treating nicotine dependence in medical settings: A stepped-care model. In C.T. Orleans 8 J. Slade, Nicotine Addiction: Principles and management (pp. 145-161). New York: Oxford Univ. Press:

Petersen, L.R., Helgerson, S.D., Gibbons, C.M., Calhoud, C.R., Ciacco, K.H., \& Pirchford, K.C. (1988). Employee smoking behavior changes and attitudes following a restrictive policy on worksite smoking in a large company. Public Health Reports, 103, 115-122.

Peto, R., Lopez, A.D., Boreham, J., Thun, M., \& Heath, C. (1992). Mortality from tobacco in developed countries: indirect estimation from national vital statistics. The Lancet, 339, 12671278.

Peto, R., Lopez, A.D., Boreham, J., Thun, M., \& Heath, C. (1994). Mortality from smoking in developed countries: 1950 - 2000: indirect estimates from national vital statistics. New York: Oxford University Press.

Pierce, J.P. (1991). Progress and problems in international public health efforts to reduce tobacco usage. Annual Review of Public Health, 12, 383-400.

Pieterse, M.E., Seydel, E.R., Mudde, A.N., \& de Vries, H. (1994). Uitvoerbaarheid en effectiviteit van een minimaal stoppen-met-roken programma voor de huisartpraktijk [Feasibility and effectiveness: of a minimal smoking cessation program for general practitioners]. Tijdschrift Gezondbeidsbevordering, 15, 57-71.

Pommerleau, C.S., Carton, S.M., Lutzke, M.L., Flessland, K.A., \& Pomerleau, O.F. (1994). Reliability of the Fagerström Tolerance Questionnaire and the Fagerström Test for Nicotine Dependence. Addictive Beharviors, 19, 33-39.

Prochaska, J.O., \& DiClemente, C.C. (1983). Stages and processes of self-change of smoking: Toward an integrative model of change. Jowrnal of Consulting and Clinical Psychology, 51, $390-395$.

Prochaska, J.O., \& DiClemente, C.C. (1991). Stages of change in the modification of problem behaviors. Progress in Bebavior Modification, 28, 184-218.

Prochaska, J.O., DiClemente, C.C., \& Norcross, J.C. (1992). In search of how people change: Applications to addictive behaviors. American Psychologist, 47, 1102-1114.

Prochaska, J.O., DiClemente, C.C., Velicer, W.F., \& Rossi, J.S. (1993). Standardized, individualized, interactive, and personalized self-help programs for smoking cessation. Health Pycholo $8 y, 12,399-405$.

Prochaska, J.O., Velicer, W.R., DiClemente, C.C., \& Fava, J. (1988). Measuring processes of change: Applications to the cessation of smoking. Journal of Consulting and Clinical Psychology, $56,520-528$.

Pucci, L.G., \& Haglund, B. (1994). 'Naturally smoke free': A support program for facilitating worksite smoking control policy implementation in Sweden. Health Promotion International, 9, $177-187$.

Radecki, T.E., \& Zdunich, C.D. (1993). Tobacco sales to minors in 97 US and Canadian communities. Tobacco Control, 2, 300-305.

Reid, D.J., Kolloran, A.J., McNeill, A.D., \& Chambers, J.S. (1992). Choosing the most effective health promotion options for reducing a mation's smoking prevalence. Tobacco Control, 1, 185-197.

Repace, J.I. (1993). Tobacco smoke pollution. In C.T. Orleans \& J. Slade, Nicotine Addiction: Principles and management (pp. 129-142). New York: Oxford Uniw. Press. 
Rigotti, N.A., Stoto, M.A., Bierer, M.F., Rosen, A., \& Schelling, T. (1993). Retail stores' compliance with a city no-smoking law. American Joumal of Public Health, 83, 227-232.

Rimer, B.K., Orleans, C.T., Fleisher, L. Christinzio, S, Resch, N., Telepchak, I., \& Keintz, M.K.K. (1994). Does tailoring matter? The impact of a tailored guide on ratings and shortterm smoking related outcomes for older smokers. Health Education Reseanch, 9, 60-84.

Robert, H. (1992). Cigaretre health warnings: The effects of perceived severity, expectancy of occurence, and self-efficacy on intentions to give up smoking. Awstratian Psychologist, 27,109 113.

Rogers, E.M. (1983). Diffusion of inmowations (3rd ed.). New York: Free Press.

Rosenbaum, P., \& O'Shea, R. (1992). Large-scale study of Freedom From Smoking clinics: Factors in quitting. Public Health Reports, 102, 150-155.

Rosenstock, I.M., Stergachis, A., \& Heaney, C. (1986). Evaluation of smoking prohibition policy in a health maintenance organization. American Joumal of Public Health, 76, 1014-1015.

Rothwell, K. (1992). The interaction of smoking and workplace bazards: Risks to bealth. Geneva: Office of Occupational Health, and Tobacco or Health Programme (WHO).

Ruwaard, D., \& P.G.N. Kramers (Eds). (1993). Volksgezondheid Toekomst Verkenning. De gezondbeidstoestand van de Nederlandse bevolking in de periode 1950-2010 [Public Health Status and Forecasts: The health status of the Dutch population over the period 1950-2010.]. RIVM. Den Haag: SDU.

Ryan, J., Zwerling, G., \& Orvav, E.J. (1992). Occupational risks associated with cigarette smoking: A prospective study. American Joumal of Public Health, 82, 29-32.

Salina, D., Jason, L.A., Hedeker, D., Kaufman, J., Lesondak, L., McMahon, S.D., Taylor, S., \& Kimball, P. (1994). A follow-up of a media-based worksite smoking cessation program. American Joumal of Community Psychology, 22, 257-271.

Sanson-Fisher, R.W., Schofield, M.J., \& See, M. (1992). Availability of cigarettes to minors. Australian Joumal of Public Health, 16, 354359 .

Schaapveld, K., Bergsma, E.W., van Ginneken, J.K.S., \& van de Water, H.P.A. (1990). Setting priorities into prevention. Leiden: TNO-NIPG.

Schachter, S. (1982). Recidiwism and self-cure of smoking and obesity. American Psychologist, 37, 436-444.

Schalk, M.J.D. (1989). Determinanten wan veelvuldig kortdurend ziekteverzuim [Determinants of frequent short-term sickleave]. Den Haag: Delwel.

Schepel, M.P. (1992). Overzicht rechtszaken over rookoveriast [presentation]. [Overview of lawsuits concerning passive smoking]. Workshop 'Een rookvrije werkplek: veiliger en gezonder", organized by the World Health Organization. Den Haag: Stichting Volksgezondheid en Roken.

Schoberger, R., Kunze, M., \& Fagerström, K.O. (1996). Motivation for smoking cessation and the influence of nicotine dependence. Third International Congress of Behavioral Medicine. Abstractbook, p. 139. Amsterdam.

Schofield, M.J., Considine, R., Boyle, C.A., \& Sanson-Fisher, R. (1993). Smoking control in restaurants: The effectiveness of self-regulation in Australia. American journal of Public Health, 83, $1284-1288$.

Schotborg, E.J., \& Breteler, M.H.M. (1994). Smoking cessation: determinants of success. Nijmegen: University Press. 
Schröer, C., Soeters, J., Nijhuis, F., Custers, T., \& Philipsen, J. (1984). Werk en ziekte deel 2: De werknemensenquete. Maaistricht: University Maastricht.

Schwarz, J.L. (1987). Reniew and evaluation of smoking cessation metbods: The United States and Canada, 1978-1985. US Department of Health and Human Services (Publication No 87-2940). Washington, DC: National Cancer Institute.

Sees, K.L. (1990). The smoke-free workplace. Joumal of Psychoactive Drugs, 22, 479-483.

Serxiner, S., Catalano, R., Dooley, D., \& Mishra, S. (1991). Tobacco Use: Selection, stress, or culture? Journal of Occupational Medicine, 33, 1035-1039.

Shiffman, S. (1984). Coping with temptations to smoke. Joumal of Consulting and Clinical Psychology, so, 71-85.

Shopland, D.R., \& Burns, D.M. (1993). Medical and public health implications of tobacco addiction. In C.T. Orleans \& J. Slade, Nicotine Addiction: Principles and management (pp. 105-128). New York: Oxford University Press.

Simonich, W.L. (1991). Government antismoking policies (American University Studies; Series X Political Science, Vol 30). New York: Peter Lang.

Sloan, R.P. (1987). Workplace health promotion: A commentary on the evolution of a paradigm. Health Education Quarterly, 14, 181-194.

Smit, H.A., Hoeymans, N., Bueno de Mesquita, H.B., \& Kromhout, D. (1993). Roken [Smoking]. In D. Ruwraard, \& P.G.N. Kramers (Eds), Volksgezondbeid Toekomst Verkenning De gezondbeidstoestand wan de Nederlandse bevolking in de periode 1950-2010 (pp. 567-572). RTVM. Den Hang: SDU.

Sorensen, G., Beder, B., Prible, C.R., \& Pinney* J. (1995). Reducing smoking at the workplace: implementing a smoking ban and hypnotherapy. Joumal of Occupational and Environmental Medicine, 37, 453-460.

Sorensen, G., Glasgow, R.E., \& Corbett, K. (1990). Involving work sites and ather organizations. In Bracht, N, (Ed.), Health promotion at the community level (pp. 158-84). Newbury Park: Sage.

Sorensen, G., Lando, H., \& Pechacek, T.F. (1993). Promoting smoking cessation at the workplace. Results of a randomized controlled intervention study. Joumal of Occupational Medicine, 35, 121-126.

Sorensen, G., \& Pechacek, T. (1989). Implementing nonsmoking policies in the private sector and assessing their effects. New York State Jowmal of Medicine, 89, 11-15.

Sorensen, G., Pechacek, T., \& Pallonen, U. (1986). Occupational and worksite norms and attitudes about smoking cessation. American Joumal of Public Health, 76, 544549.

Sorensen, G., Rigotti, N., Rosen, A., \& Prible, R. (1991). Effects of a worksite nonsmoking policy: evidence for increased cessation. American Joumal of Public Health, 81, 202-204.

Sorensen, G., Thompson, B., Glanz, K., Feng, Z., Kinne, S, DiClemente, C., Emmons, K., Heimendinger, J., Probart, C., \& Lichtenstein, E. (1996). Work site-based cancer prevention: Primary results from the Working Well Trial. American Journal of Publich Health, 86, 939947.

Speer, F., \& Mission, S. (1968). Tobacco and the nonsmoker. Archives of Environmental Health, 16, 443-446.

Spoth, R. (1991). Smoking cessation program preferences associated with stage of quitting. Addictive Bebaviors, $16,427-440$. 
Sprangers, M. (1988). Response shift and the retrospective pretest: On the asefulness of retrospective pretest-posttest designs in detecting training related response shift. Den $\mathbb{H}$ laag: SVO.

Stave, G.M., \& Jackson, G.W. (1991). Effect of a total work-site smoking ban on employee smoking and attitudes. Joumal of Occupational Medicine, 33, 884890 .

Steenland, K. (1992). Passive smoking and the risk of heart disease. JAMA, 267, 94-99.

Stephens, T., Jackson, K., Garrison, C., Blair, S., \& Kronenfeld, J. (1989). Smoking behaviors and attitudes in the workplace. Health Education Research, 4, 245-249.

Stoffelmayr, B.E., Benishek, L., Coelho, R., Mavis, B., \& Moallemian, P. (1991). Worksite smoking reduction: A review of research and programs. In J.P. Mayer \& J.K. Davis (Eds), Worksite bealth promotion: Needs, approaches, and effectiveness. Lansing: Michigan Department of Public Health.

Strasser, P.B. (1991). Smoking cessation programs in the workplace: Review and recommendations for occupational health nurses. AAOHN Journal, 39, 42-438.

Strecher, V.J., DeVellis, B.M., Becker, M.H., \& Rosenstack, I.M. (1986). The role of self-efficacy in achieving health behavior change. Health Education Quarterly, 13, 73-91.

Strecher, V.J, Kreuter, M., Den Boer, D.J., Kobrin, S., Hospers, H., \& Skinner, C.S. (1994). The effects of computer-tailored smoking cessation messages in family practice settings. Jourmal of Family Practice, 39, 262-268.

Strecher, V.J., Rimer, B.K., \& Monaco, K.D. (1984). Development of a new self-help guide Freedom from smoking for you and your family. Health Education Quarterly, 16, 101-112.

Stuart, K., Borland, R., \& McMurray, N. (1994). Self-efficacy, health lacus of control, and smoking cessation. Addictive Behaviors, 19, 1-12.

Sussman, S., Witney-Saltiel, A., Budd, R.J., Spiegel, D., Brannon, B.R., Hansen, W.B., Johnson, C.A., \& Flay, B.R. (1989). Joiners and nom-joiners in worksite smoking treatment: pretreatment smoking by significant others, expectations to quit as predictors. Addictive Behaviors, 14, 113-119.

Swinkels, H. (1994). Trendcijfers gezondheidsenquete: aspecten van (on)gezond gedrag, 1989-1993. [Trend figures Netherlands Health Interview Survey; aspects of (un) healthy behaviour, 19891993]. Maandbericht Gezondheidsstatistiele (CBS), 7, 5-14.

Tate, J.C., \& Schmitz, J.M. (1993). A proposed revision of the Fagerström Tolerance Questionnaire. Addictive Behaviors, 18, 135-143.

Thompson, B., Emmons, K., Abrams, D., Ockene, J.K., \& Feng, Z. (1995). ETS exposure in the workplace: Perceptions and reactions by employees in 114 work sites. Jommal of Occupational and Environmental Medicine, 9, 1086-1092.

Tiffany, S.T. (1991). The application of $1980^{*}$ s psychology to $1990^{\prime}$ s smaking research. British Joumal of Addiction, 86, 617-620.

Trigg, A.B., \& Bosanquet, N. (1992). Tax harmonisation and the reduction of European smoking rates. Journal of Health Economics, 11, 329-346.

Tweede Kamer (1986). Nota 2000. Over de ontwikkeling van gezondheidsbeleid: feiten, beschowwingen en beleidsvoomemens. Zitting 1985-1986, kamerstuk 19 500, nrs 1-2-3. Rijswijk: Ministerie var WVC.

Tweede Kamer (1994). Gezond en wel: Het kader van het volksgezondheidsbeleid 1995-1998 [Health and wellbeing: Scope of Dutch public health policy 1995-1998]. Kamerstuk 24 126, nurs 1-2. Rijswijk: Ministerie van WVC. 
US Department of Health and Human Services (1982). The bealth consequences of smaking: Cancer. A repront of the Swrgeon General (DHHS Publication No. 82-50179). Washington, DC: U.S. Government Printing Office.

US Department of Health and Human Services: (1983). The bealth conseqwences of smaking: Cardiovascular disease: A repont of the Surgeon General (DHHS Publication No. 84-50204). Washington, DC. U.S. Government Printing Office.

US Department of Health and Human Services (1985). The bealth consequences of smoking: Cancer and Chronic Lung Disease in the workplace. A report of the Surgeon General. (DHHS Publication No. 85-50207). Washington, DC. U.S. Government Printing Office.

US Department of Health and Human Services (1986). The Health Consequences of involuntary smoking. A report of the Surgean General (DHHS Publication No. 87-8398). Washington, DC: US Public Health Service.

US Department of Health and Human Services (1988). The Health consequences of smoking: Nicotine Addiction. A repont of the Surgean General (DHHS Publication No. 88-8406). Washington, DC: U.S. Government Printing Office.

US Department of Health and Human Services (1989). The bealth consequences of smoking: 25 years of progress. A report of the Surgeon General (Publication No. (CDC) 89-8411). Washington, DC: U.S. Government Printing Office.

US Department of Health and Human Services (1990). The health benefits from smoking cessation. A report of the Surgeon General (Publication No. (CDC) 90-8416). Washington, DC: U.S. Government Printing Office.

US Department of Health and Human Services (1994). Preventing Tobacco Use among young people: A report of the Surgeon General. Washington, DC: U.S.Government printing office.

Van der Goor, I.A.M., Van Oers, H.A.M., Bongers, I.M.B., \& Garretsen, H.F.L. (1996). Riskante leefgewoonten in Rotterdam anno 1994: Een onderzoek naar bet gebruik van alcobol, slaap-en kalmerende middelen, tabak, basj en maribuana en de deelname aan kansspelen onder de Rotterdamse bevolking [Hazardous habits in Rotterdam anno 1994]. Rotterdam: Instituut voor Verslavingsonderzoek (IVO).

Van der Rijt, G., Brokx, L., \&x Zeeman, G. (1993). De uitstraling van stop met roken cursussen: Een onderzoek naar de invloed van de stop met roken cursus in de omgeving van de deelnemer [Spin-off from smoking cessation courses: A study on the influence of smoking cessation courses on the social environment of participants]. Tijdschrift woor Alcohol en Drugs, 19, 2-15.

Van Deursen, C.G.L., Rant, H., \& Garretsen, H.F.L. (1988). Alcoholgebruik roken en verzuimdiagnoses bij Rotterdamse gemeenteambtenaren [Alcohol consumption, smoking, and absenteeism among public servants in Rotterdam]. Tijdschrift voor Alcobol en Drugs, 15, 25-33.

Van Deursen, C.G.L. \& Teeuwen, J.H.M., (1988). Arbeidssituatie, leefstijl en ziekteverzuim bij Rotterdamse gemeenteambtenaren [Work situation, lifestyle, and absenteeism among public servants in Rotterdam]. Tijdschrift Sociale Gezondheidszorg, 66, 223-227.

VanOss-Marin, B., Marin, G., Perez-Stable, E.J., Otero-Sabogal, R., \& Sabogal, F. (1990). Cultural differences in attitudes toward smoking: Developing messages using the theory of reasoned action. Joumal of Applied Social Psychology, 20,478-493.

Van Proosdi, V (1957). Roken: Een individueel-en socialgeneeskundige studie [Smoking: a study in individual- and social medicine] [PhD thesis]. Amsterdam: Noord-Hollandsche Uitgeversmaatschappij. 
Van Reek, J, \& Adriaanse, H. (1987). Smoking policy in the Necherlands since the fifties: one factor in the social dynamics of changes in smoking behaviour. Health Policy, 7, 361-368.

Velicer, W.F., DiClemente, C.C., Rossi, J.S., \& Prochaska, J.O. (1990). Relapse situations and selfefficacy: An integrative model. Addictive Bebaviors, 15, 271-283.

Velicer, W. F, Prochaska, J.O., Bellis, J.M., DiClemente, C.C. Rossi, J.S, Fava, J.L., \& Steiger, J.H. (1993). An expert system intervention for smoking cessation. Addictive Behaviors, 18, 269-290.

Velicer, W.F., Prochaska, J.O., Rossi; J.S., \& Snow, M.G. (1992). Assessing outcome in smoking cessation studies. Pyjebological Bullettin, 11l, 23-41.

Velicer, W.F., Rossi, J.S., Ruggiero, L., \& Prochaska, J.O. (1994). Minimal interventions appropriate for an entire population of smokers. In Richmond $\mathrm{R}$ (Ed), Interventions for smokers: An international perspective (Pp. 69-92). Baltimore: Williams \& Wilkins.

Warburton, D.M., Revell, A.D., \& Thompson, D.H. (1991). Smokers of the future. British Jourmal of Addiction, 86, 621-625.

Warner, K.E., Smith, R.J., Smith, D.G., \& Fries, B.A. (1996). Health and economic implications of a worksite smoking cessation program: A simulation analysis. Jowmal of Occupational and Environmental Medicine, 38, 981-992.

Weber. A. (1984). Annoyance and irritation by passive smoking. Preventive Medicine, 13, 618-25.

Wester, J. (1957). Publikaties van de gezondheidsrad: Roken en Longkanker [Publications from the Health Council: Smoking and lung cancer]. Nederlands Tijdschrift Geneeskunde, 101, 459463.

WHO (1995). Country profiles. Fifth WHO seminar for a Tobacco-free Europe. Warsaw, 26-28 October 1995.

Willemsen, M.C. \& De Vries, H (1993). Stoppen met roken via de werkplek: Een onderzoek bij PTT-Telecom [Smoking cessation in the worksetting: A study at PTT-Telecom]. Tijdscbrift voor Saciale Gezondheidszorg, 71, 251-257.

Willemsen, M.C., \& De Vries, H. (1995). Evaluation of a smoking cessation program consisting of a self-help method and a group program. Tobacco Contral, 4, 351-354.

Willemsen, M.C., \& De Vries, H. (1996). Saying "No" to environmental tobacco smoke: Determinants of assertiveness among nonsmoking employees. Preventive Medicine, 25, 575-582.

Willemsen, M.C., De Vries, H., \& Genders, R. (1995). Roken op het werk: Ervaren hinder van tabaksrook en steun voor niet-rokenbeleid [Smoking at work: Hindrance from environmental tobacco smoke and support for smoking policy]. Tijdscbrift woor Sociale Gezond heidszorg, 73, 448-454.

Willemsen, M.C., De Vries, H., \& Genders, R. (1996). Annoyance from environmental tobacco smoke and support for no-smoking policies at eight large Dutch workplaces. Tobacco Control, $5,132-138$.

Willemsen, M.C., De Vries, H., \& Genders, R. (1997). Long-term effectiveness of two Dutch worksite smoking cessation programs. Manuscript submitted for publication.

Willemsen, M.C., De Vries, H, Genders, R., \& Oldenburg, B. (1997). Smoking cessation programs in an enriched environment: Can we expect a spin-off effect on smokers who do not participate?. Manuscript submitted for publication.

Willemsen, M.C., De Vries, H., Van Breukelen, G., Oldenburg, B. (1996). Determinants of intention to quit smoking among Dutch employees: The infuence of the social environment. Preventive Medicine, 25, 195-202. 
Willemsen, M.C., Haarsen, A., Zeeman, G., \& De Vries, H. (1996). Invoering van rookbeleid in organisaties: Prakrische richtijnen [Implementation of smoking policies in organizations: practical guidelines]. Tijdschrift voor Sociale Gezondbeidszorg, 74, 363-365.

Willemsen, M.C., Brug, J., Uges, R.A., \& Vos de Wael, M.L. (1997). Validity and reliability of selfreported exposure to environmental tobacco smoke in work offices. Mamuscript submitzed for publication:

Windsor, R.A., Baranowski, T., Clark, N., \& Cutter, G. (1994). Evaluation of bealth promotion and education programs. Palo Alto: Mayfield.

Wooden, M., \& Bush, R. (1995). Smoking cessation and absence from work. Preventive Medicine, $24,535-540$.

Woodruff, T.J., Rosbrook, B., Pierce, J., \& Glantz, S.A. (1993). Lower levels of cigarette consumption found in smoke-free workplaces in California. Arcbives of Internal Medicine, 28, 14851493.

Wynder, E.L. 8 Graham, E.A. (1950). Tobacco smoking as a possible etiological factor in bronchiogenic carcinoma: A study of six hundred and eighty-four proved cases. JAMA, 143, 329. 336. 


\section{Summary}

The Dutch national smoking rate (35\%) seems to have almost stabilized since 1990 and is among the highest in Western-Europe. The Dutch governmen's actions have been limited in the past and it is questionable whether this will substantially change in the near future. In order to bring down national smoking rates, additional efforts are needed from national health organizations. It is argued that the workplace may be an attractive setting for anti-smoking programs. However, this potential has not yet been realized in the Netherlands. The objective of this thesis was to examine whether the worksite could be an effective channel to reach adult Dutch smokers and to encourage them to quit smoking. To this end, studies were undertaken in several large Dutch worksites, using both descriptive and longitudinal data.

Chapter 2 reviews the literature on the harmful consequences of smoking, the determinants of smoking cessation, and the strategies to reduce smoking in worksites. One important issue that emerged from the analysis in Chapter 2, was the difference in perspective between public health advocates and employers. For health educators, smoking is an important target behavior, because it is the single most important cause of premature illness and death and thus deserves to be singled out in health promotion campaigns. Working smokers comprise an important target group, since smoking prevalence among workers is high, especially among bluecollar workers. For employers, passive smoking seems to be at least as important, due to the social problems that are associated with passive smoking at the workplace. For worksites in which the elimination of second-hand smoke has high priority, smoking policies are more important than smoking cessation programs. The determinant study revealed that smoking cessation programs should aim at changing the cognitive determinants of smoking cessation and should help smokers acquire the necessary skills to quit. Smoking cessation programs can be an adjunct to smoking policies and, vice versa, smoking policies might encourage employees to quit smoking. Mass media strategies may be needed to create supportive environments for quitting in worksites.

Chapter 3 examines the extent to which Dutch employees are bothered by tobacco smoke and which smoking restrictions they prefer. Descriptive data are presented using a representative sample of smoking and nonsmoking employees $(\mathrm{N}=1480)$ from eight large companies in four sectors of Dutch industry. It was found that $35 \%$ of nonsmoking employees felt it was (very) annoying when their colleagues smoked during work time, and $78 \%$ thought a smoky work environment 
was harmful to their health. About two-thirds of nonsmokers were sometimes / often bothered by environmental tobacco smoke (ETS) at their workplace. Most nonsmokers and many smokers rejected the individual solution approach (no explicit policy), as endorsed by the tobacco industry, and prefered smoking restrictions. In three sectors of industry, there was much support among employrees for a general smoking ban, with the exception of smoking in work areas specially designated for this purpose. These results could encourage more companies to implement smoking restrictions and they may be used as reference data by companies wanting to develop effective smoking policies.

Chapter 4 examines the influence of the social environment in worksites on employees' intention to quit smoking by applying the attitude - social influence efficacy expectation (ASE-) model. Regression analyses conducted with 509 smoking employees from eight Dutch worksites indicated that attitude, social pressure from people outside the worksetting (partner, children) and self-efficacy explained $23 \%$ of the variance for intention. Past behavior increased the adjusted $\mathrm{R}^{2}$ from .23 to .29 . Social influences in the worksite were unrelated to employees" intentions to quit smoking. It was conciuded that people outside the work situation have a much greater influence on smokers' intention to quit than people at work, despite the many hours smokers spend in a work-environment.

Chapter 5 focusses on nonsmokers' assertiveness with regard to colleagues who smoke. Assertiveness can help regulate smoking in worksites by enhancing the salience of nonsmoking social norms. Cross-sectional data were collected from 898 nonsmoking Dutch employees. Fifty-one percent of nonsmoking employees asked co-workers not to smoke. Assertive behavior is more common in worksettings, than in public places outside the worksite. Assertive respondents had colleagues who more often acted assertively toward smokers at work, had a more positive attitude to asking colleagues not to smoke, and had a higher perceived self-efficacy. Moreover, assertive employees more often perceived hindrance from environmental tobacco smoke (ETS) and had more negative opinions about the health consequences of ETS at work. These latter results suggest that what matters is whether ETS is perceived as both bothersome and harmful. It is likely that both conditions must be met for nonsmokers to behave assertively. Worksite educational programs could focus more on increasing nonsmokers' awareness of the harm caused by regular exposure to ETS at work. However, the effectiveness of such strategies is as yet unknown. 
Chapter 6 presents the results from a quasi-experimental evaluation of a worksite smoking cessation intervention in the Netherlands. The program was implemented in one site of PTT-Telecom, and compared with a no-intervention control site of the same company. Subjects were smoking employees who wanted to quit smoking. The intervention consisted of an offer of a self-help guide, a group program, a telephone quit line and a tailored letter of advice. At three-months followup, the program resulted in significantly higher point-prevalence quit rates ( $11 \%$ versus $2 \%$ ), but these differences were not sustained at 12 months. It was concluded that comprehensive multi-component programs may be needed to achieve a sustained impact on worksite smoking prevalence in the Netherlands.

Chapter 7 presents data on the effectiveness of a comprehensive program that was developed following the experience with the PTT-Telecom pilot program. The comprehensive program consisted of self-help manuals, group courses, a mass media campaign, smoking policies, and program continuation strategies. In a quasi-experimental design, four large worksites received the comprehensive program, while four received a minimal program consisting of only self-help manuals. At 14 months follow up, $16 \%$ of the participants in the comprehensive program had quit smoking, compared to $12 \%$ in the minimal program. Furthermore, the exact effect of treatment on smoking cessation depended on nicotine dependency levels. Medium and heavy smokers had a substantially higher chance of success with the comprehensive smoking cessation program than very light smokers. The mass media campaign and group courses helped initial quitters maintain their non-smoking status (sustained quitting). The results suggested that from a public health perspective, a minimal program might have a larger impact than a comprehensive program because it may be easier to diffuse nation wide. A two-step strategy might also be used as a diffusion strategy in which first minimal programs are marketed to worksites. In a second effort, more comprehensive programs are offered that might appeal to employers wanting to provide more heavily addicted smokers with intensive treatment.

Chapter 8 examines whether an enriched environment consisting of mass media and policy changes has an effect on participation rates in worksite smoking cessation programs and whether an 'enriched milieu' might have a spin-off effect on smokers who did not participate in cessation programs and on nonsmokers' assertiveness and supportive behavior. Random samples from eight large worksites (1730 
respondents) were analyzed for changes from baseline to 18 months follow-up. It was concluded that a mass-media campaign could improve participation in the cessation program, but was unlikely to have an additional effect on nonparticipating smokers with respect to cognitive and behavioral changes. Smoking restrictions were found to have an impact on nonsmokers" assertiveness and intolerance. Exposure to exhibitions, leaflets, and newsletters was less effective among blue-collar workers.

Chapter 9 is a general discussion of the results from the various studies brought together in this thesis, followed by a review of methodological limitations, and suggestions for future research. Three main conclusions can be drawn from the research in this thesis: a. comprehensive worksite smoking cessation programs are more effective in helping moderate to heavy Dutch smoking employees quit smoking than no intervention or minimal interventions; $b$. the difference in overall effectiveness between the minimal program (self-help manuals) and the comprehensive program was not very large. Due to their greater ease of implementation, minimal programs seem more suitable for nation wide diffusion; c. more research is needed on how the adoption, implementation and effectiveness of smoking cessation programs in worksites are affected by contingency factors such as organizational structure and decision-making style in orgarizations. 


\section{Samenvatting}

Het doel van deze dissertatie was te onderzoeken of de werkplek een geschikt kanaal kan zijn om volwassen rokers te bereiken en te stimuleren om met roken te stoppen. Dit is onderzocht met behulp van cross-sectionele and longitudinale studies bij enkele grote Nederlandse bedrijven. In hoofdstuk 1 wordt opgemerkt dat het percentage rokers in Nederland één van de hoogste in West-Europa is (35\%). Overheidsmaatregelen om het roken terug te dringen zijn tot nu toe minimaal geweest. Om het roken in Nederland verder te verminderen zijn daarom additionele inspanningen nodig van nationale gezondheidszorgorganisaties. Eén van de mogelijke wegen om rokers te bereiken is de arbeidssituatie. Deze mogelijkheid is nog onvoldoende benut.

In hoofdstuk 2 wordt literatuur besproken over de gezondheidsschade van roken, over psychologische determinanten van stoppen met roken en over strategieën om het roken op de werkplek terug te dringen. Een belangrijk thema dat tevens naar voren komt, is het verschil in perspectief dat vanuit de vollksgezondheid en vanuit de arbeidssituatie wordt ingenomen met betrekking tot roken in de arbeidssituatie. Roken is een belangrijke oorzaak van vroegtijdige ziekte en -sterfte in de maatschappij. Rokende werknemers vormen een belangrijke doelgroep voor de gezondheidsvoorlichting, omdat de rookprevalentie onder werkenden hoog is, met name onder handarbeiders. Voor een arbeidsorganisatie spelen de gezondheidsaspecten van rolken een minder belangrijke rol, maar vormt de overlast door passief roken vaak meer een probleem. Bij bedrijven die het terugdringen van rookoverlast een hoge prioriteit geven, zijn rookbeperkende maatregelen dan ook belangrijker dan stoppen-met-roken programma's. Stoppen-met-roken programma's kunnen een ondersteuning vormen van rookbeleidsmaatregelen en vice versa kan een effectief rookbeleid rokers stimuleren om te stoppen met roken. Uit een literatuuroverzicht van de determinanten van stoppen met roken bleek dat stoppen-met-roken programma's zich dienen te richten op het veranderen van cognitieve determinanten van stoppen met roken en op het vergroten van vaardigheden om te kunnen stoppen met roken. Tot slot kunnen massamediale strategieën noodzakelijk zijn om de sociale omgeving van rokers te beïnloeden zodat het niet-roken op de werkplek makkelijker wordt.

In hoofdstuk 3 wordt onderzocht hoeveel overlast werknemers ondervinden van tabaksrook op het werk en aan welke rookbeperkende maatregelen zij de voorkeur geven. De onderzoeksgegevens zijn afkomstig van een representatieve 
steekproef van 1480 werknemers afkomstig uit acht grote bedrijven uit vier bedrijfssectoren. Het bleek dat $35 \%$ van de niet-rokers het lastig tot zeer lastig vond als hun collega"s rookten tijdens het werk en dat $78 \%$ vond dat een rokerige werkomgeving schadelijk was voor hun gezondheid. Ongeveer tweederde van de niet-rokers zei hinder te ondervinden van omgevingstabaksrook op het werk. De meeste nietrokers, maar ook veel rokers, staan niet achter de slogan van de tabaksindustrie: 'Roken? Ook dat lossen we samen op', maar geven de voorkeur aan rookbeperkingen. In drie van de vier onderzochte bedrijfstypen bestond veel steun onder de werknemers voor een algemeen rookverbod met uitzondering van speciale rookruimten. Deze gegevens kunnen voor meer bedrijven een stimulans zijn om rookbeperkende maatregelen in te voeren.

Hoofdstuk 4 onderzoekt de invloed van collega"s en chefs op het voornemen van werknemers om te stoppen met roken in vergelijking met andere determinanten. Hiervoor werd gebruik gemaakt van het attitude - sociale invloed - effectiviteitsverwachting (ASE) model. Een regressie analyse bij 509 rokende werknemers in acht grote bedrijven wees uit dat attitude, ervaren sociale invloed van mensen buiten de werksetting (partner, kinderen) en de eigen-effectiviteitsverwachting gezamenlijk $23 \%$ van de variantie in intentie om te stoppen verkllaarden. Door toevoeging van de variable 'aantal eerdere stoppogingen' nam de verklaarde variantie verder toe met $6 \%$. Collega's en chefs bleken geen invloed te hebben op iemands intentie om te stoppen met roken. De conclusie was dat mensen uit de privé-omgeving (partner, vrienden) een grotere invloed lijken te hebben op iemands besluit om te stoppen met roken dan personen uit de arbeidssituatie, ondanks het feit dat veel werknemers relatief veel tijd doorbrengen in een arbeidssetting.

Hoofdstuk 5 onderzoekt hoe assertief niet-rokers zijn in gezelschap van collega"s die roken. Een assertieve houding van niet-rokers kan bijdragen aan het saillanter maken van niet-roken normen binnen bedrijven. Cross-sectionele data werden verzameld bij 898 niet-rokende werknemers. Eenenvijftig procent van de niet-rokers vraagt wel eens aan collega's om niet te roken. Assertief gedrag komt vaker voor in de arbeidssituatie dan in publieke ruimten buiten de arbeidssituatie. Assertieve respondenten bleken collega"s te hebben die ook assertief waren, hadden een positievere attitude ten aanzien van het vragen aan collega's om niet te roken en hadden een hogere eigen-effectiviteitsverwachting met betrekking tot assertief gedrag. Verder bleek dat assertieve werknemers vaker last ondervinden van omgevingstabaksrook en dat ze negatievere opvattingen hebben over de gezondheidsschade door passief 
roken. Deze laatste bevindingen suggereren dat niet-rokers omgevingstabaksrook zowel hinderlijk als schadelijk moeten vinden, voórdat ze tot assertief gedrag overgaan. Voorlichtingsprogramma's zouden zich meer kunnen richten op het vergroten van het besef van niet-rokers dat passief roken schadelijk is. De effectiviteit van dergelijke programma's is echter onbekend.

Hoofdstuk 6 presenteert de resultaten van een pilot-studie naar de effectiviteit van een stoppen-met-roken programma voor werknemers. Het programma werd ingevoerd in een district van PTT-Telecom en werd vergeleken met een controle district van hetzelfde bedrijf. Het onderzoek had betrekking op werknemers die van plan waren om te stoppen met roken. Het programma bestond uit het aanbieden van een zelfhulpgids, een groepscursus, een telefonische hulplijn en een op de roker afgestemde brief met stop-adviezen. Bij de drie-maanden nameting bleek het programma significant meer stoppers op te leveren dan de controlegroep $(11 \%$ versus $2 \%$ ), echter na 12 maanden bleek dit verschil vrijwel verdwenen te zijn. De conclusie was dat een meer uitgebreid programma nodig is om effecten over een langere periode vast te houden.

Hoofdstuk 7 beschrijft een studie naar de effectiviteit van een dergelijk uitgebreid stoppen-met-roken bedrijfsprogramma. Het uitgebreide programma bestond uit zelfhulpgidsen, groepscursussen, een massamediale campagne, rookbeperkende maatregelen en continueringsstrategieën. In een quasi-experimentele onderzoeksopzet ontvingen vier grote Nederlandse bedrijven het uitgebreide programma en vier bedrijven een minimaal programma bestaande uit alleen een zelfhulpgids. Bij de 14 maanden nameting bleek dat $16 \%$ van de deelnemers aan het uitgebreide programma van het roken af was, vergeleken met $12 \%$ in het minimale programma. Het exacte effect van onderzoeksconditie op stoppen met roken bleek af te hangen van de mate waarin een respondent 'nicotineverslaafd" was. Matig tot zwaar verslaafde rokers bleken een substantieel grotere kans op succes na deelname aan het uitgebreide programma, terwijl zeer lichte rokers even veel baat hadden bij een uitgebreid als een minimaal programma. Met name de massa mediale campagne en de groepscursussen bleken de kans te vergroten dat stoppers het niet-roken vol houden. Het relatief goede resultaat van het minimale programma is vooral vanuit het perspectief van volksgezondheid interessant, omdat een minimaal programma vermoedelijk gemakkelijker op grote schaal kan worden verspreid onder Nederlandse bedrijven dan een uitgebreid programma. 
Hoofdstuk 8 onderzoekt of massamediale activiteiten (tentoonstellingswanden, brochures, berichten in bedrijfsbladen) en rookbeperkende maatregelen de deelname aan het stoppen-met-rokenbedrijfsprogramma kunnen vergroten. Ook wordt bekeken of deze activiteiten invloed kunnen hebben op rokers die niet deelnemen aan stopprogramma's en op de wijze waarop niet-rokers zich opstellen ten opzichte van rokers (assertief) en stoppers (ondersteunend). Bij een a-selecte steekproef onder de werknemers in de acht bedrijven (1730 respondenten) werd gezocht naar veranderingen tussen voormeting en 18-maanden nameting. Anti-roken tentoonstellingen in de bedrijven bleken een gunstig effect te hebben op participatie in het stoppen-metroken programma. Er werden geen effecten gevonden van massamediale voorlichting en rookbeleidsmaatregelen op cognities en stopgedrag van rokers. De conclusie was dat massamediale activiteiten de participatie aan een stopprogramma in een bedrijf kunnen vergroten, maar dat ze daarbuiten weinig effect hebben op rokende werknemers. Verder bleek dat rookbeperkende maatregelen een positief effect hebben op de assertiviteit en intolerantie van niet-rokers ten opzichte van rokende collega's. Tot slot bleek nog dat de blootstelling aan tentoonstellingswanden, brochures en berichten in bedrijfsbladen minder optimaal was bij 'handarbeiders' dan bij 'witte boorden werknemers'.

Hoofdstuk 9 bestaat uit een algemene discussie van de bevindingen uit de afzonderlijke studies in dit proefschrift, gevolgd door een bespreking van methodologische tekortkomingen en aanbevelingen voor toekomstig onderzoek. Er kunnen tenminste drie belangrijke conclusies worden getrokken uit het onderzoek in dit proefschrift. Ten eerste: urtgebreide stoppen-met-roken bedrijfsprogramma's zijn effectiever dan geen interventie of minimale interventies. Vooral de zwaarder verslaafde rokers hebben baat bij meer intensieve programma's. Ten tweede: het bovengenoemde verschil in effectiviteit is niet erg groot. Gezien het grote gemak waarmee minimale programma's in bedrijven zijn in te voeren, lijken minimale programma's meer geschikt voor verspreiding op grote schaal. Tot slot is er meer onderzoek gewenst naar de vraag op welke wijze de implementatie en effectiviteit van stoppenmet-roken bedrijfsprogramma's afhangen van factoren als bedrijfsstructuur en besluitvormingsstijl. 


\section{Dankwoord}

Dit proefschrift is het resultaat van toegepast onderzoek waarbij zowel wetenschappers als mensen uit 'de praktijk' betrokken zijn geweest. Vanuit de Universiteit Maastricht is Hein de Vries een grote stimulans geweest. Zonder zijn initiatief zou dit onderzoek er niet zijn geweest. Hein heeft mij geleerd om niet te snel tevreden te zijn en heeft mij aangespoord om meer uit het onderzoek te halen dan ik zelf soms voor mogelijk hield. Aart Mudde, bij wie ik het 'vak' heb geleerd, bedank ik voor het feit dat hij ook daarna steeds klaar stond om mijn vragen te beantwoorden. Ron Genders heeft als onderzoeksassistent met enthousiasme zijn bijdrage aan het onderzoek geleverd. Naast de onvermijdelijke klusjes van alledag heeft Ron een van de bedrijven begeleid bij het invoeren van het stoppen-met-roken programma. Lilian Lechner, mijn kamergenoot op de vakgroep, bedank ik voor het frequente meezoeken naar oplossingen voor problemen die zich in het onderzoek voordeden. Gerard van Breukelen dank ik voor zijn adviezen op het gebied van de statistiek. De meeste data voor dit onderzoek zijn verkregen door middel van telefonische interviews uitgevoerd door het MEMIC, Centrum voor Data en Informatiemanagement. Ik wil met name Gregor Franssen, Robert Klinkenberg, Mieke Witte en de enquêtrices van bedanken voor de vele uren die zij aan het onderzoek hebben besteed.

De volgende buitenlandse deskundigen wil ik bedanken voor hun adviezen over het stoppen-met-roken bedrijfsprogramma en/of het uitvoeren van het onderzoek: Vic Strecher (University of Chappel Hill, VS), Michael Eriksen (Center for Disease Control, VS), Wayne Velicer (University of Rhode Island, VS) en Brian Oldenburg (Queensland University of Technology, Australië).

Het stoppen-met-roken programma is ontwikkeld in nauwe samenwerking met toekomstige 'verspreiders" ervan. Een studiereis in 1989 naar de Verenigde Staten, gevolgd door vele discussie-middagen over de (on)mogelijkheden van stoppen-metroken bedrijfsprogramma's, hebben geleid tot een vruchtbare samenwerking met Arno Haartsen (Vereniging van Integrale Kankercentra) en Grieto Zeeman (Stichting Volksgezondheid en Roken).

In bedrijven werden werkgroepen opgericht die het programma implementeerden. Ik wil de mensen in deze werkgroepen hartelijk danken voor hun inspanningen. Een speciale dank is op zijn plaats voor de voorzitters van de werkgroepen, omdat zij een grote persoonlijke inspanning pleegden om het programma in hun bedrijf tot een succes te maken: Ferdy van Rijn, Cees van der Giesen, De heer Smout, George van de Kant, Wilma Gathier, Laurens Banus, Mirjam Deckers, Kitty 
Creemers en Karen Overdijkink. Ik ben Eef Hollman zeer erkentelijk voor haar onbezoldigde assistentie bij het opzetten van het programma bij één van de bedrijven.

Tot slot wil ik Jacqueline op de Weegh, Louk Peters en Peter W/illemsen bedanken voor het nalezen en corrigeren van (delen van) het manuscript.

Maastricht, januari 1996 


\section{Curriculum Vitae}

Marc Willemsen werd op 13 november 1963 in Velp (gemeente Rheden) geboren. $\mathrm{Na}$ het behalen van het Atheneum diploma in Arnhem begon hij in 1982 aan de psychologie opleiding aan de Katholieke Universiteit Nijmegen. In 1988 studeerde hij af in de vakgroep Cultuur- en Godsdienstpsychologie. Vanaf 1989 is hij werkzaam bij de vakgroep Gezondheidsvoorlichting (GVO) aan de Universiteit Maastricht. Eerst was hij als onderzoeksassistent betrokken bij de ontwikkeling en evaluatie van interventies voor de huisartspraktijk om patiënten te helpen bij het stoppen met roken. In $1990 \mathrm{kreeg}$ hij een aanstelling als toegevoegd onderzoeker om een stoppen-met-roken programma voor werknemers bij PTT-Telecom te evalueren. In 1992 volgde een aanstelling als universitair docent. Van 1993 tot 1996 verrichtte hij het grootste deel van het onderzoek dat in dit proefschrift is beschreven in de funktie van toegevoegd onderzoeker. Sinds 1996 heeft Marc Willemsen een door de Stichting Volksgezondheid en Roken gefinancierde post-doc aanstelling bij de vakgroep GVO. De bedoeling van deze positie is om het onderzoek naar stoppen-metroken interventies in de arbeidssituatie te continueren en uit te breiden. 